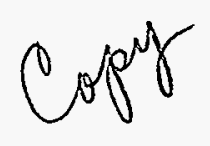

\title{
LOCH LINNHE ‘94 Current Meter Array Operations and On-Site Analysis
}

\author{
David H. Chambers \\ Holger E. Jones
}

August 11, 1995

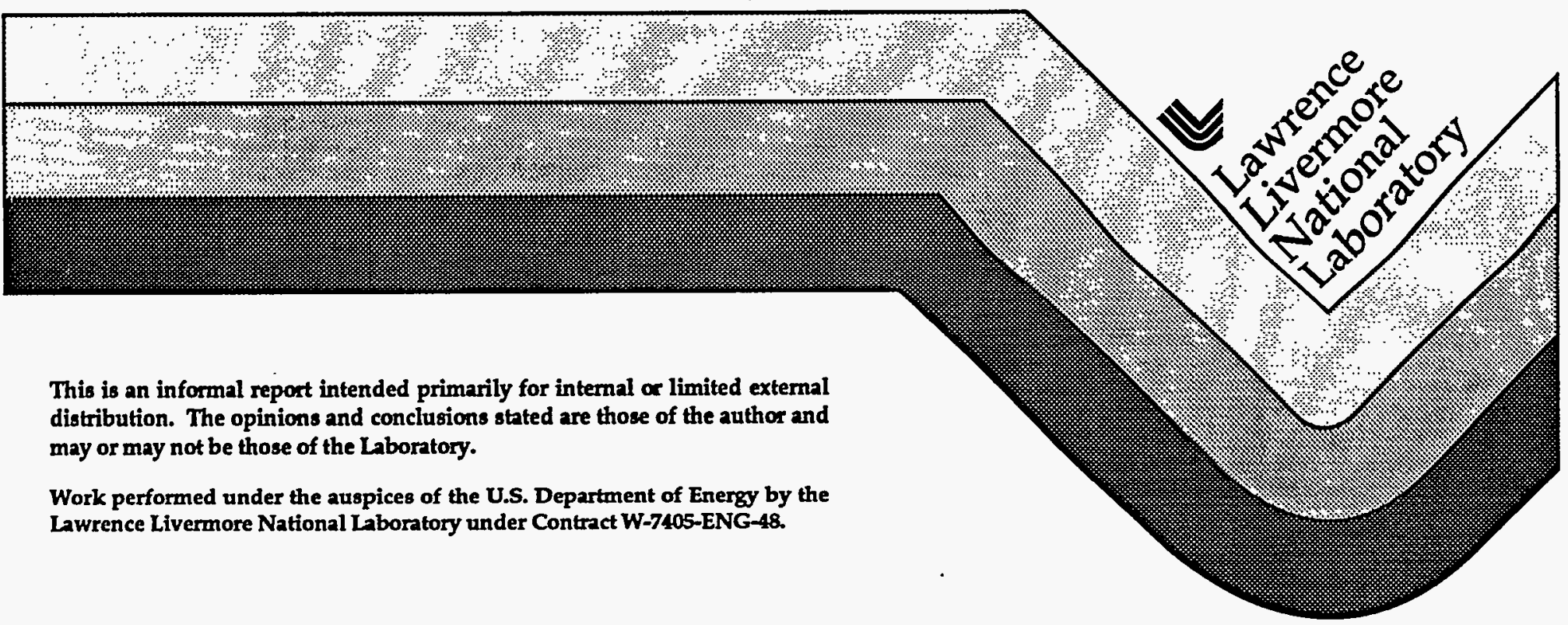




\section{DISĊLAIMER}

This document was prepared as an account of work sponsored by an agency of the United States Government. Neither the United States Government nor the University of California nor any of their employees, makes any warranty, express or implied, or assumes any legal liability or responsibility for the accuracy, completeness, or usefulness of any information, apparatus, product, or process disclosed, or represents that its use would not infringe privately owned rights. Reference herein to any specific commercial product, process, or service by trade name, trademark, manufacturer, or otherwise, does not necessarily constitute or imply its endorsement, recommendation, or favoring by the United States Government or the University of California. The views and opinions of authors expressed herein do not necessarily state or reflect those of the United States Government or the University of California, and shall not be used for advertising or product endorsement purposes.

This report has been reproduced directly from the best available copy.

Available to DOE and DOE contractors from the Office of Scientific and Technical Information P.O. Box 62, Oak Ridge, TN 37831

Prices available from (615) 576-8401, FTS 626-8401

Available to the public from the National Technical Information Service

U.S. Department of Commerce 5285 Port Royal Rd.,

- Springfield, VA 22161 


\section{DISCLAIMER}

Portions of this document may be illegible in electronic image products. Images are produced from the best available original document. 


\section{Table of Contents}

$\begin{array}{lll}1.0 & \text { INTRODUCTION } & \text { Page } 2\end{array}$

1.1 Summary of Test Operations ....................................2

2.0 CMA CONFIGURATION \& SETUP.....................................

2.1 Platform \& Sensor Description ....................................

2.2 Assembly \& Deployment.........................................6

3.0 DATA ACQUISITION \& PROCESSING .............................6

$3.1 \quad$ Equipment ..................................................................6

3.2 Receiving \& Archiving ...............................................11

3.3 Data Analysis ..............................................................12

4.0 DATA SUMMARY \& ASSESSMENT ..............................13

4.1 Operational Assessment ................................................13

5.0 SUMMARY .........................................................................14

APPENDIX .............................................................................15 


\section{INTRODUCTION}

This report documents the operation and on-site data analysis of the LLNL Current Meter Array (CMA) which was fielded at Loch Linnhe '94. The CMA is a large floating array of 10 sensors which measure horizontal current near the water surface. The measurements are used to interpret radar images of the water surface. This experiment was conducted as a part of the Joint UKVUS Radar Ocean Imaging (ROI) Program. It was held at Loch Linnhe, Scotland in September 1994. The experiment consisted of measuring natural and ship-generated internal waves (IWs) in Loch Linnhe and imaging them with a land-based, dual frequency, dual-polarization real aperture radar operated by the UK. The goal was to determine the relationship between the amplitude of IWs as measured by instrumentation deployed in the water and the modulation they produce in radar images of the water surface. An abbreviated list of participating organizations and assets deployed are as follows:

\section{Organization}

DRA Farnborough (UK)

Royal Marine Auxiliary Service (UK)

Dunstaffnage Marine Laboratory (UK)

University of Southampton (UK)

The Underwater Centre (UK)

RACAL (UK)

DRA Malvern, Thorn-EMI (UK)

LLNL (US)
Assets

R/V Colonel Templer, test direction

Collie (Dog-class tug)

$R / V$ Calanus, shear spars, various in-water instruments

laser slope gauge

R/V Loch Shiel, test support

DGPS receivers and analysis

Marine Cliffside Radar (MCR)

CMA, profiling S4/CTD meter, meteorological instruments, on-site radar analysis

\subsection{Summary of Test Operations}

In a typical day of test operations the IW generating ships (R/V Colonel Templer and Collie) together make four to six passes up and down the long axis of Loch Linnhe (see site geometry figure 1). This gives each instrument four to six data runs per day. During each run the ship passes through the footprint of the radar and past the in-water instrumentation sites (R/V Calanus and the CMA). In addition, the R/V Loch Shiel would tow the University of Southampton's laser slope gauge across the ship track after the ship passed. The in-water instrumentation sites were set just outside the radar footprint. The radar continuously imaged the water surface during each day's runs. The CMA and shear spars also continuously measured horizontal water velocities during each day. CMA data was continuously transmitted through a telemetry link from the moored array to the CMA shore station at Fort William. The spar data were stored in sensor memory and retrieved at the end of the day. The S4/CTD meter was profiled at hourly intervals during the day. The test director radioed an estimate of the time of closest point of approach (CPA) of the ship with the CMA during each run. The GPS receivers continuously monitored the positions of the IW generating ship, CMA, and Calanus though the position data was not available on site. A total of 56 runs were performed over 13 days of operation beginning September 4, 1994. No runs occurred on Sept. 6 to allow the in-water instrumentation moorings to be moved closer to the radar footprint. Further details of the test operations can be found in reference 1. 


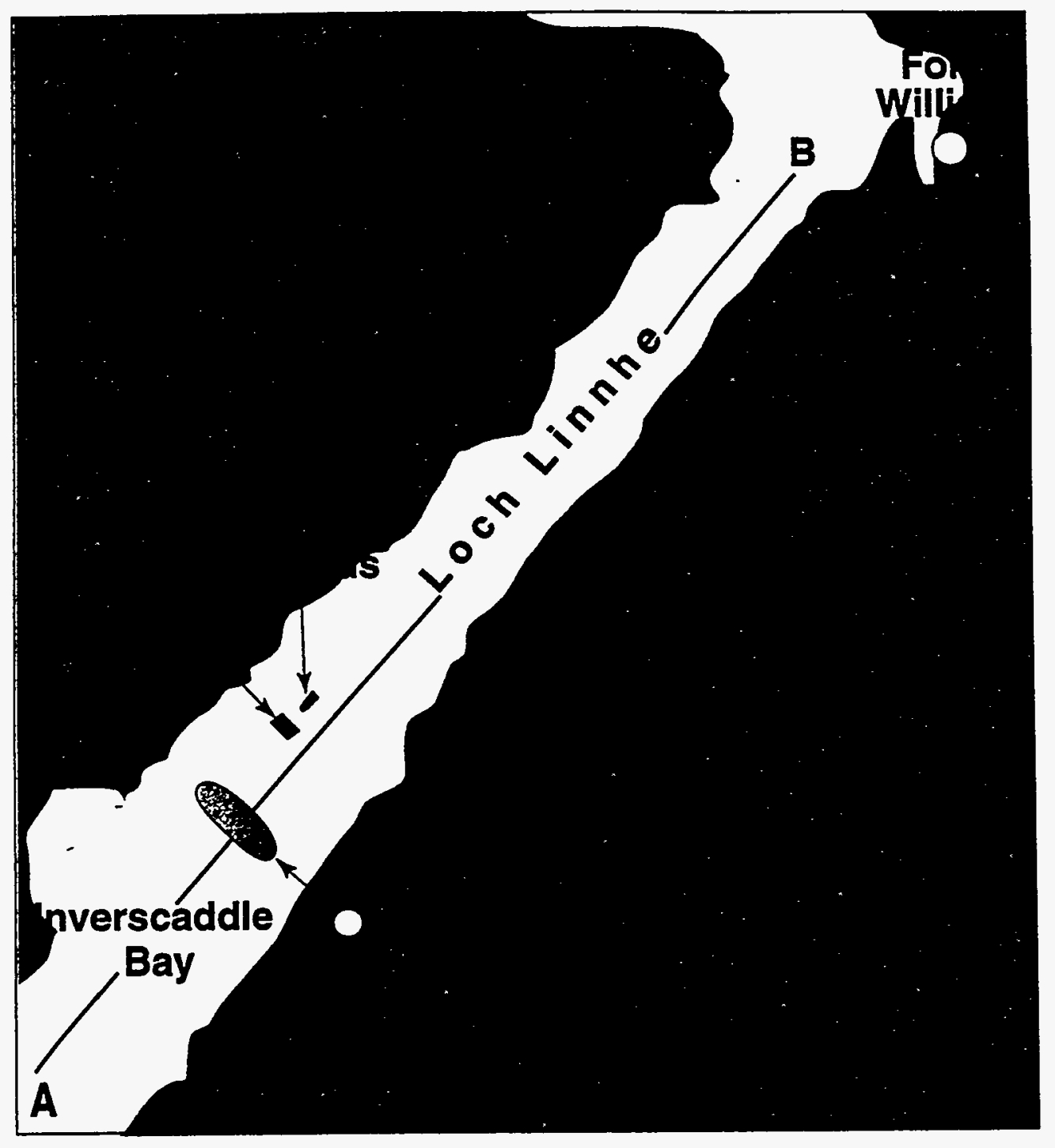

Figure 1 Chart of Loch Linnhe showing radar hillside and footprint, nominal ship track, and nominal mooring locations of current meter array and $\mathrm{R} / \mathrm{V}$ Calanus. 


\section{CMA CONFIGURATION \& SETUP}

\subsection{Platform \& Sensor Description}

The CMA is a large frame structure 36 meters long and 5 meters wide from which ten S4 electromagnetic current meters are suspended on vertical struts at a depth of two meters below the water surface. The sensors are equally spaced along the length of the rectangular frame at 3.75 meter intervals, staggered between port and starboard sides (see figure 2). The vertical struts are mounted on the frame at pivoting joints. These joints allowed the struts to be secured in a horizontal position for towing then rotated to a vertical position for deployment. The array was moored with its long axis perpendicular to the nominal ship track and its bow approximately 100 meters from the ship's closest point of approach (CPA). In this configuration the direction of the currents associated with ship-generated internal waves would be approximately parallel to the array axis.

The S4 current meters are electromagnetic devices manufactured by InterOcean Systems, Inc, in San Diego, CA. They measure the magnitude and direction of the water current in a horizontal plane. In addition, they have internal tilt meters, magnetic compass, and associated electronics that can record data internally, compensate for sensor tilting, and report current relative to magnetic north or relative to its own fixed coordinate system. Each sensor operates on its own long-life batteries. For this experiment the sensors were configured to report currents relative to their own fixed coordinate system. The sensors were carefully mounted on the vertical struts so that their internal $x$ coordinate was aligned with the long axis of the array. The S4s sample the current every half second but were configured to report 20 sample averages (10 second averaging time) to the telemetry system. Both magnitude and direction of the current were reported in addition to the magnetic compass reading.

In addition to the $\$ 4$ current meters, a meteorological station, a telemetry system, and a differential GPS receiver station were mounted on the CMA. The met station provided measurements of wind speed and direction, humidity, air and water temperature, and CMA orientation. These are essential in interpreting the radar images. The met station included two wind anemometers, one mounted on a tower 10 meters above water level (typical of wind measurements associated with radar images of the ocean surface) and the other mounted on the CMA frame approximately 1 meter above the water for comparison. The met station also included a precision compass which was used to monitor the precise orientation of the CMA as it moved slightly in its mooring in response to tidal currents. The GPS receiver was provided by RACAL to monitor the precise position of the CMA during the experiment.

The S4 meters and met stations were connected by cables to a multiplexer and telemetry station which transmitted the data at a set rate to the shore station via an RF link. The shore station was set up near the Underwater Centre in Fort William, approximately 5 miles from the CMA. The collected data from all ten sensors was transmitted in bursts at close to the $\$ 4$ sampling rate, once every ten seconds. The data from the met stations was sampled once every minute. The telemetry system was powered by lead-acid batteries which were mounted in a box on the frame near the telemetry box. The met stations and GPS receiver had their own batteries. In addition to data transmission, the telemetry system was designed with a remote power management capability. A series of "tones" broadcast from the shore station to the CMA would switch the main power from the battery box off and on in order to conserve battery power and reduce the need to replace batteries while the CMA was deployed. The battery voltages for the telemetry system and met stations were also monitored. 
Target

Track

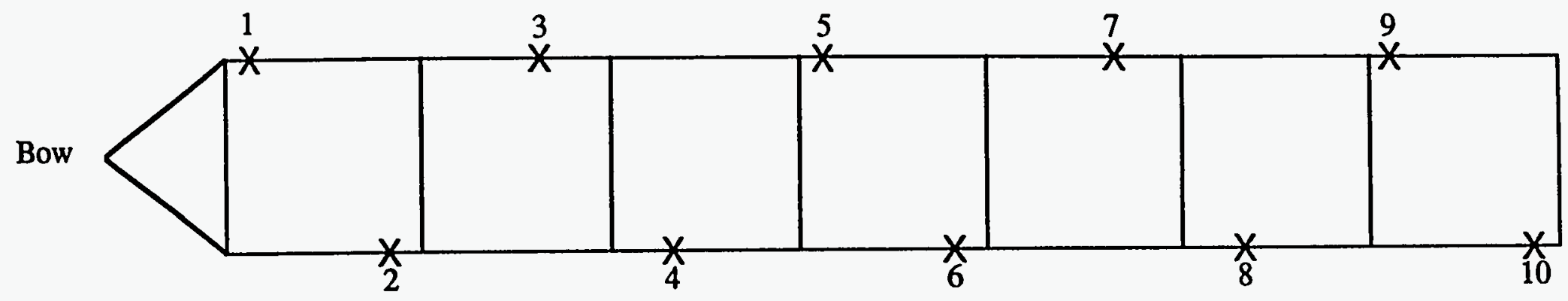

en

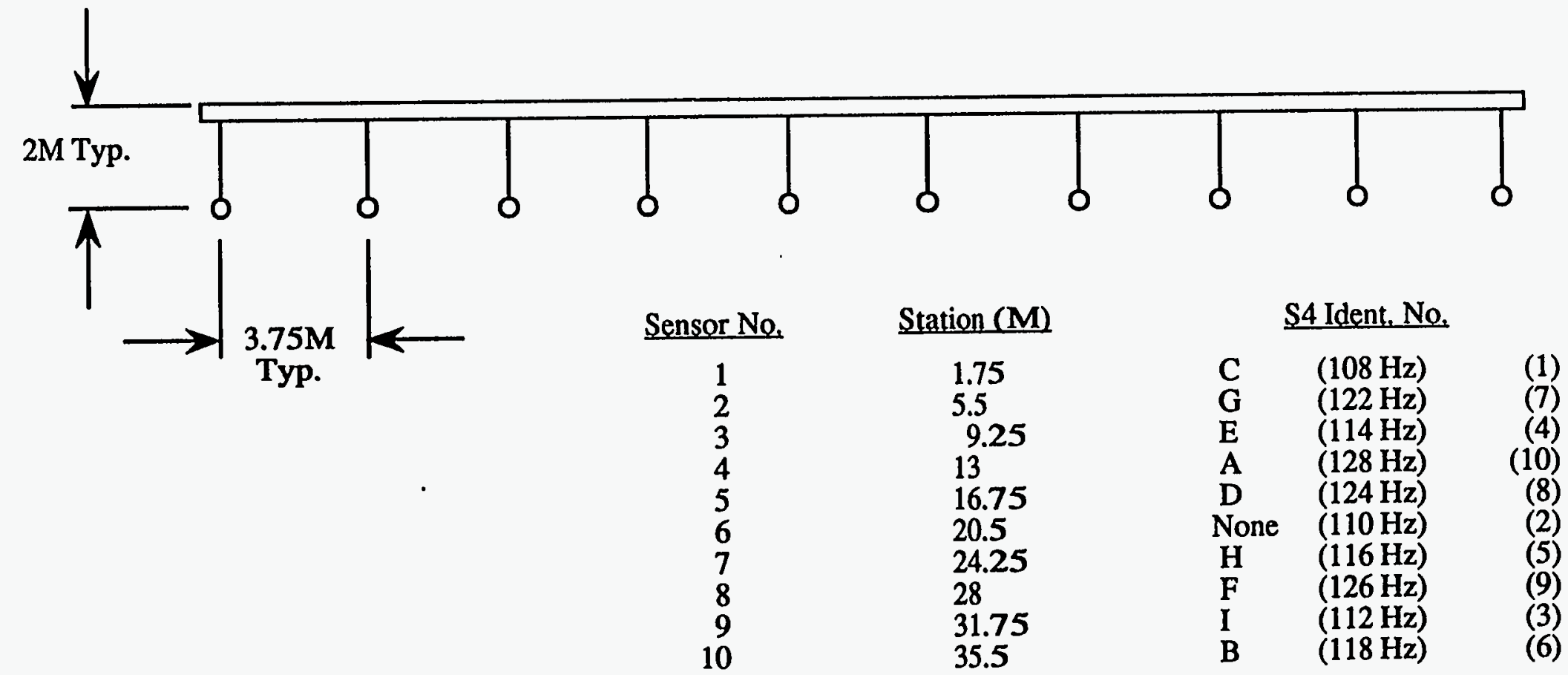

Figure 2 LL94 Current Meter Array Sensor Configuration 


\subsection{Assembly and Deployment}

The disassembled CMA structure and support equipment was packed into a transportainer which doubled as the shore station when empty. Data acquisition and analysis computers and related equipment were shipped separately in crates. The transportainer was shipped by boat while the crates were shipped by air freight. The transportainer arrived at the test site by August 28 when assembly began at a loading dock next to a basin at the Loch Linnhe end of the Caledonian Canal at Corpach, Scotland. The analysis computers and some other electronic equipment shipped by air freight sustained some damage during transit. Fortunately, this damage did not prevent CMA operation and on-site analysis, however certain technical difficulties encountered in set-up might have been caused by transit damage.

The CMA assembly (figure 3) was completed on August 30 after two days of work in constant rain. Due to the large dry weight (around 10,000 lb.) of the assembled CMA two cranes provided by the Underwater Centre were used to lift the CMA into the canal basin. The CMA was towed out of the basin, through the final lock on the canal into Loch Linnhe, then to the Underwater Centre pier at Fort William by the tug Loch Shiel where it was secured. At Fort William, the telemetry and battery boxes were mounted on the structure and the telemetry systems checked out. At this time it was discovered that the power management system was not working properly. After several troubleshooting attempts which proved unsuccessful it was decided to monitor the battery power levels closely and swap out batteries manually as needed throughout the experiment. As part of the checkout before deployment the CMA was towed in a circular pattern to check out the S4 responses, to confirm that the $\$ 4$ current reference axes were all aligned properly with long axis of the CMA structure, and to verify which directions corresponded to positive values of the current as reported by the S4s. After these checkouts the CMA was towed to the mooring site on September 2nd and secured in a four-point mooring (figure 4).

\section{DATA ACQUISITION AND PROCESSING}

\subsection{Equipment}

All CMA data processing equipment were located in the transportainer shore station at Fort William (figure 5). These included the RF link receiver station and four computers for analysis and archiving of the data. Overall the equipment performed adequately during the experiment. Deviations from perfect performance were probably due to minor damage received in shipping.

The telemetry system was based on Arlan Telesystems data networking products. This is a spread spectrum technology which carries multiplexed RS232 serial data via packet switched virtual circuits. The aggregate system data rate is $200 \mathrm{kbps}$. The Arlan 110 and accompanying transceiver, the Arlan 010 served as base station. The base station received incoming telemetry from the CMA and demultiplexed the data into 8 possible serial streams which connected to our computer equipment for recording and analysis. The base station also had a dedicated serial port, which we used to monitor port status and reset port characteristics. We used three of the possible eight ports for telemetry system status, multiplexed CMA sensor data, and meteorological data.

We used up to three computers to collect data and monitor system status during data collection (see figure 6). A Quadra 950 processed incoming data arriving from four separate serial lines. These lines were used specifically for multiplexed CMA sensor data, remote meteorological data, local meteorological data, and telemetry system status. Furthermore, the multiplexed CMA data and remote meteorological data were physically split so that a Powerbook Macintosh $180 \mathrm{C}$ simultaneously collected and stored, without processing, the raw data streams. This was our 


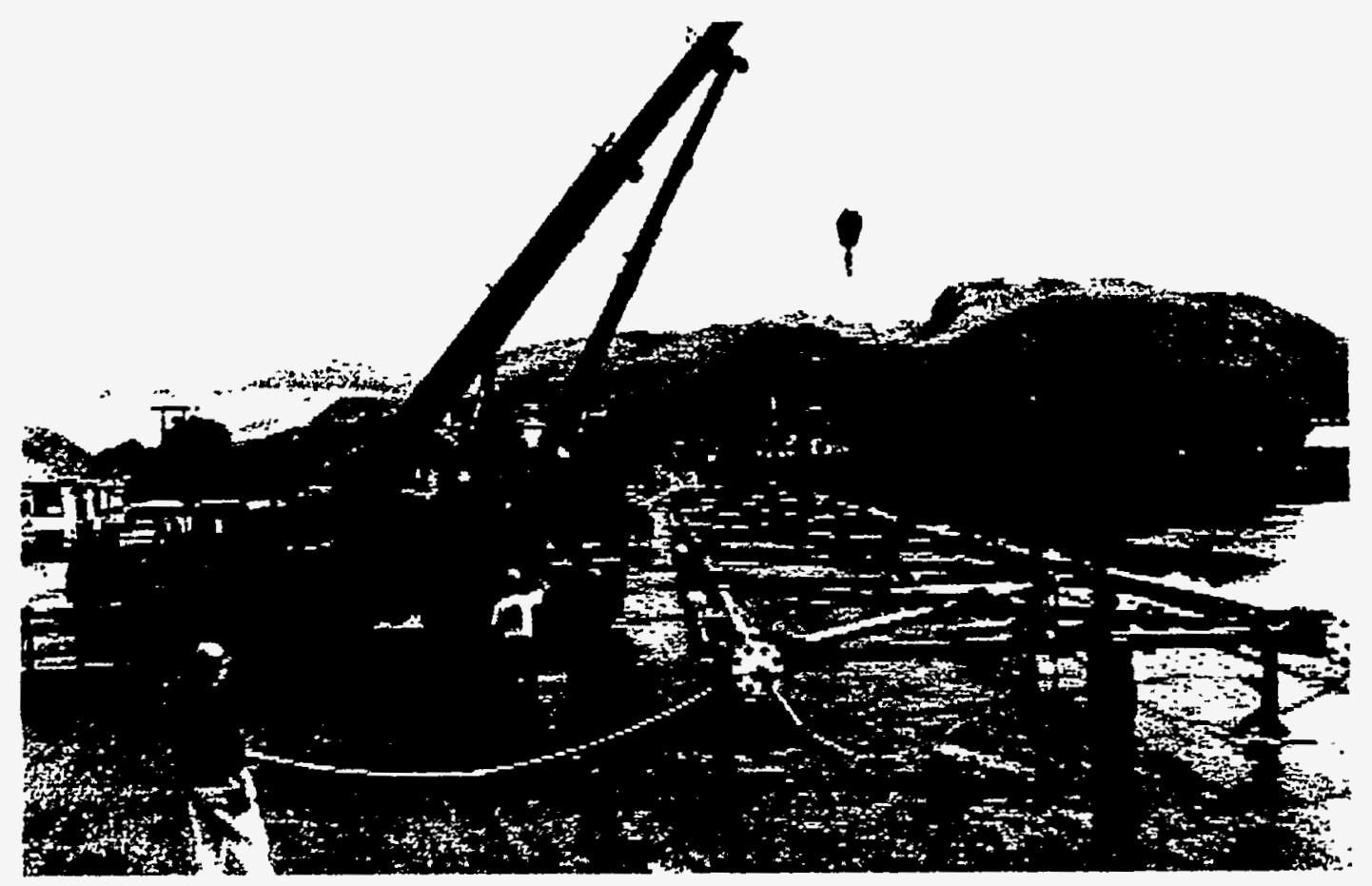

Figure 3 Current Meter Array on assembly stands at Caledonian Canal, Corpach prior to deployment 


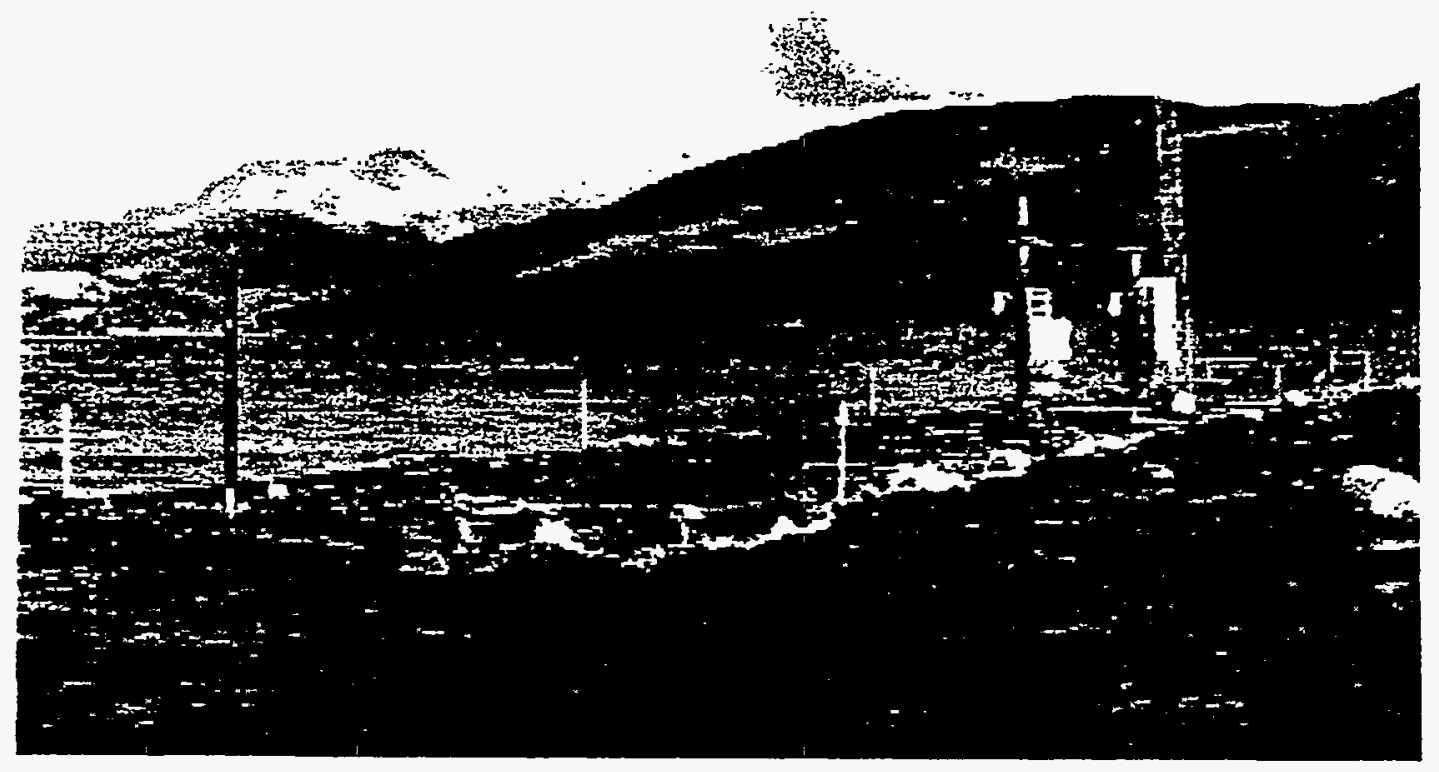

Figure 4 Current Meter Array at mooring 


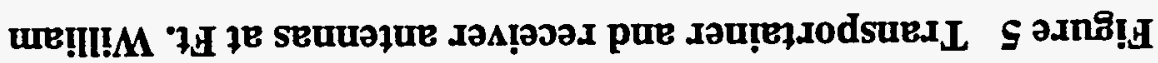

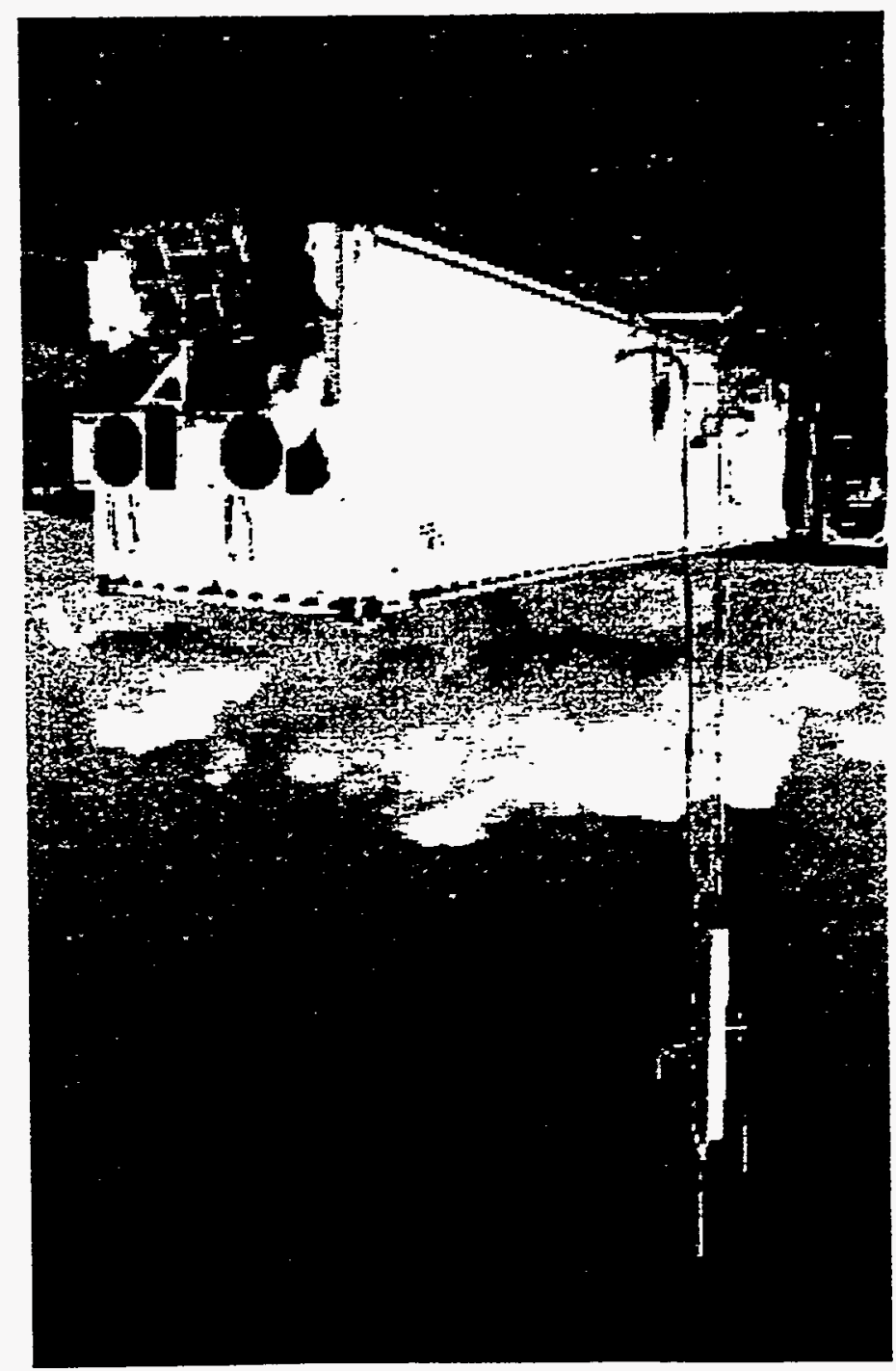




\section{CMA Data Flow}

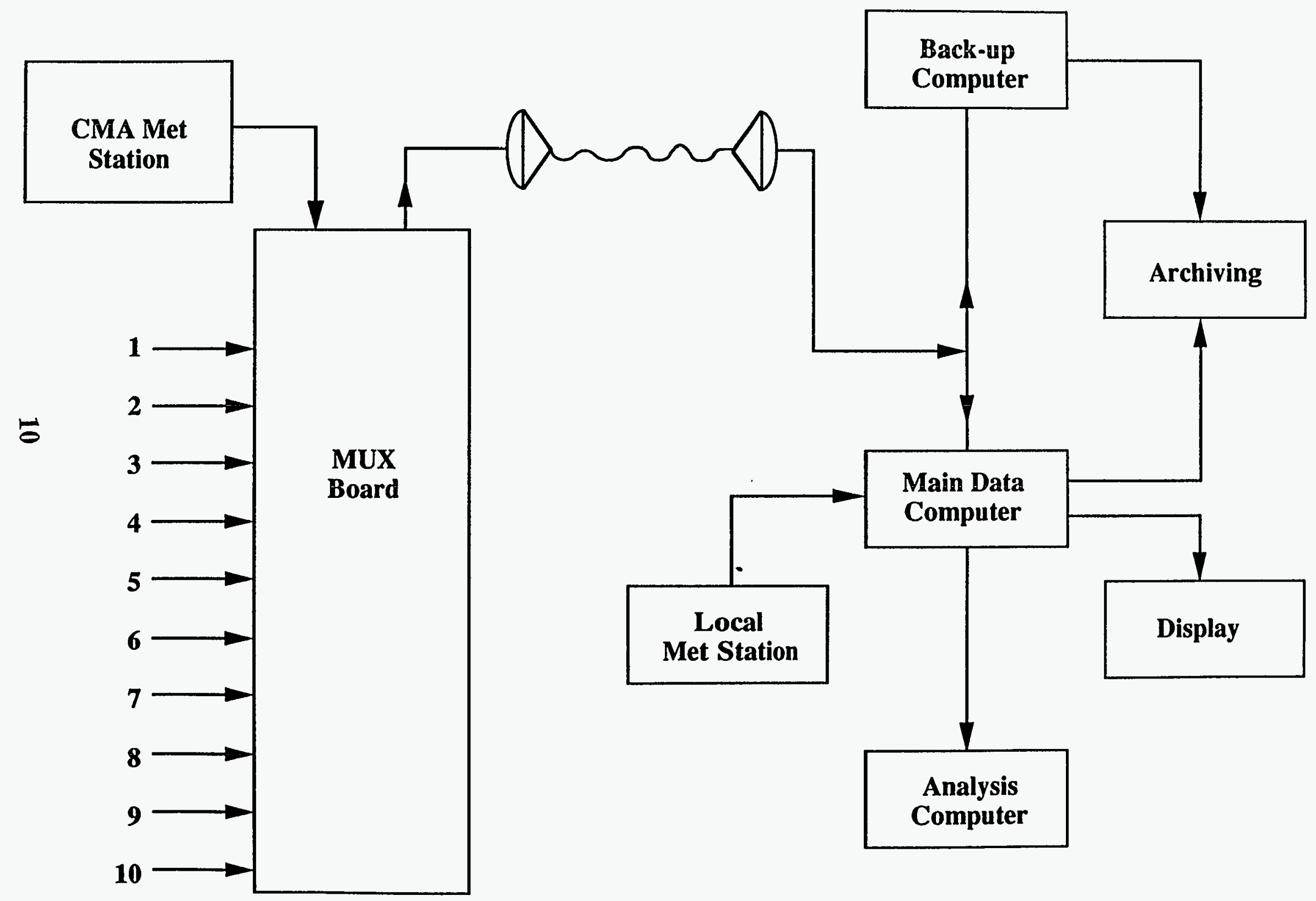


backup data collection system. A second Quadra 950 was used to process collected data. This computer was networked to the other Quadra and Powerbook and file transfers were initiated after each run. The fourth computer, a DOS based portable, was used to monitor telemetry status via the dedicated Arlan 110's control port.

The Arlan Telemetry system did have some trouble initially. The remote based network unit (Model 120) on the CMA failed during the first couple of days, however we had a spare available. Once the spare was installed the system ran quite well for the duration of the experiment. We did from time to time monitor traffic statistics such as packet loss, and found these numbers to be quite high. Although data transfer was transparent to packet loss, the system seemed strained, especially with regard to continuous retries. We recommend a system characterization be performed to better understand this problem before further deployment.

The computer and data acquisition system performed well except for a couple of problems that could be attributed to damage received during shipping. For the computer system, we were operating with a bad serial port for the first couple of days. Data loss looked like dropouts occurring at frequencies of one or two per 10 minutes per channel, so they were not discovered at first until direct comparisons were made to the data arriving at the backup computer (Powerbook). We also incurred damage to the Quadra 950 used for post-processing and analysis. This computer was sensitive to jostling, so we relocated this system to minimize physical contact, where it performed reasonably well under the circumstances. For the acquisition system, once serial ports were remapped to bypass the bad port, the system operated flawlessly during the remainder of the experiment.

\subsection{Receiving and archiving}

Incoming serial data was collected and maintained in buffers by the Communications Toolbox, an Apple Systems technology. The remainder of the acquisition and analysis functions were executed using Matlab, a general data processing and analysis environment obtained from Mathworks, Inc. Matlab communicated directly with the Comm Toolbox via external functions (MEX files). These MEX files had the responsibility of parsing the incoming data and converting it to engineering units. This approach worked well, as data was fed directly to Matlab using its native data format. The data was then stored and simultaneously displayed.

The data display was broken up into six sections. These were 1) a scrolling stack plot of North or $\mathrm{Y}$ component of multiplexed CMA data, 2) a scrolling stack plot of East or $\mathrm{X}$ component of multiplexed CMA data, 3) a direct digital readout panel with CMA data (current value) and status (increasing, decreasing, stuck sensor, or no report), local and remote met (all available metrics), and telemetry status, 4) a system log display, 5) remote wind speed and direction plots, and 6) local wind speed and direction plots. This display required two monitors.

The incoming data was collected and stored immediately. This approach was done in order to minimize loss in case of a crash as compared to buffering the incoming data and saving periodically. The CMA and remote met data was also collected by a backup computer which saved the data to disk as collected without processing. This data could then be played back at some later time into the receiving system and processed as if it were arriving in real time. We did use this data to reprocess the runs affected by the bad serial port on the main acquisition computer. After each run the processed data was backed up to two additional independent external drives, one located on the main acquisition computer, and the other connected to the backup computer. The CMA data was also transferred to a post-processing computer for near real-time analysis and display. This entire process took about 5-10 minutes after each run, however the communication channels still acquired data during this time so continuity was maintained. 


\subsection{Data Analysis}

The CMA data from a run was transferred to the post-processing computer for analysis shortly after the completion of the run. For each run a gray-scale image of the cross-track current and strain rate was produced. If waves were apparent in the images an estimate of their phase speed was calculated and a composite time series of current and strain rate was obtained. The current and strain rate images were produced by first removing long term trends from the 10 time series obtained from 10 sensors on the array. The detrending was accomplished by averaging together the 10 time series into a single time series over the run ( -60 minutes duration). A fourth order polynomial was fit to the average then subtracted from each of the original 10 time series. This has the effect of removing slow trends which affect the array as a whole such as tidal currents. Next each time series was filtered using a 7 point $(70 \mathrm{sec})$ running median filter followed by a low pass Butterworth filter ( 6 th order) with cutoff frequency of $0.02 \mathrm{~Hz}$. This eliminated high frequency sensor and environmental noise. The median filter has the desirable property of filtering noise without much smearing of sudden changes in the internal wave signal. The subsequent low-pass filter was used to smooth out the high frequency "jitter" in the median-filtered time series. As discussed above, each time series is a sample of the cross-track current at a given sensor location along the array. The ten time series together are a 10 point sample of the evolving spatial pattern of the current. After filtering, the 10 samples of the spatial pattern are fit with a 4th order polynomial using the sensor locations. This fit is done for each time sample, giving a set of coefficients which are functions of time. The polynomial fit has the effect of spatially smoothing the data. The strain rate is obtained by analytically differentiating the polynomial fit. The current and strain rate images were produced by using the polynomial fit to interpolate the smoothed pattern at a resolution of 1 meter.

Figures A1 through A? in the Appendix show the resulting current and strain rate images from each run. The images begin at the time of closest approach of the ship and cover an interval of 40-60 minutes afterward. Internal waves appear as bands lighter or darker than average inclined at an angle across the images. The angle of inclination is determined by the propagation speed and direction of the waves across the array. Ship generated waves would be expected to appear first at the bow of the array and propagate to the stern producing bands inclined from lower left to upper right. They would first appear at a time determined by their group speed and the distance between the CMA bow and the ship track (see figures s2r1, s7r3, and s10 1 ). Their inclination angle is related to their phase speed. Other internal waves which may be present naturally would generally appear at times uncorrelated with the passage of the ship and may propagate from stern to bow of the array. Examples of these natural waves can be seen in several images (see figures $s 2 r 1, s 2 r 3$, and especially s10r3 \& r4).

When a banded feature is observed in the current and strain rate images at the expected time of arrival for an internal wave an estimate of the propagation velocity is obtained using two complementary approaches. Each approach uses the idea that wave forms measured by the sensors should be time shifted copies of each other for a propagating internal wave. This ignores for now the small amount of distortion introduced by the dispersion as the wave propagates across the array aperture. As discussed above the time delays should progress systematically across the array with the shortest time delay at sensor 1 near the bow and the longest at sensor 10 near the stern. The time delay between any two sensors is equal to their separation distance divided by the phase speed of the wave. An estimate of the phase speed can then be obtained simply from a determination of onset times. Practical considerations in determining the precise onset time of a wave in the presence of environmental noise drove us to find less direct but more robust methods using the same basic principle.

The first method for finding phase speed is based on the idea that the time-delay cross-correlations between sensor time series should be maximum when the time delays are equal to the onset time differences for the internal waves. The second method is based on the idea that the mean-square 
differences between time-delayed sensor measurements should be minimum when the time delays are equal to the onset time differences. In the actual implementation of these phase speed estimation methods a given sensor is chosen to be a reference, sensor 1 say. Time delays relative to the reference sensor were then calculated for the other sensors for a given phase speed $c$ using relative sensor locations. The time series for the other sensors were then shifted by these calculated time delays. If the correlation method was used the shifted time series were multiplied together than integrated in time to obtain a single value for the collective cross-correlation for the delayed time series. If the mean-square difference method was used, the mean-square differences between each sensor and the reference was calculated. These differences were then summed and time integrated to obtain a single measure of the collective mean-square difference between the reference and the other sensors. In each method the process was repeated using a different value for $c$ until a curve of correlation or mean-square difference as a function of $\mathrm{c}$ was generated. We repeated this procedure using different sensors as reference thus generating ten curves of correlation or meansquare difference. The positions of the minima of the mean-square difference curves and the maxima of the correlation curves gave estimates of the actual phase speed of the wave. Typically, these were averaged together to obtain a single phase speed estimate and an estimate of the error. For some reason not understood the correlation method always gave phase speed estimates greater than the difference method. The error in the phase speed estimate is typically around $10 \%$.

The final processing for runs in which a wave form was measured and phase speed estimated was the calculation of a single time series representing the best measurement of the current and strain rate wave forms. These time series were obtained by time shifting each sensor time series by an amount calculated from the estimated phase speed then averaging the series together. These series were considered to be the final estimates of the current and strain rate magnitudes and wave forms as seen by the array. They were the basis of peak strain rate and current estimates and were used in the subsequent MTF analysis. Figures _ through _ show the current and strain rate time series obtained in the field for the runs we consider candidates for ship-generated internal waves.

\section{DATA SUMMARY AND ASSESSMENT}

\subsection{Operational Assessment}

The CMA operated as designed during the experiment with the exception of the remote power management system. However, the failure of this system was not fatal to data collection. The CMA operated with nine functioning sensors for the first two serials of data collection on September 4 and 5. On September 6 the moorings were moved closer to the radar footprint. The experiment was resumed on September 7 with Serial 4 . The CMA operated nominally with all ten sensors working through the remainder of the experiment with the exception of September 10 when it was shut down due to battery problems. Data from fifty ship runs was recorded out of a total of fifty six in the experiment.. Two runs, Serial 1 Run 2 and Serial 7 Run 3, were found to have features which are strong candidates for ship-generated internal waves. Three more runs, Serial 7 Runs 1 and 7, and Serial 10 Run 1, were found to have moderately strong features which are candidates for shipgenerated internal waves. Another five runs, Serial 3 Run 1, Serial 5 Run 2, Serial 7 Run 2, Serial 12 Run 2, and Serial 13 Run 1, had weak features which may be ship-generated internal waves. The remaining runs did not have any obvious features which could be considered ship-generated waves. All of the strong and moderate cases were produced by the larger ship, the Colonel Templer. Two of the weak runs, Serial 5 Run 2 and Serial 12 Run 2, were recorded during runs of the Collie, the smaller ship. Further processing may confirm these weaker features as produced by ship-generated internal waves. Of the eight priority radar images, two coincide with the strong CMA signatures, one with a moderate case, and one with a weak case (see Table A1). It is not known at this time why the top radar priority runs do not exactly coincide with the strongest CMA signatures. 


\section{SUMMARY}

The CMA performed adequately during the Loch Linnhe 1994 experiment. Five strong candidates for ship-generated internal waves were obtained. In addition there are five weaker cases which may prove to be ship-generated internal waves after further processing. The strong cases were all generated by the R/V Colonel Templer. Further analysis plans include applying a model-based processor to enhance weak signals, and a systematic study of the correlation between signature visibility and environmental conditions (stratification, wind, etc.). 


\section{APPENDIX}

This appendix contains a table of Loch Linnhe runs followed by the current and strain rate images produced in the field. Also included are the current and strain rate time series for the runs considered candidates for ship-generated internal waves at this time.

This work was performed under the auspices of the Department of Energy by the Lawrence Livermore National Laboratory under contract W-7405-Eng-48. 


\subsection{Tabular Summary}

A summary of run conditions, environmental conditions, and general appearance of signals in the radar and CMA images is presented in Table 3.1.

\begin{tabular}{|c|c|c|c|c|c|c|c|c|c|c|c|c|c|}
\hline Date & $\begin{array}{l}\text { Senal } \\
\text { Run } \\
\text { No. }\end{array}$ & Ship & \begin{tabular}{|} 
Ship \\
Speed \\
$(\mathrm{m} / \mathrm{sec})$
\end{tabular} & $\begin{array}{l}\text { Ship } \\
\text { Dir. } \\
\text { (up/down } \\
\text { loch) }\end{array}$ & $\begin{array}{c}\text { Radar } \\
\text { Configuration* }\end{array}$ & $\begin{array}{l}\text { Avg. } \\
\text { Wind } \\
\text { Speed } \\
(\mathrm{m} / \mathrm{sec})\end{array}$ & $\begin{array}{c}\text { Avg. } \\
\text { Wind Dir. } \\
\text { (deg. } \\
\text { from) }\end{array}$ & $\begin{array}{c}\text { Max } \\
\text { BV } \\
\text { Freq. } \\
\text { (rad/sec) }\end{array}$ & $\begin{array}{l}\text { X-band } \\
\text { Image } \\
\text { Signal } \\
\text { Sirength }\end{array}$ & $\begin{array}{c}\text { S-bend } \\
\text { Image } \\
\text { Signal } \\
\text { Sirength }\end{array}$ & $\begin{array}{l}\text { Radar } \\
\text { Analysis } \\
\text { Prionity }\end{array}$ & $\begin{array}{c}\text { CIMA } \\
\text { Image } \\
\text { Signal } \\
\text { Strength }\end{array}$ & $\begin{array}{l}\text { Added } \\
\text { Camments }\end{array}$ \\
\hline \multirow{4}{*}{$9 / 4,94$} & & & & & & & & & & & & & \\
\hline & SIRI & CI & 1 & Down & BAGPAG, $X$ & 5.0 & 269 & 0.16 & None & & & None & \\
\hline & SIR2 & $\mathrm{CI}$ & 2 & Up & BAGPAG,XS & 5.5 & 275 & 0.11 & Strong & Weak & & Strong & \\
\hline & SIR3 & $\mathrm{CT}$ & $T$ & Down & & & & 0.15 & & & 3 & None & \\
\hline \multirow[t]{3}{*}{$975 / 94$} & S2RI & $\mathrm{CT}$ & 2 & Up & BAGPAG,XS & 7.0 & 255 & 0.13 & None & None & & None & \\
\hline & 5222 & CT & $T$ & Down & BAGPAG, $\mathrm{X}$ & 8.7 & 238 & 0.11 & None & & & None & \\
\hline & $52 R^{3}$ & $\mathrm{CI}$ & $\overline{2}$ & $U_{p}$ & BAGPAG, $\mathrm{X}$ & 5.0 & 263 & 0.09 & None & & & None & \\
\hline \multirow[t]{3}{*}{$9 / 1 / 94$} & SSKR & $\mathrm{Cr}$ & 3 & $U_{p}$ & BAGPAG, XS & 4.0 & 228 & 0.08 & Weak & Weak & & Weak & \\
\hline & $53 R_{2}$ & $\mathrm{Cr}$ & 4 & Down & $B A G P A G, X$ & 3.0 & 283 & 0.09 & Uncertain & & & None & \\
\hline & S3R3 & $\mathrm{CI}$ & 3 & Up & BAGPAG, $X$ & 3.0 & 319 & 0.09 & Uncertain & & & None & \\
\hline \multirow{6}{*}{$978 / 94$} & SARI & CI & 4 & Down & Bistatic $(5 m)$ & 8.5 & 69 & 0.05 & None & & & None & \\
\hline & SAR2 & $\mathrm{CT}$ & 3 & $U_{p}$ & Bistaticlim) & 8.4 & 62 & 0.05 & Uncertain & & & None & \\
\hline & S4R & $\mathrm{CT}$ & 4 & Down & Bistatic(22m) & 8.7 & 60 & 0.04 & Uncertain & & & None & \\
\hline & SAR4 & CT & 3 & $U_{p}$ & Bistatic (44m & 8.9 & 37 & 0.06 & None & & & None & \\
\hline & $\$ 4 R 3$ & $\mathrm{CT}$ & 4 & Down & Bistatic $(90 \mathrm{~m})$ & 6.8 & 38 & 0.06 & None & & & None & \\
\hline & S4R6 & $\mathrm{CT}$ & 3 & Up & BAGPAG,XS & 5.8 & 74 & 0.05 & Uncertain & & & None & \\
\hline \multirow[t]{4}{*}{979794} & ISSRI & CT & 4 & Down & BAGPAG, $X$ & 4.2 & 242 & 0.05 & Weak & & & None & \\
\hline & S5R2 & Coltie & 4 & Down & BAGPAG, $X$ & 3.7 & 247 & 0.05 & Moderate & & & Weak & \\
\hline & SSSR3 & $\mathrm{CT}$ & 3 & $U_{p}$ & BAGPAG, XS & 4.1 & 243 & 0.06 & Moderate & Weak & & None & \\
\hline & SSR4 & Colle & 3 & Up & BAGPAG,XS & 3.7 & 249 & 0.05 & Moderate & Weak & 6 & None & \\
\hline \multirow[t]{6}{*}{9710794} & S6RI & $\mathrm{Cr}$ & 4 & Down & Bistatic $(5 \mathrm{~m})$ & & & 0.06 & None & & & & No ClMA, Met \\
\hline & 5612 & Collie & 4 & Down & Bistatia (Im) & & & 0.15 & None & & & & \\
\hline & $56 R^{3} 3$ & Cr & 3 & $\mathrm{Up}_{\mathrm{p}}$ & Bistatic $(22 \mathrm{~m})$ & & & 0.07 & None & & & & \\
\hline & S6R4 & Collie & 3 & $\mathrm{Up}_{\mathrm{p}}$ & Bistatic $44 m$ ) & & & 0.08 & None & & & & \\
\hline & 5683 & $\mathrm{Cl}$ & 4 & Down & Bistatic $(90 \mathrm{~m})$ & & & 0.08 & None & & & & \\
\hline & $56+26$ & $\mathrm{CT}$ & 3 & Up & Bistatic $(145 \mathrm{~m})$ & & & 0.09 & Uncertain & & & & \\
\hline \multirow[t]{5}{*}{$9 / 1194$} & STRI & $\mathrm{CT}$ & 4 & Down & BAAGAG,XS & 3.4 & 261 & 0.14 & Moderate & Weak & & Moderate & Pass \\
\hline & $S 7 R 2$ & CT & 3 & Up & BAGPAG, $X$ & 3.0 & 286 & 0.08 & Weak & & & Weak & \\
\hline & S7R 3 & $\mathrm{CT}$ & 4 & Down & BAGPAG, $X$ & 4.1 & 220 & 0.08 & Moderate & & 4 & Strong & \\
\hline & STR4 & $\mathrm{CT}$ & 3 & $U_{p}$ & BAAGPAG, XS & 4.1 & 226 & $0 . \pi$ & Weak & Weak & & Moderate & \\
\hline & STRS & Collie & 3 & $U_{p}$ & BAGPAG, XS & 2.1 & 209 & 0.10 & Weak & Weak & & None & \\
\hline \multirow[t]{6}{*}{$9712 / 94$} & S8RT & CI & 2 & Down & Bistatic $(145 \mathrm{~m})$ & 6.0 & 60 & 0.09 & None & & & None & \\
\hline & S8R2 & Colle & 2 & Down & Bistatic $(90 \mathrm{~m})$ & 5.9 & 37 & 0.10 & None & & & None & \\
\hline & $588 \sqrt{3}$ & CT & $\mathrm{T}$ & Up & Bistatic(44m) & 5.2 & 60 & 0.09 & Uncertain & & & None & \\
\hline & S8R4 & Collie & 2 & Up & Bistatic (22m) & 3.5 & 39 & 0.10 & None & & & None & \\
\hline & SSRRS & Collie & 2 & Down & Bistatic (1Im) & 7.3 & 64 & 0.08 & None & & & None & \\
\hline & S8R6 & Collie & 2 & $U_{p}$ & Bistatic $(5 \mathrm{~m})$ & 7.5 & 61 & 0.08 & None & & & None & \\
\hline \multirow[t]{4}{*}{9713794} & |S9Rा & $\mathrm{Cr}$ & 4 & Down & BAGPAG, $X$ & 7.4 & 59 & 0.10 & Uncertain & & & None & \\
\hline & S9R2 & Collie & 4 & Down & |BAGPAG, XS & 7.3 & 38 & 0.11 & Uncertain & Weak & & None & \\
\hline & S9R3 & $\mathrm{CT}$ & 3 & Up & BAGPAG, XS & 6.8 & 38 & 0.11 & |Uncertain| & Moderate & 8 & None & \\
\hline & T9R4 & Collie & 3 & Up & BAGPAG, $X$ & 6.8 & 37 & 0.10 & None & & & None & \\
\hline \multirow[t]{4}{*}{$9 / 14 / 94$} & SIORI & $\mathrm{CT}$ & 2 & Down & BAGPAG,XS & 6.2 & 34 & 0.16 & Strong & Strong & $\mathrm{T}$ & Moderate & \\
\hline & S10R2 & Collie & 2 & Down & BAGPAG,XS & 6.4 & 34 & 0.16 & None & None & & None & \\
\hline & SIIOR3 & $\mathrm{CT}$ & $T$ & $U_{p}$ & BAGPAG, $X$ & 6.2 & 36 & 0.17 & Moderate & & 5 & None & \\
\hline & S10R4 & Collie & 2 & $U_{p}$ & BAGPAG, $X$ & 4.6 & 78 & 0.14 & Weak & & & None & \\
\hline \multirow[t]{4}{*}{9715794} & SIIRI & $\mathrm{CI}$ & 4 & Down & BAGPAG, XS & 10.9 & 52 & & Uncerain & Uncertain & & None & No Profles \\
\hline & SIIR2 & Collie & 4 & Down & BAGPAG, XS & 9.6 & 37 & & Uncertain & Uncertain & & None & \\
\hline & ISIR3 & $\mathrm{Cl}$ & 3 & $U_{p}$ & BAGPAG, $X$ & 12.1 & 42 & & Weak & & & None & \\
\hline & SIIR4 & Collie & 3 & Up & BAGPAG, $\mathrm{X}$ & 12.6 & 41 & & None & & & None & \\
\hline \multirow[t]{4}{*}{9716794} & SI2RI & $\mathrm{Cr}$ & 2 & Down & BAGPAG, $X$ & 3.8 & 2 & 0.09 & Strong & & 2 & None & \\
\hline & S12R2 & Collie & 2 & Down & BAGPAG, $X$ & 4.9 & 4 & 0.08 & Weak & & & Weak & \\
\hline & $512 R 3$ & $\mathrm{Cr}$ & $T$ & Up & BAGPAG,XS & 4.7 & 15 & 0.13 & Moderate & Weak & 7 & None & \\
\hline & SI2R4 & Collie & 2 & $\mathrm{O}_{\mathrm{p}}$ & BAGPAG,XS & 4.2 & 9 & 0.10 & None & None & & None & $\begin{array}{c}\text { Strong CMAA } \\
\text { Amb. }\end{array}$ \\
\hline \multirow[t]{4}{*}{$9 / 17 / 94$} & SI3RI & CT & 2 & Down & BAGPAG,XS & 3.3 & 25 & .07 & Moderate & Weak & & Weak & \\
\hline & SI3R2 & Collie & 2 & Down & BAGPAG, $\mathrm{X}$ & 3.9 & 354 & .18 & Weak & & & None & \\
\hline & SI3R3 & $\mathrm{Cr}$ & 1 & $U_{p}$ & BAGPAG, XS & 3.8 & 346 & .13 & Moderate & Weak & & None & \\
\hline & |SI3R4 & Collie & 2 & $\mathrm{U}_{\mathrm{p}}$ & BAGPAG, $X$ & 3.3 & 347 & .09 & Oncertain & & & None & \\
\hline
\end{tabular}

Table 3.1 LL94 Run Summary

* $\quad \mathrm{BAG}=$ Band Agile

PAG $=$ Polarization Agile

Bistatic $=$ Bistatic receiver, $\mathrm{X}$-band (receiver separation distance) 
Serial 1 , Run 1, 9/4/94
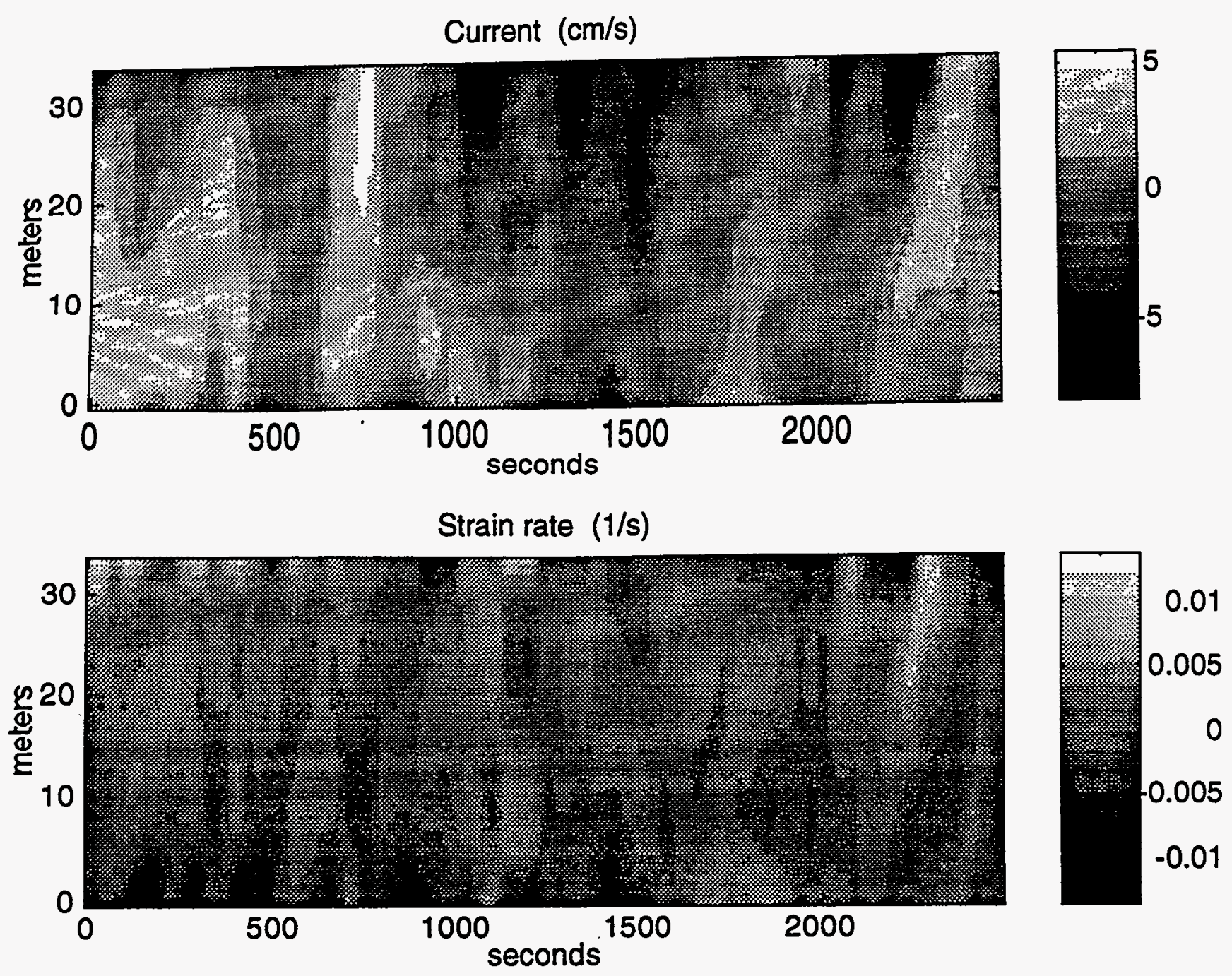
Serial 1, Run 2, 9/4/94
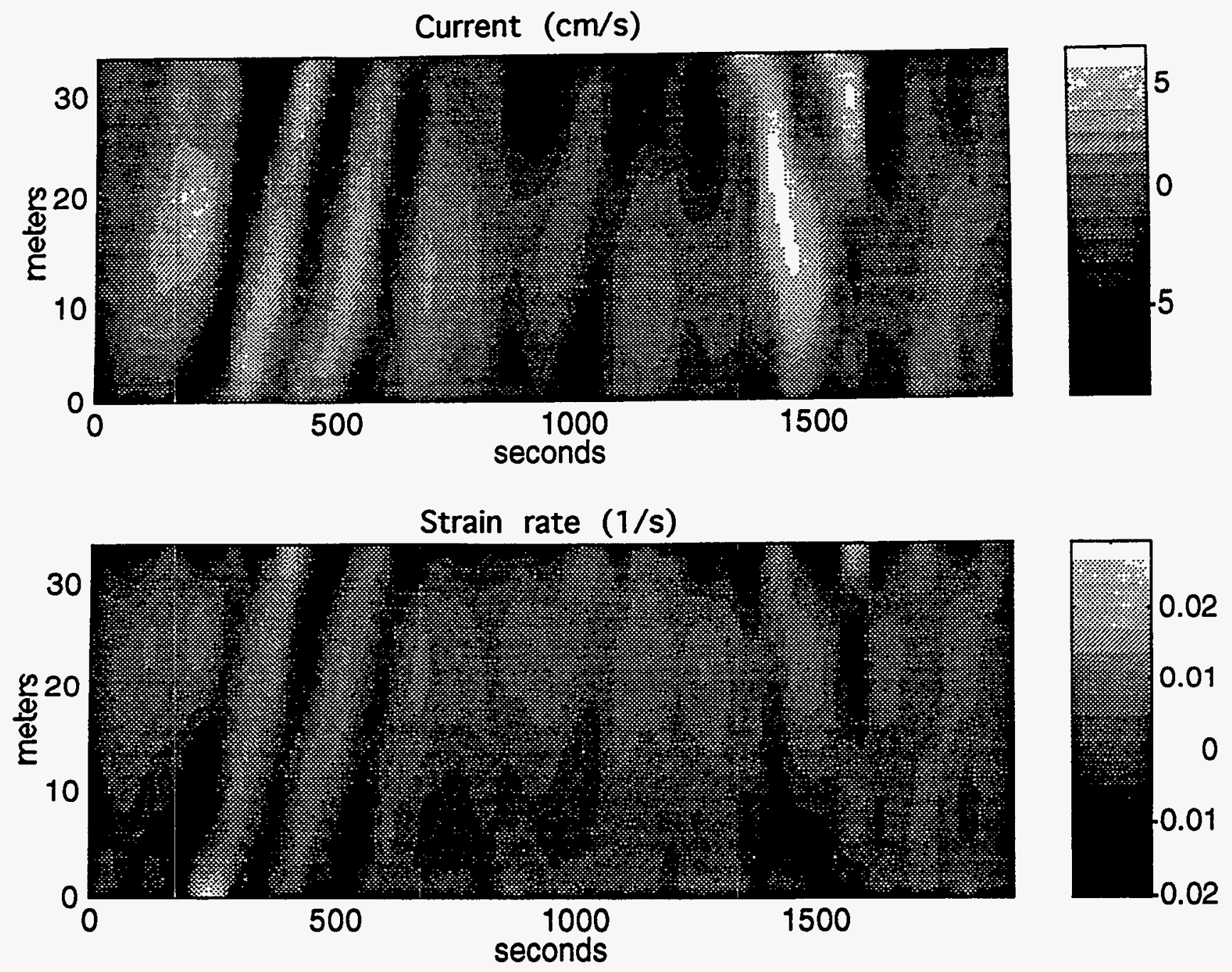

View showing outward and inward propagating waves.

Surface current and strain rate for ship-generated internal waves. 
Serial 1, Run 3, 9/4/94
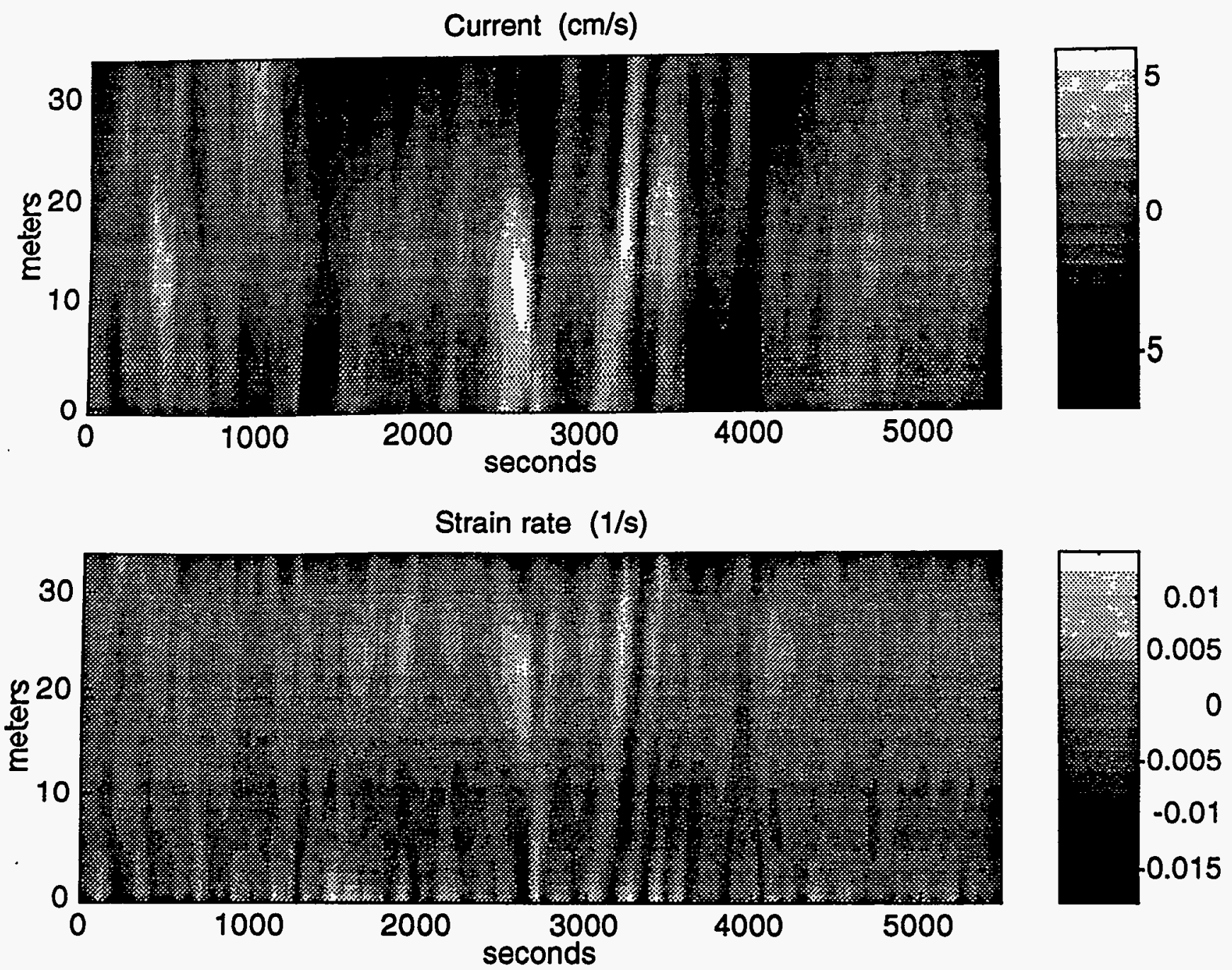
Serial 2, Run 1, 9/5/94
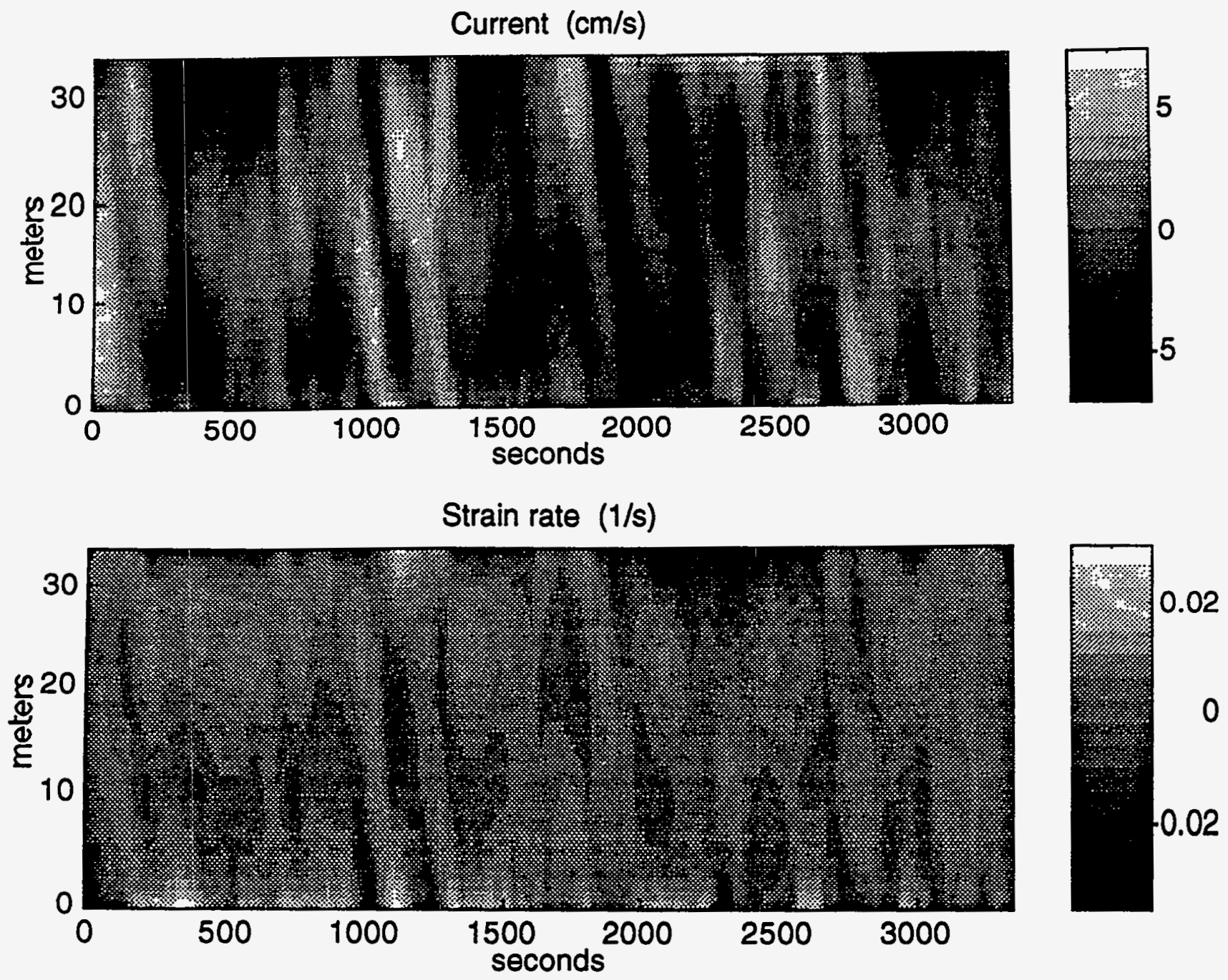
Serial 2, Run 2, 9/5/94
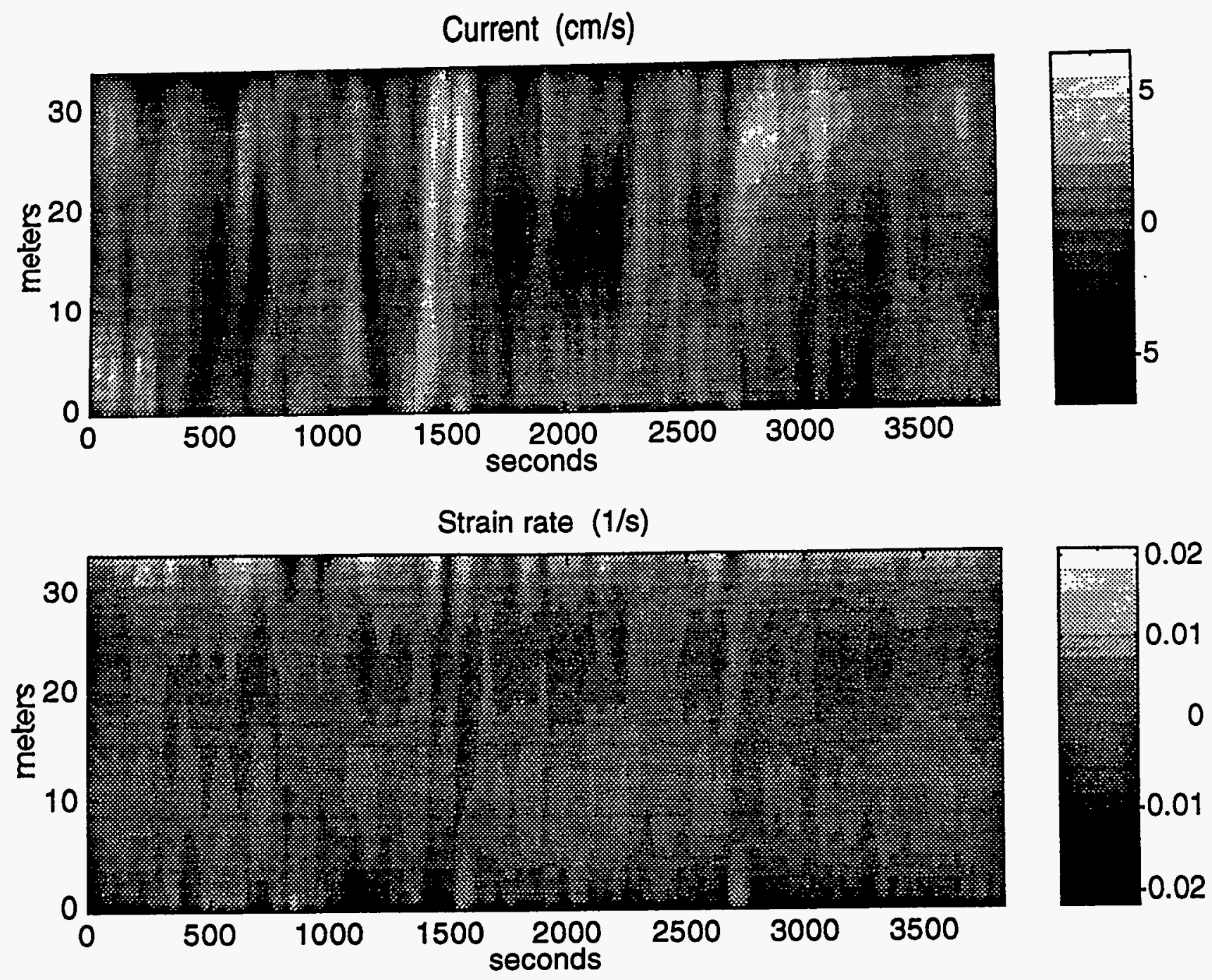
Serial 2, Run 3, 9/5/94
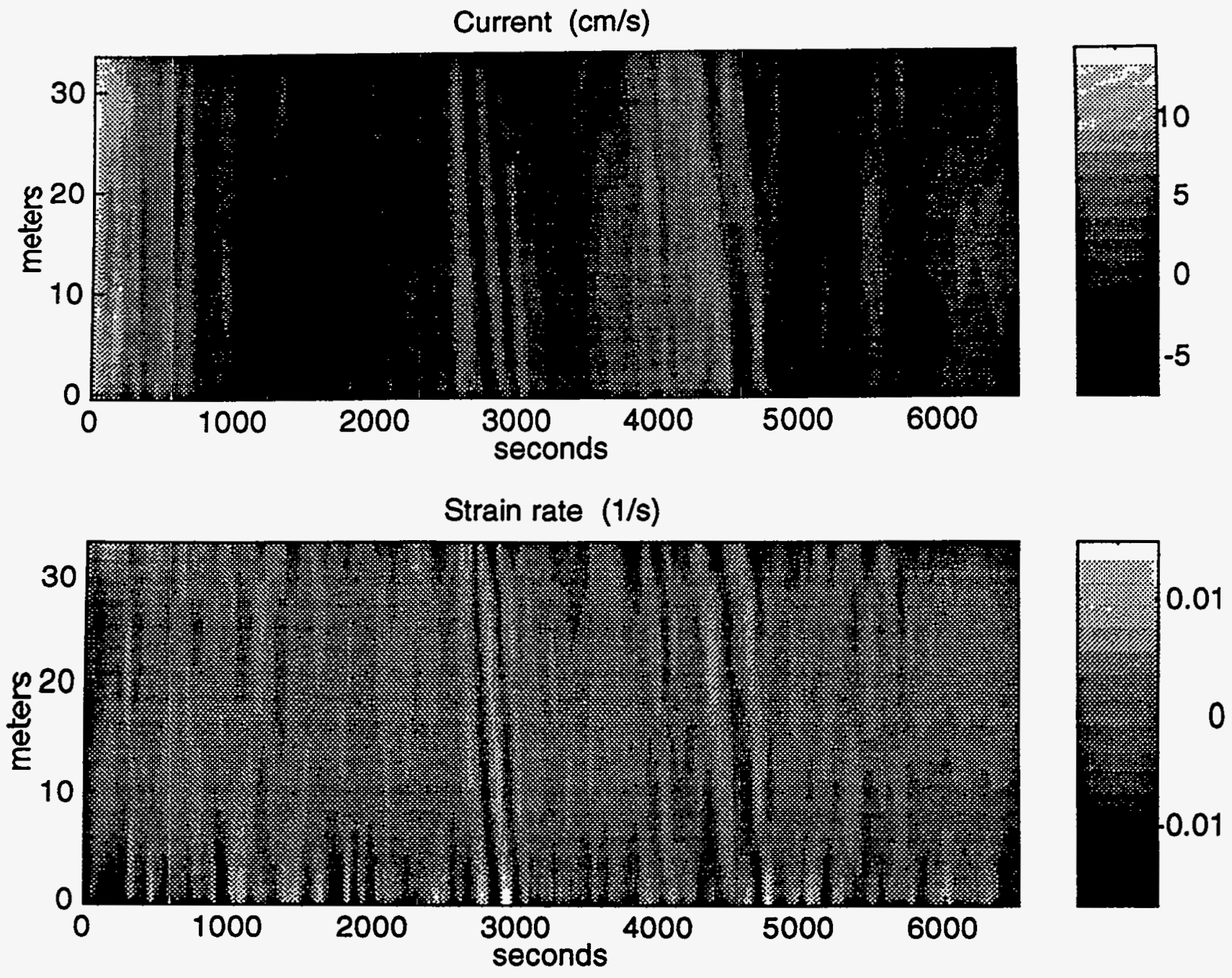
Serial 3, Run 1, 9/7/94

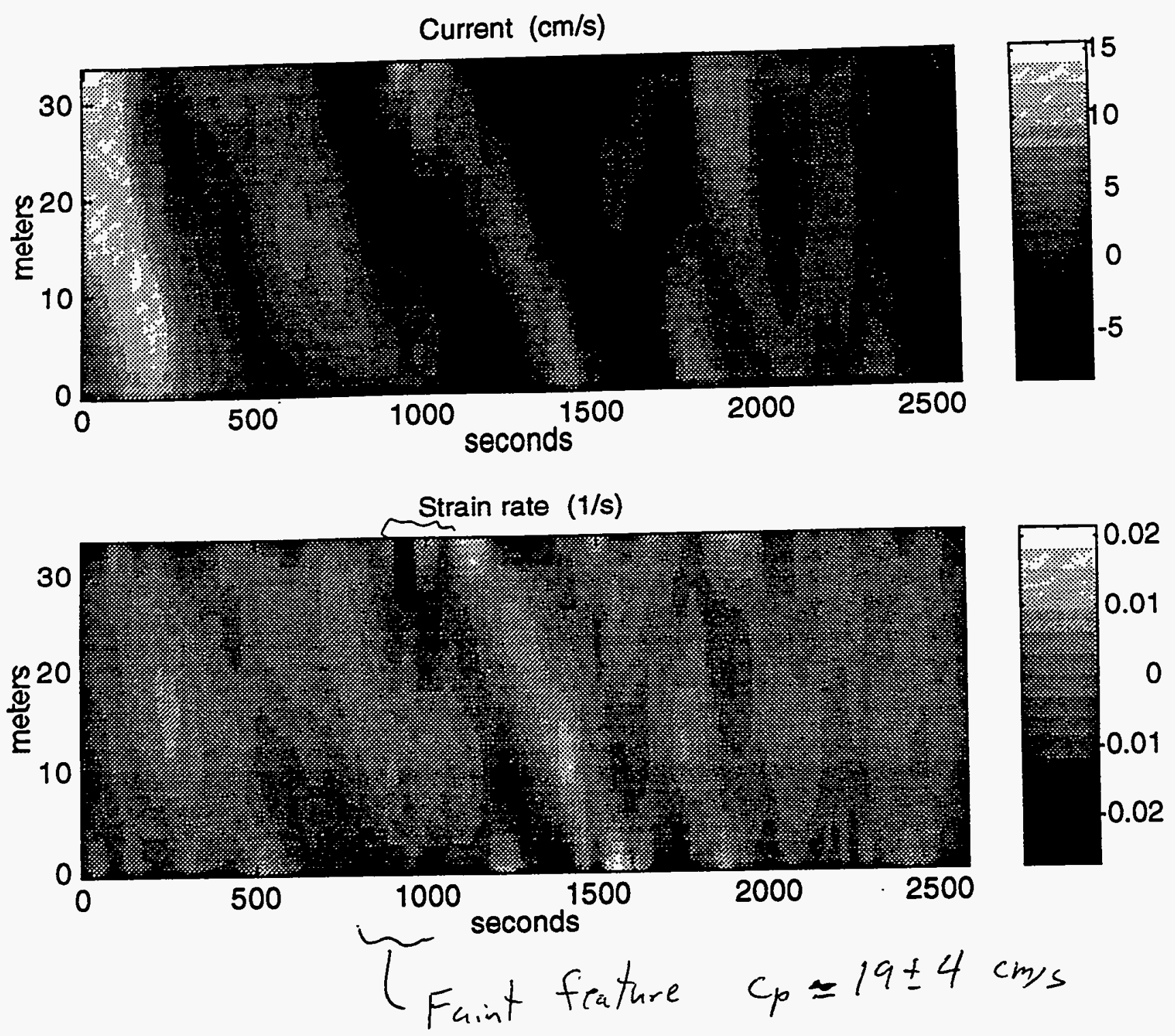


Serial 3, Run 2, 9/7/94
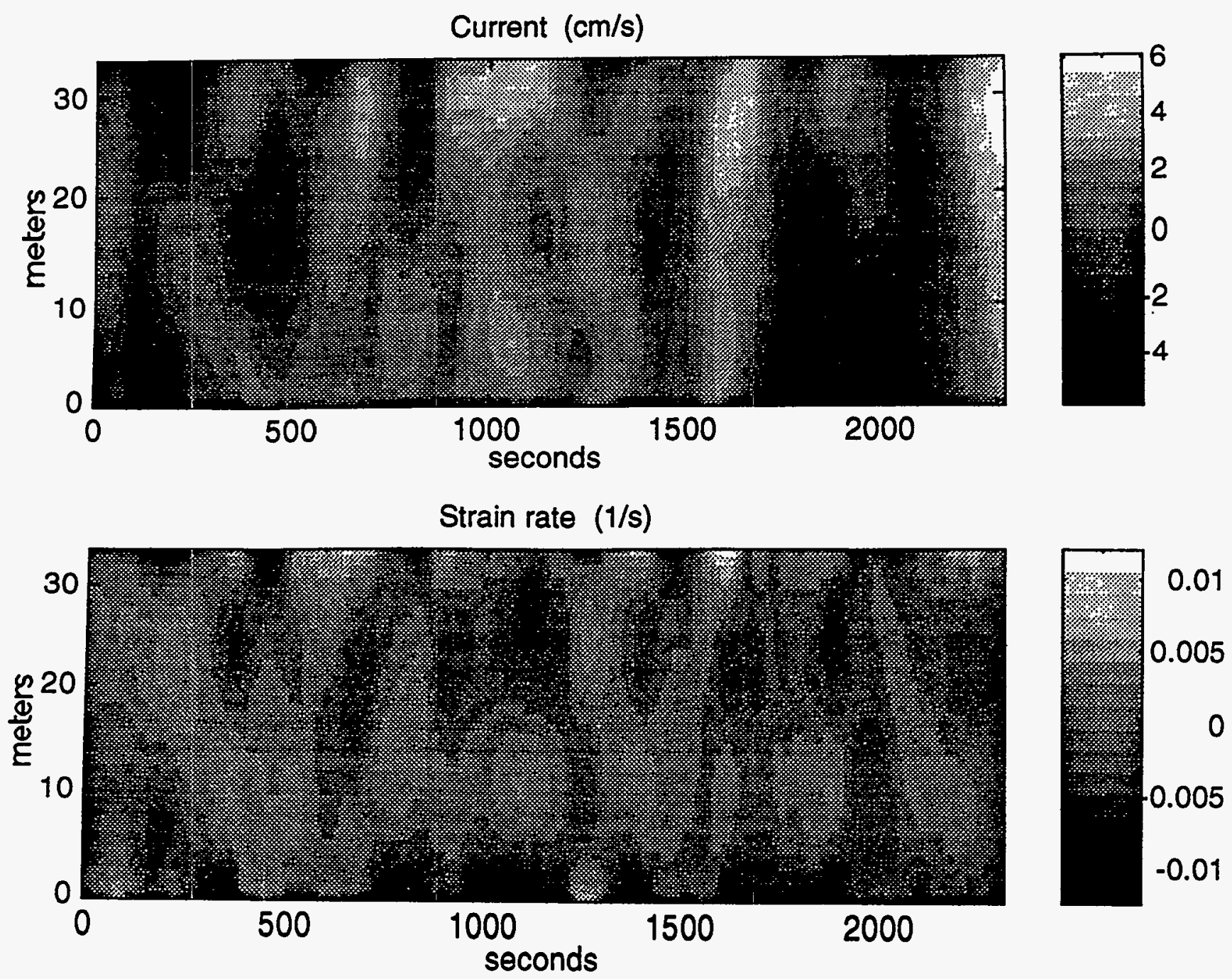
Serial 3, Run 3, 9/7/94
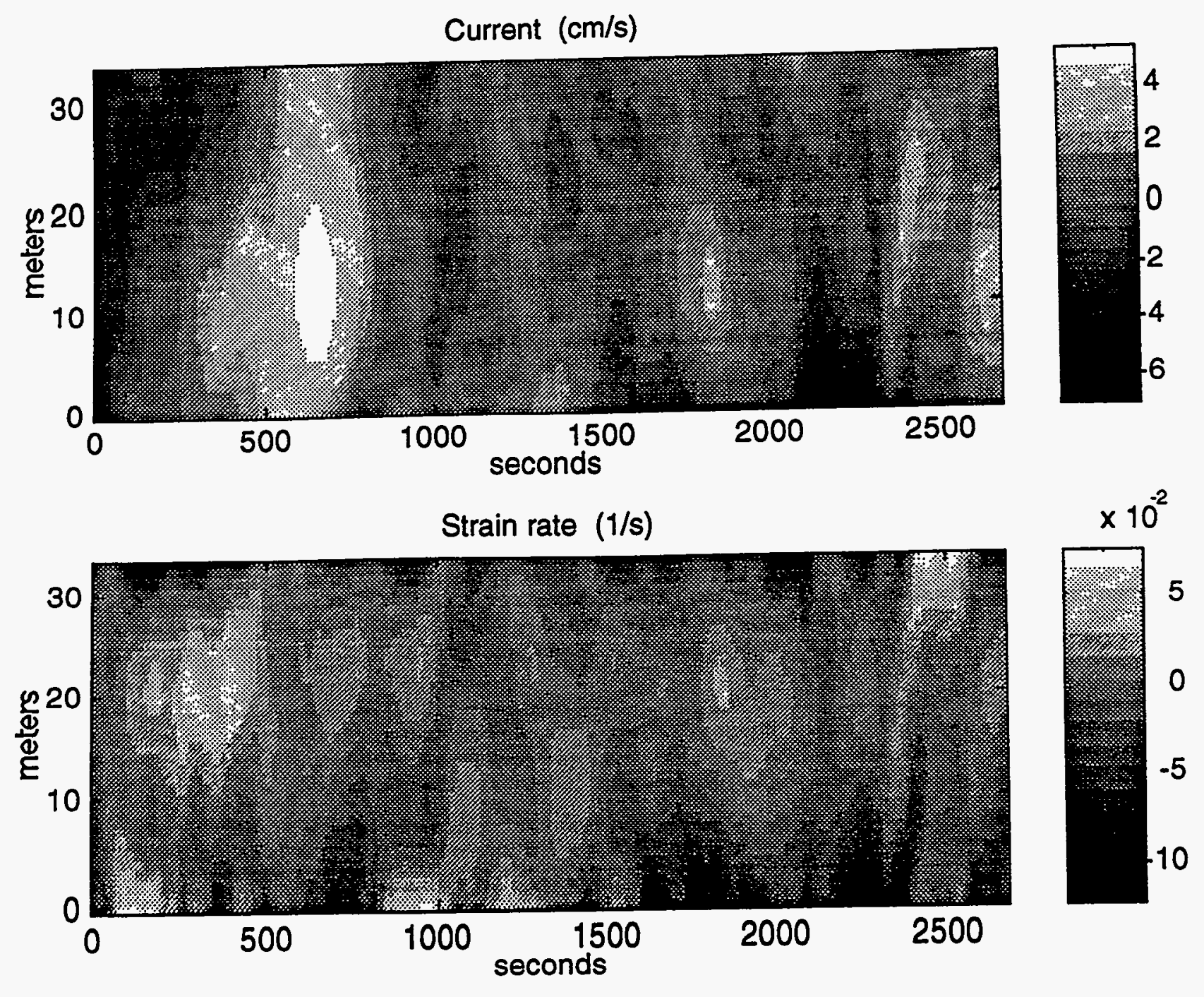


\section{Serial 4, Run 1, 9/8/94}
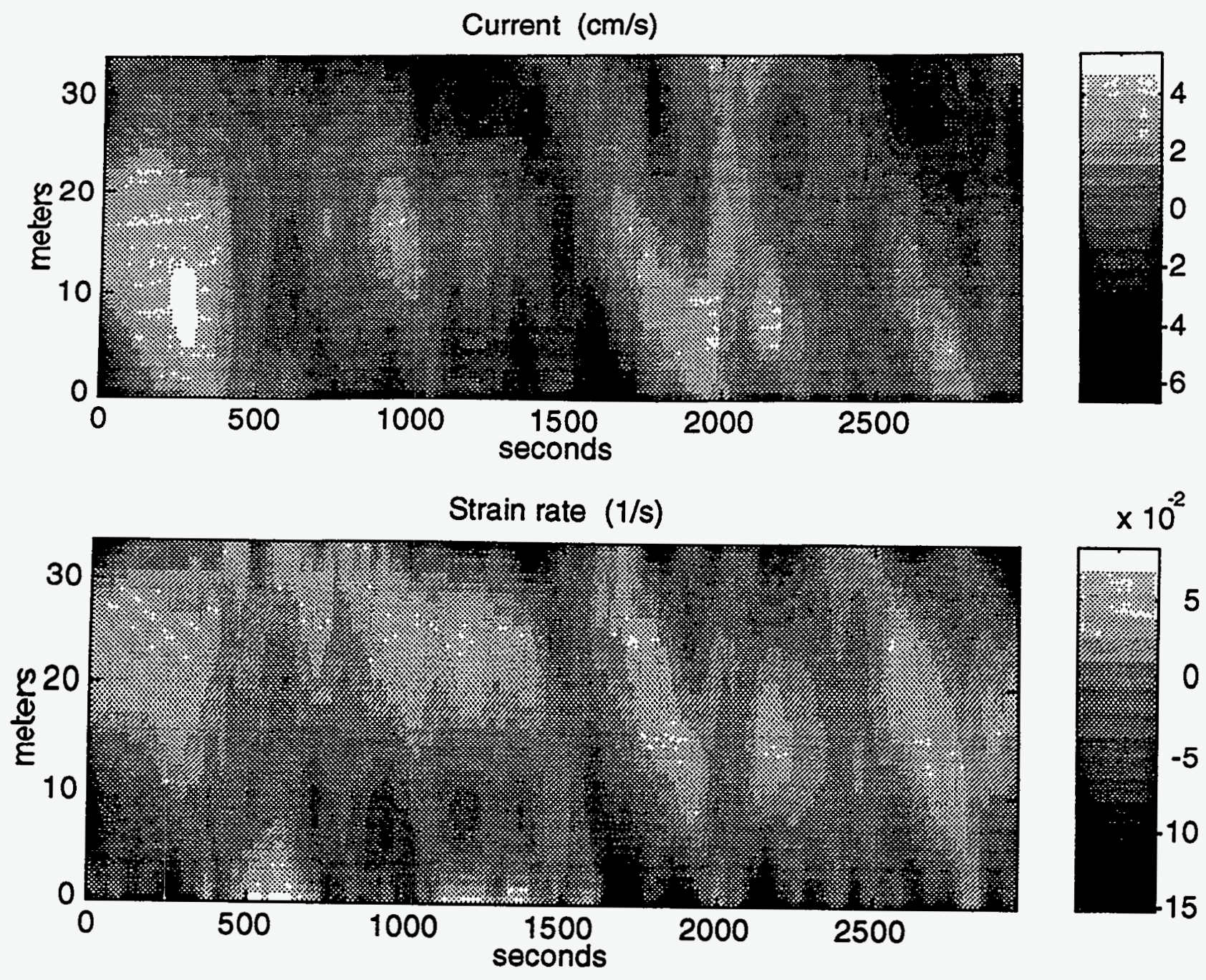
Serial 4, Run 2, 9/8/94
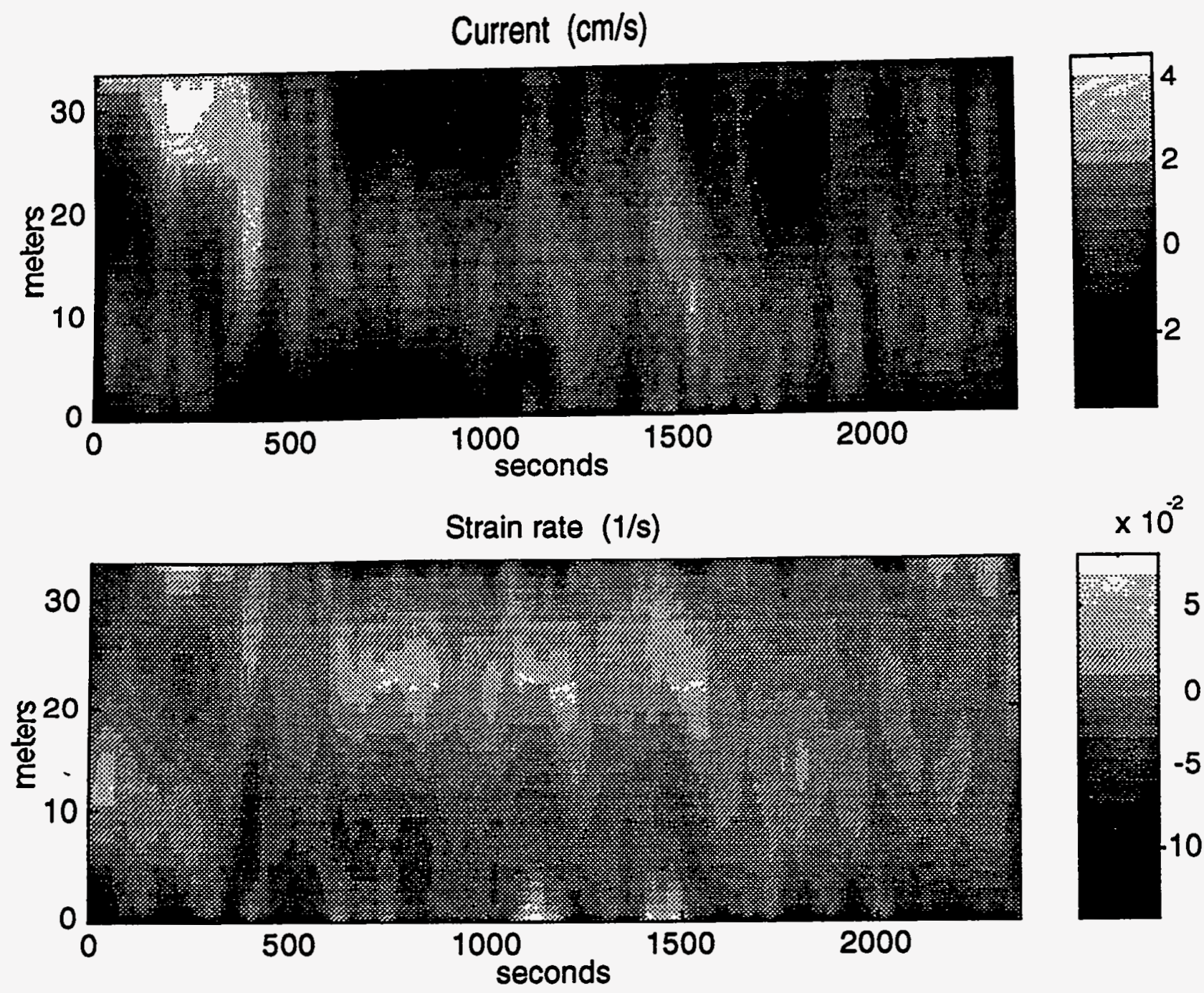
Serial 4, Run 3, 9/8/94
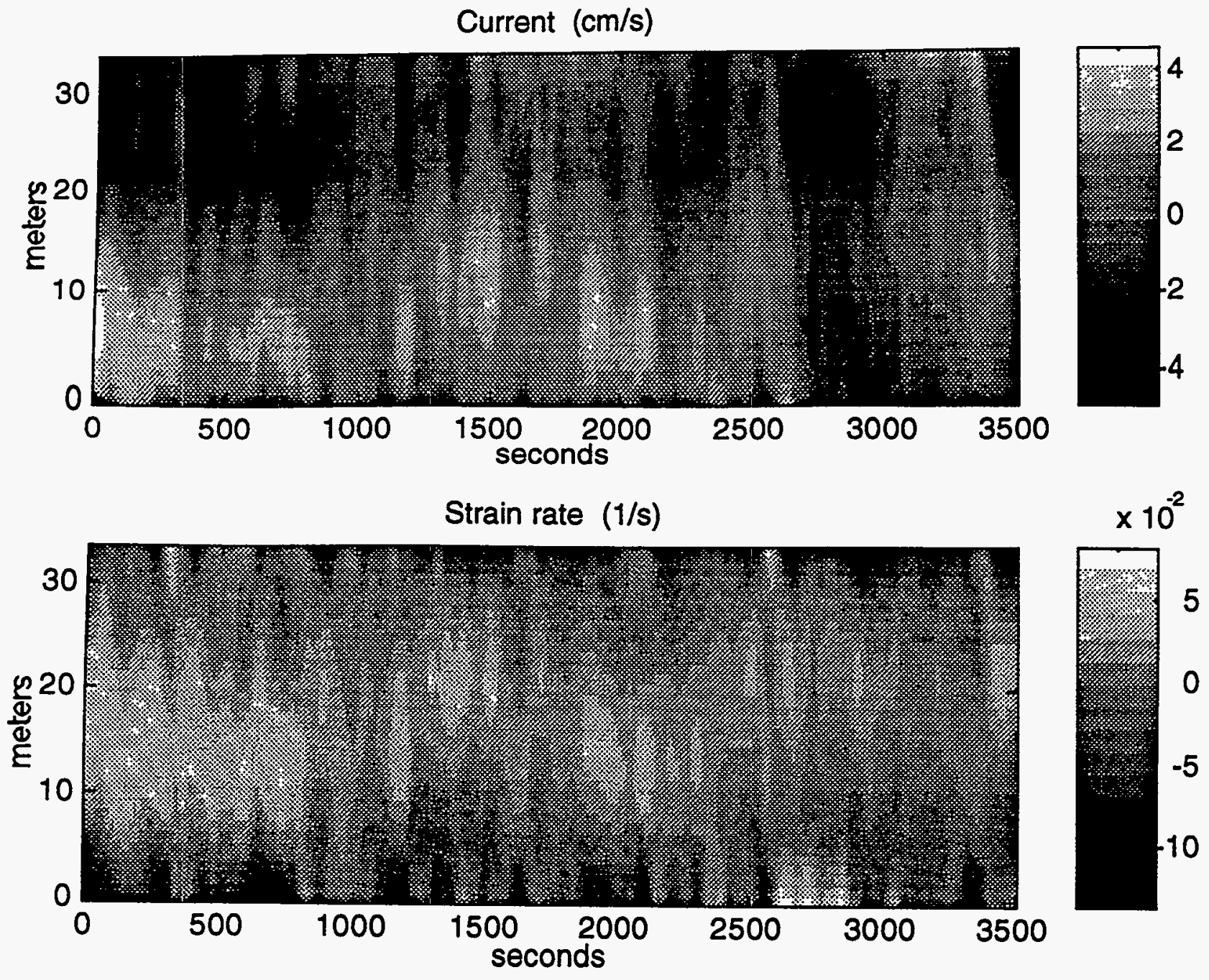
Serial 4, Run 4 9/8/94

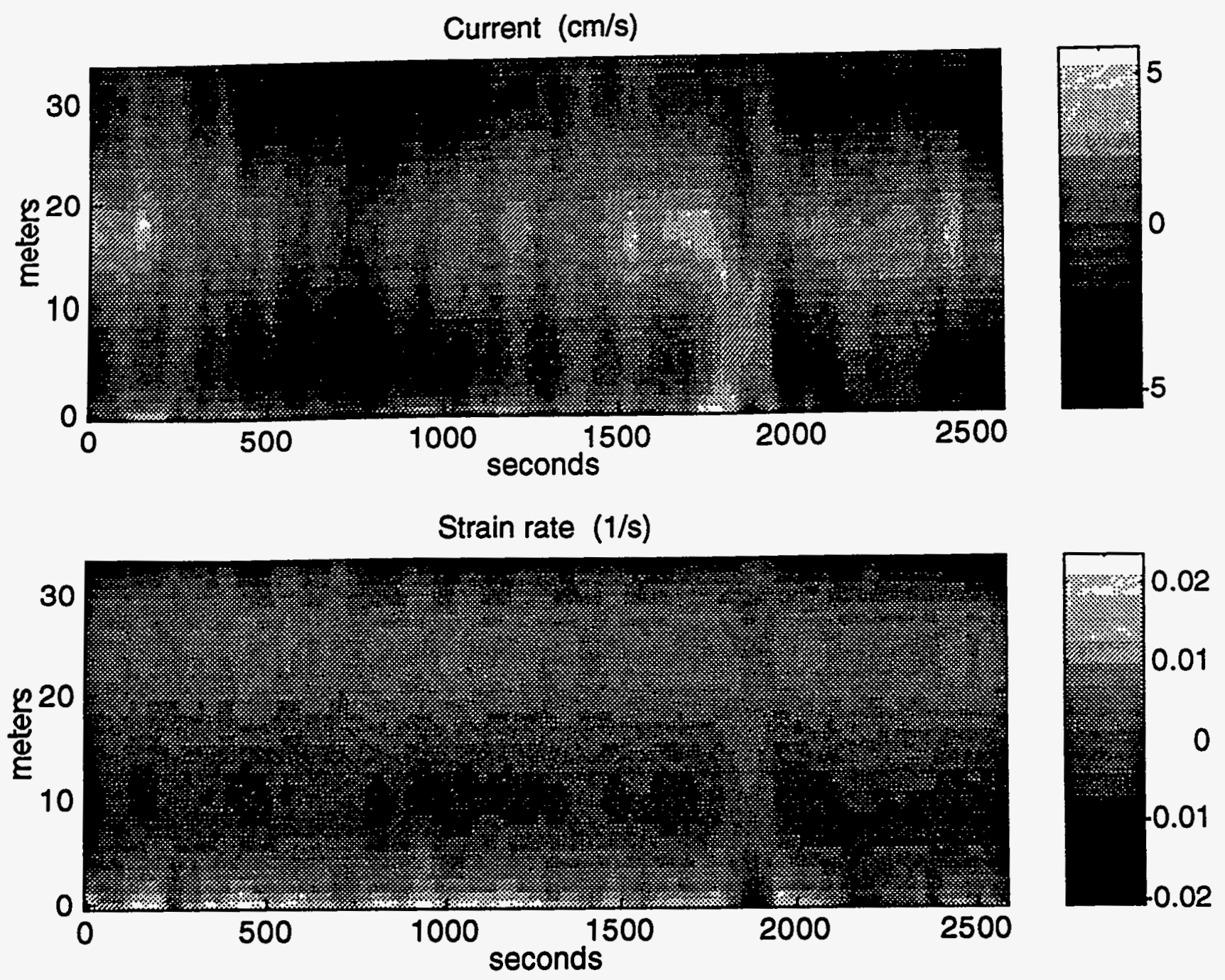


Serial 4, Run 5, 9/8/94

Current $(\mathrm{cm} / \mathrm{s})$
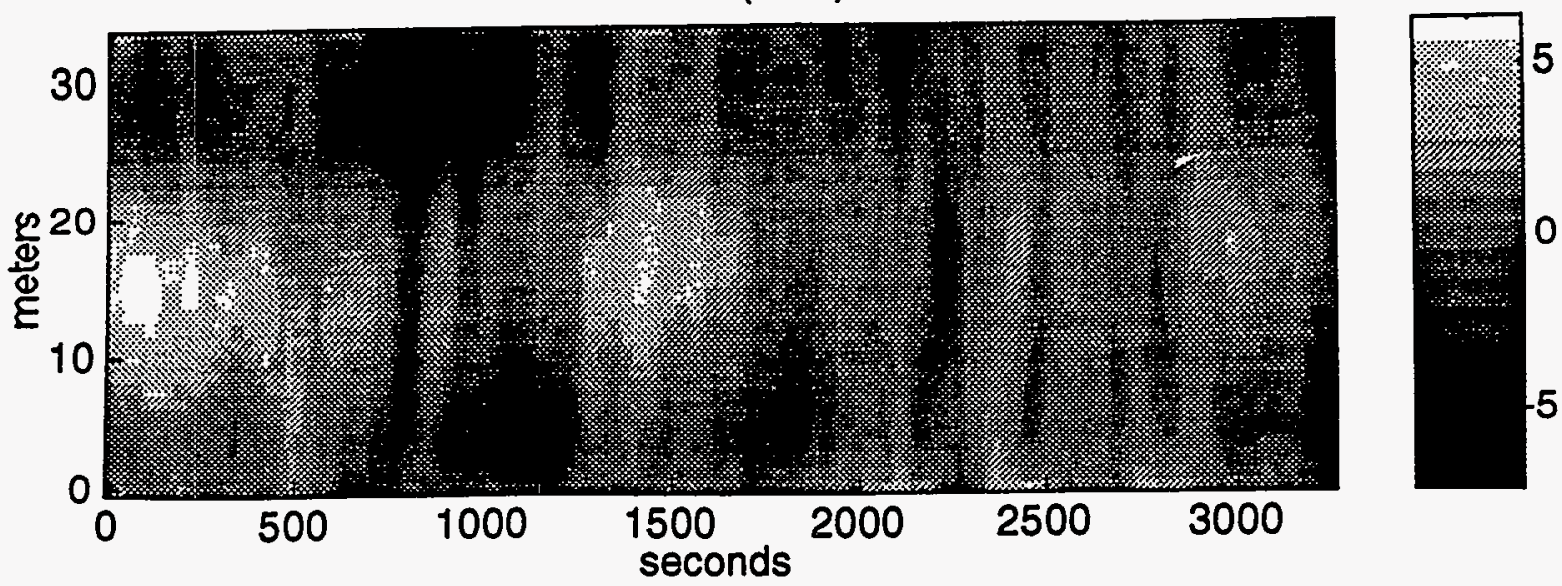

Strain rate $(1 / s)$

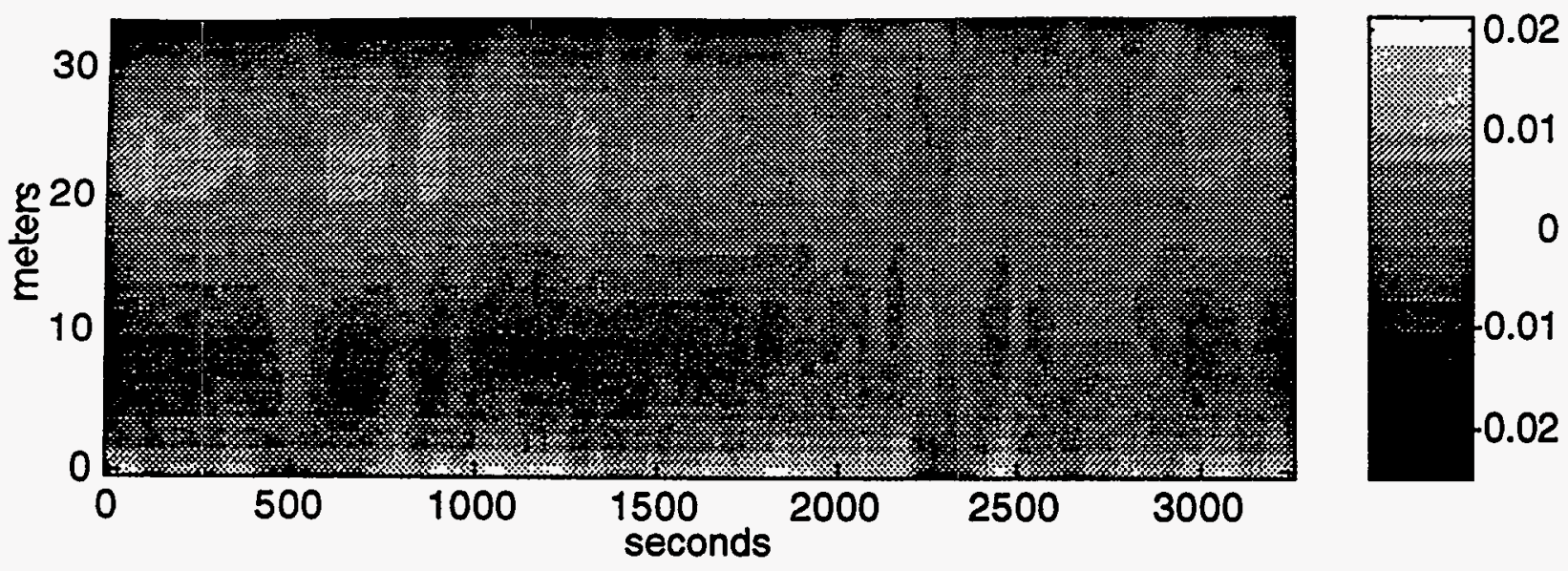


Serial 4, Run 6, 9/8/94
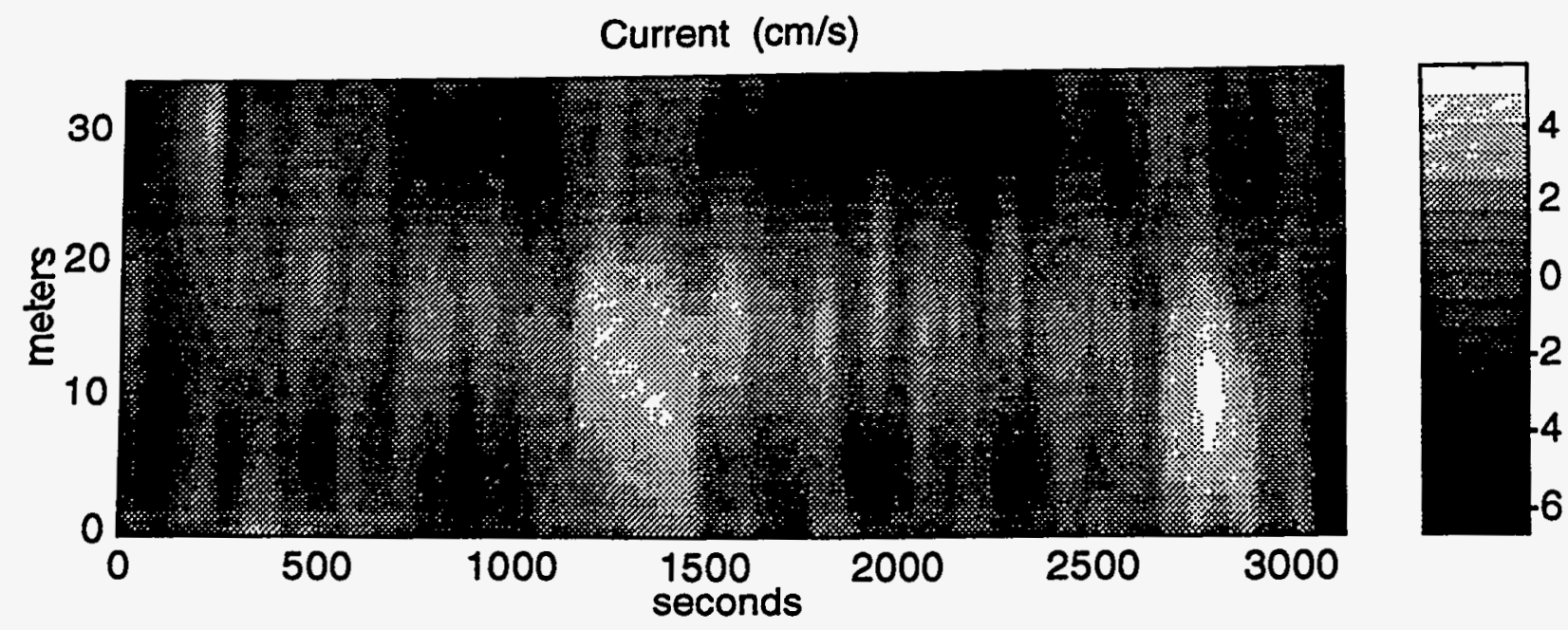

Strain rate $(1 / s)$

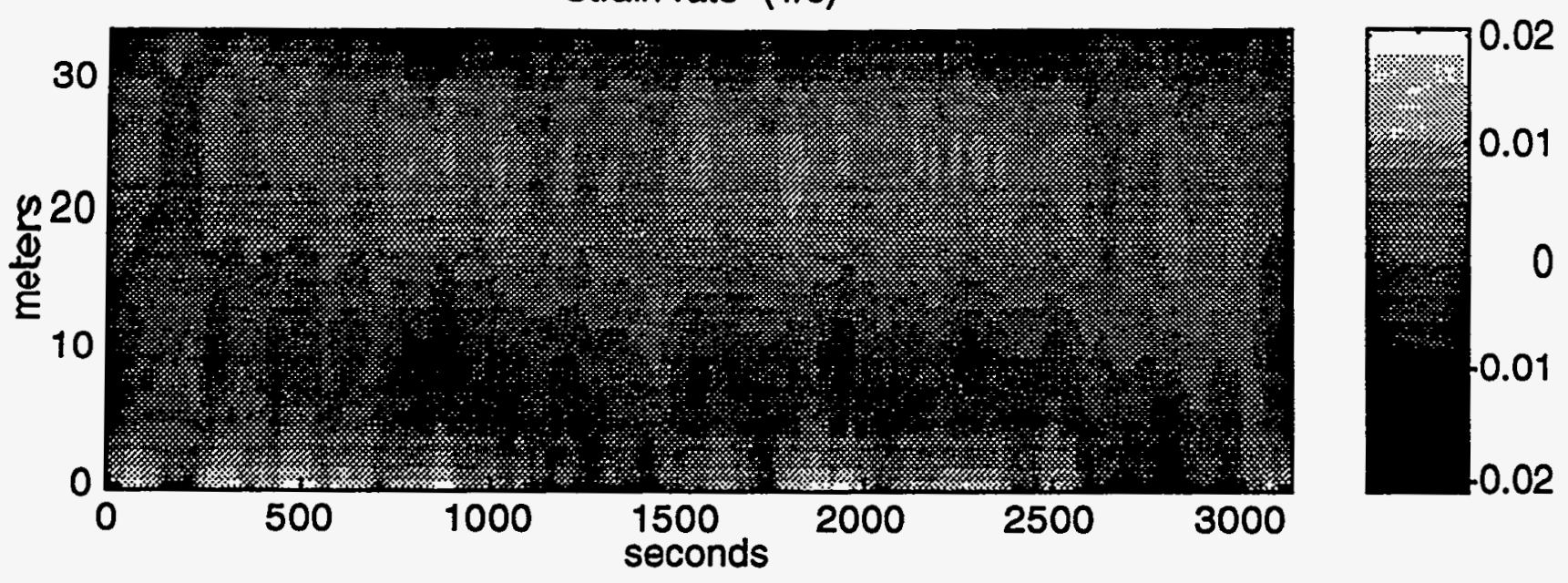


Serial 5, Run 1, 9/9/94
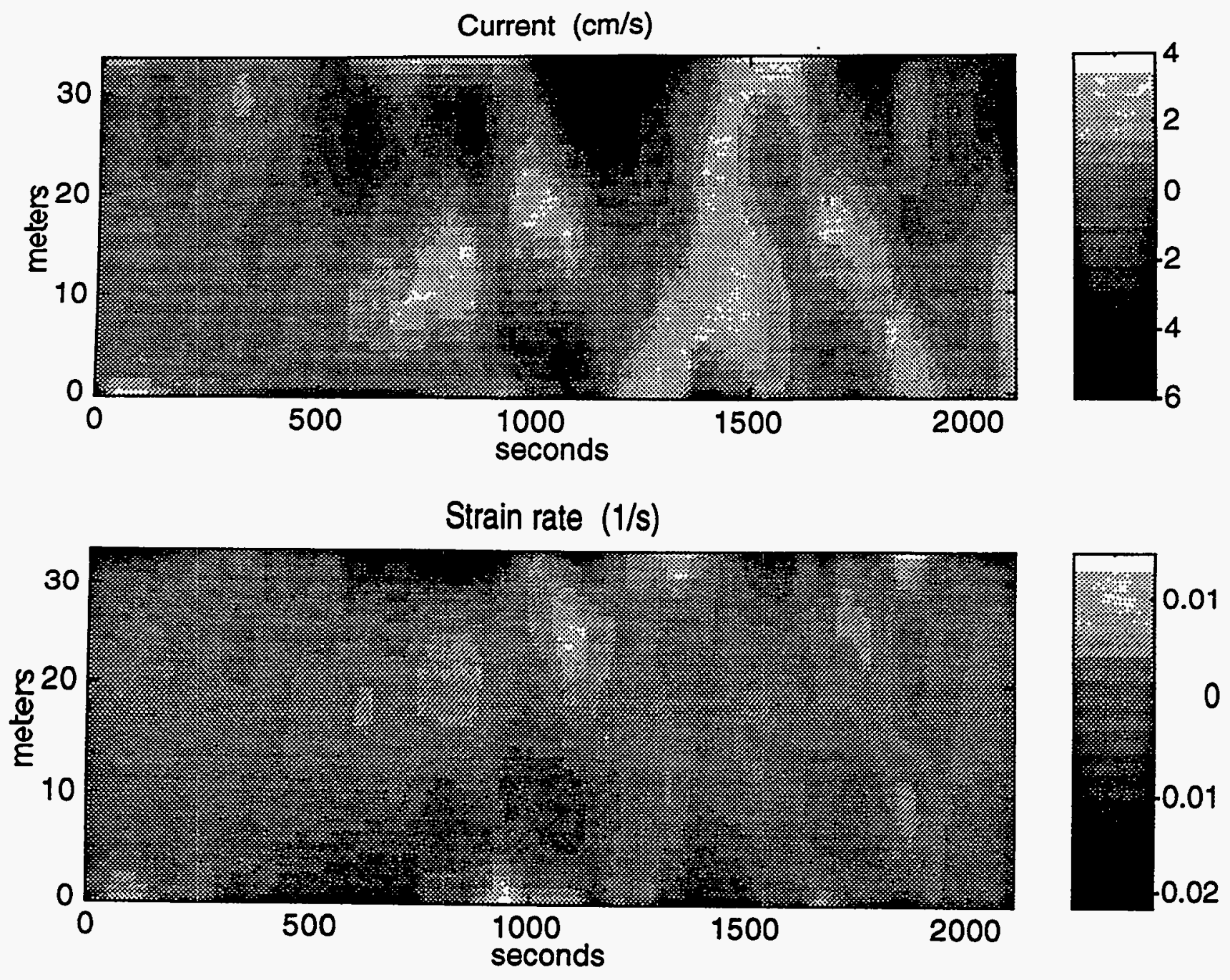
Serial 5, Run 2, 9/9/94

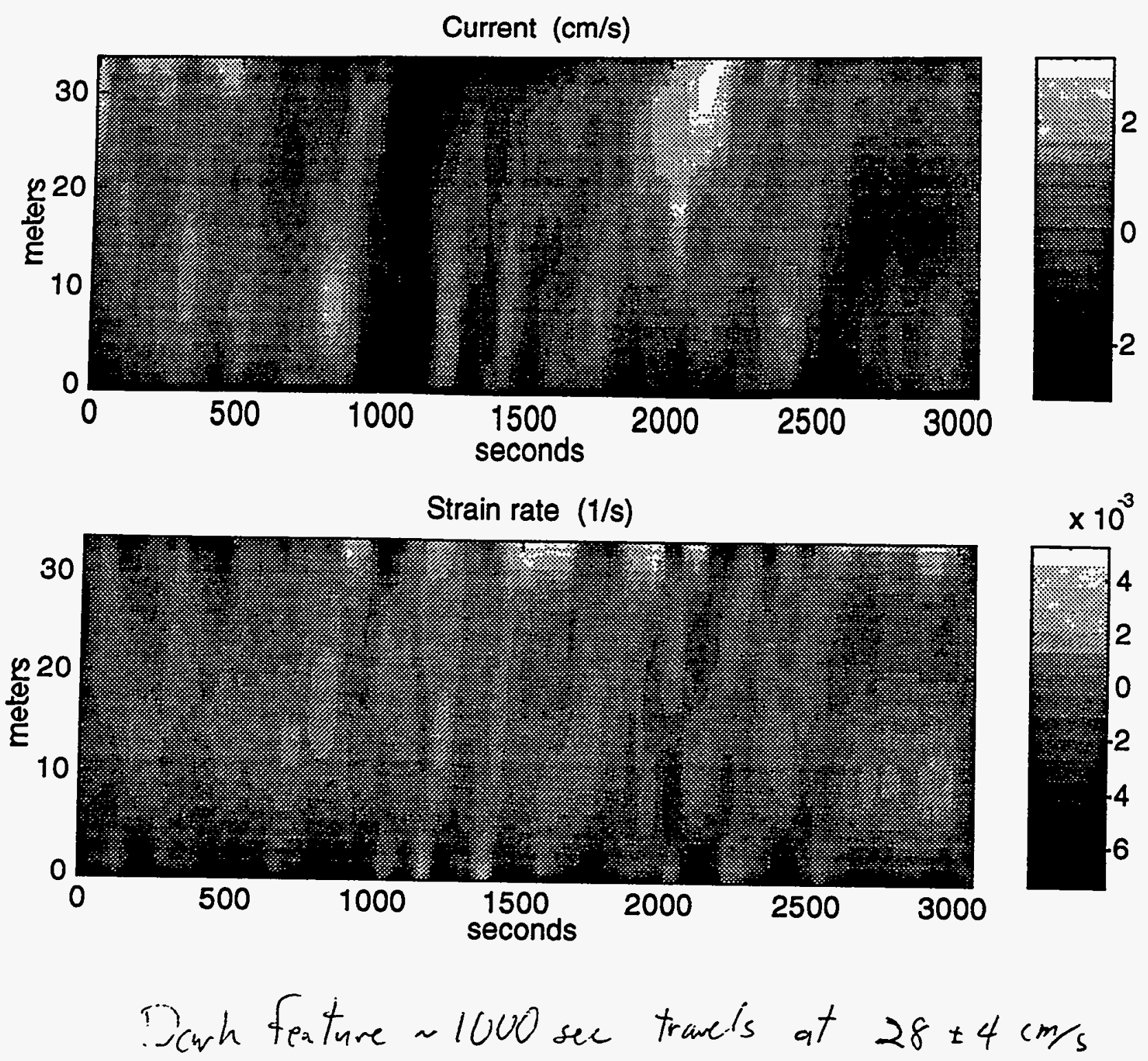


Serial 5, Run 3, 9/9/94

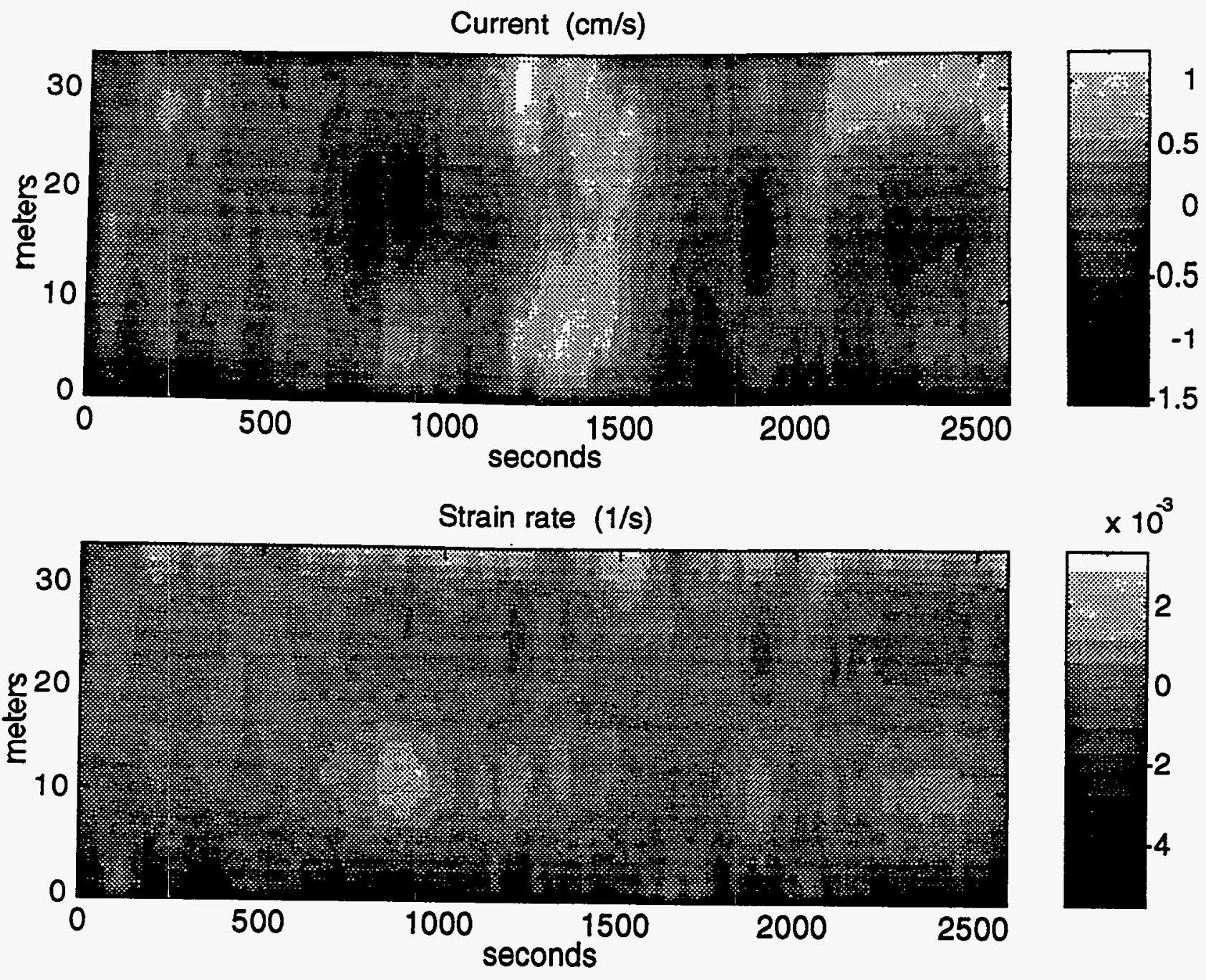


Serial 5, Run 4, 9/9/94
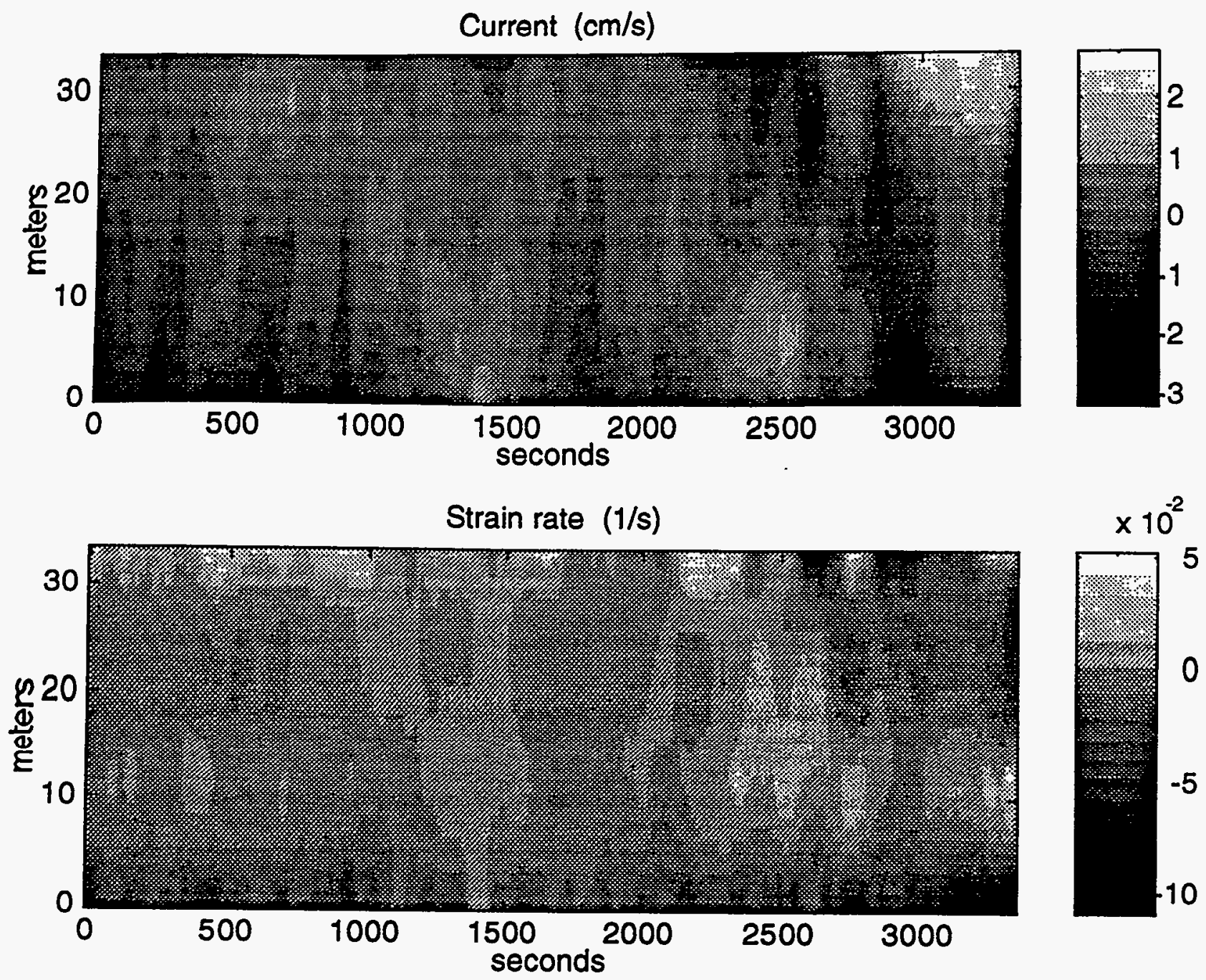
Serial 7, Run 2, 9/11/94

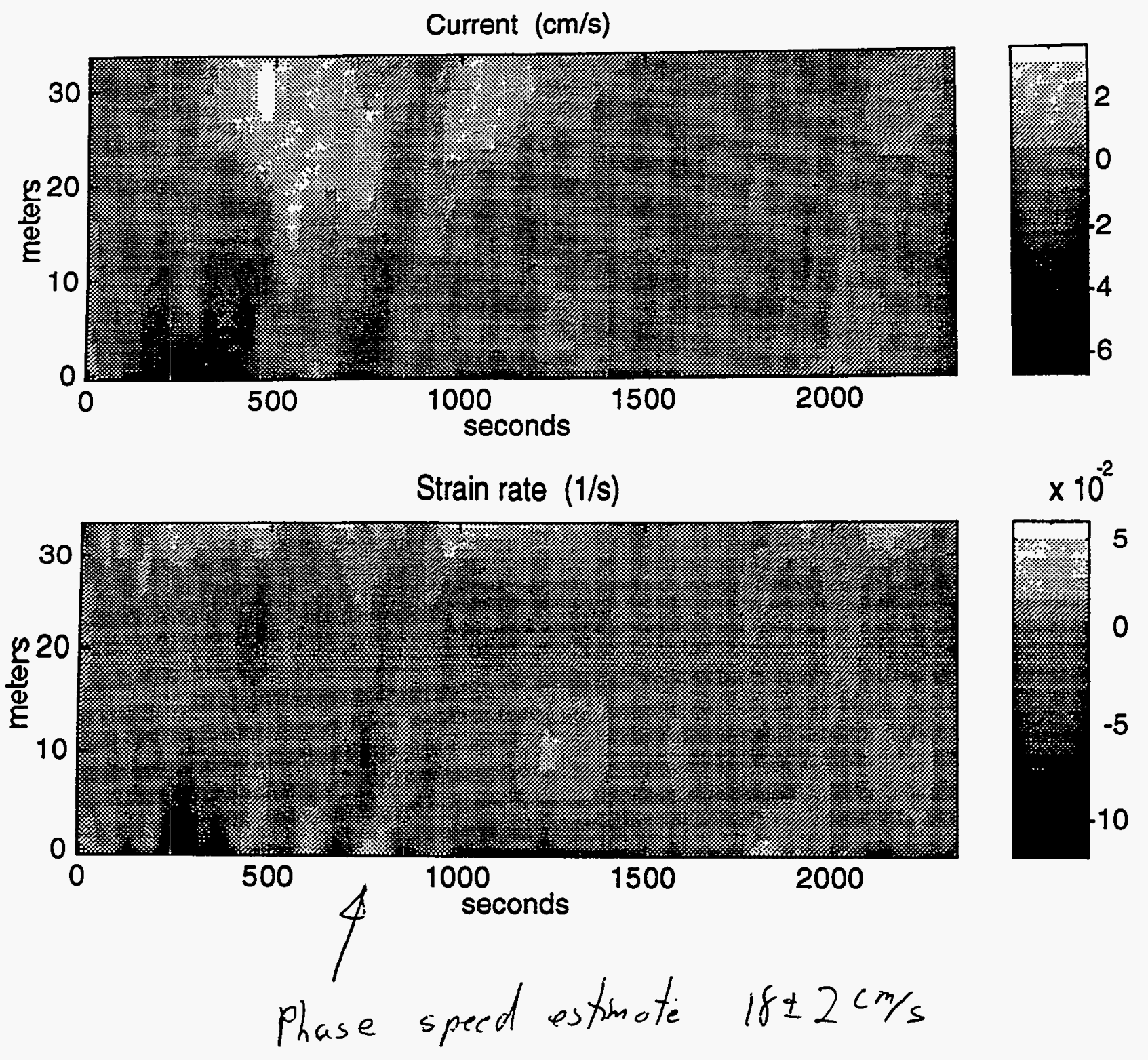


Serial 7, Run 5, 9/11/94
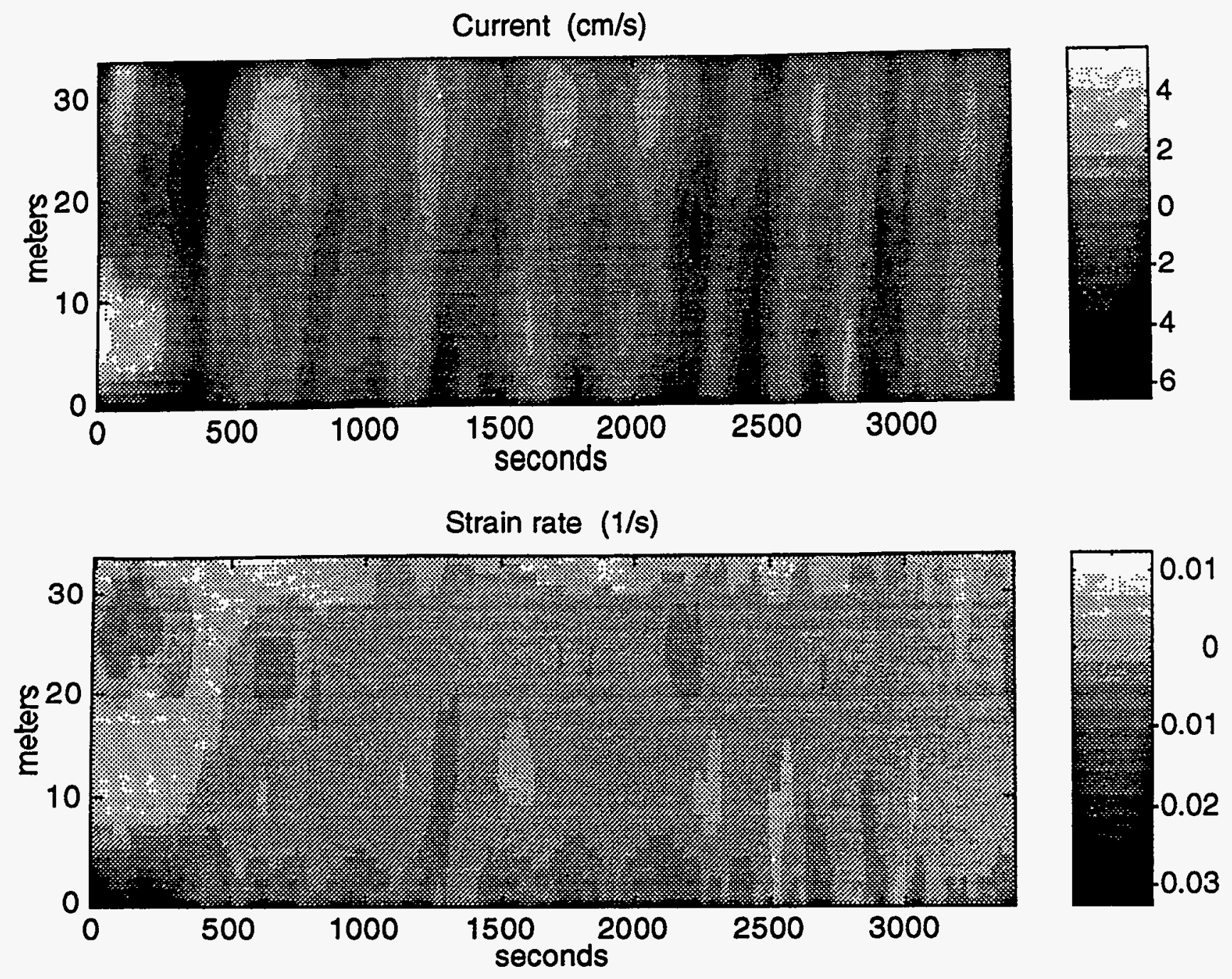
Serial 8, Run 1, 9/12/94
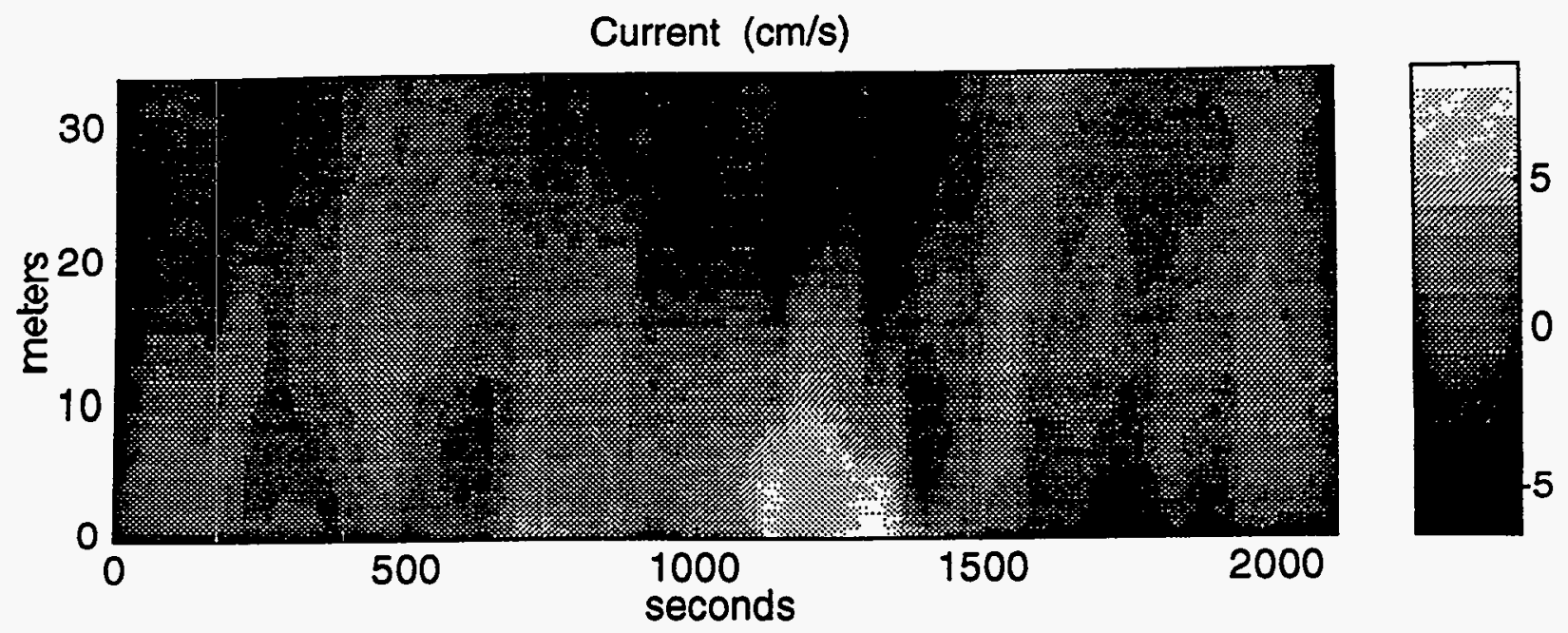

Strain rate $(1 / s)$

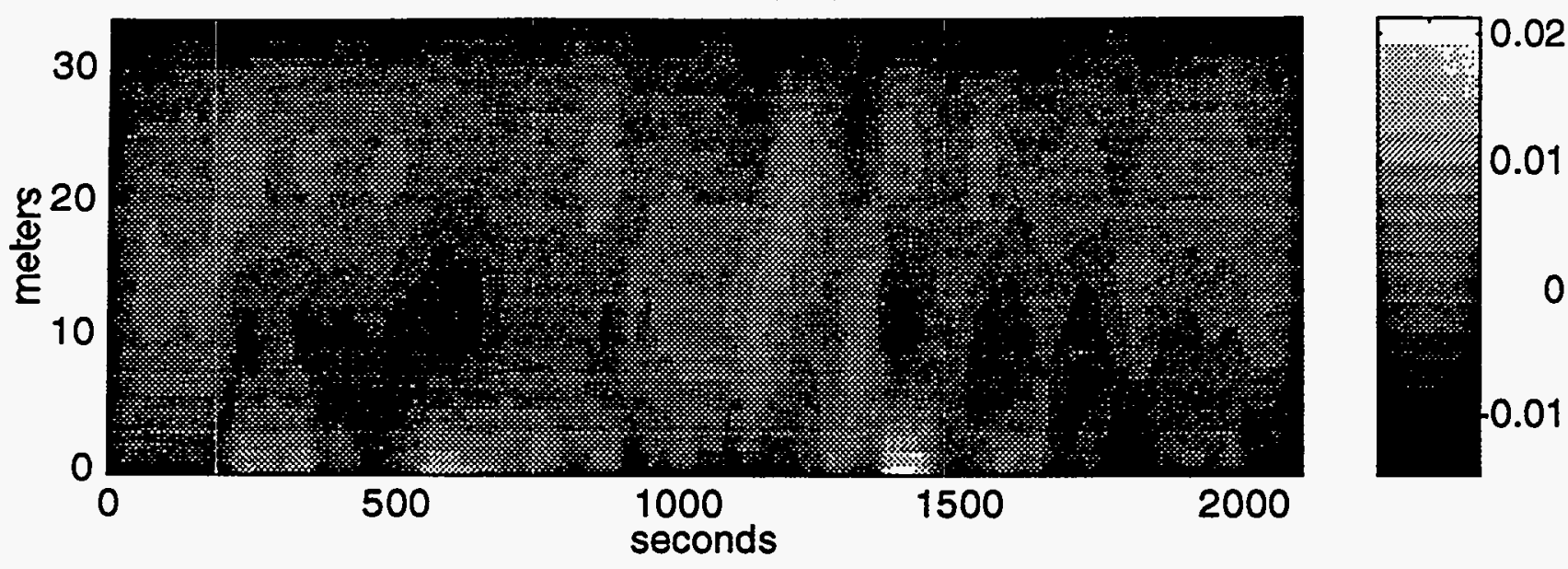


Serial 8, Run 2, 9/12/94
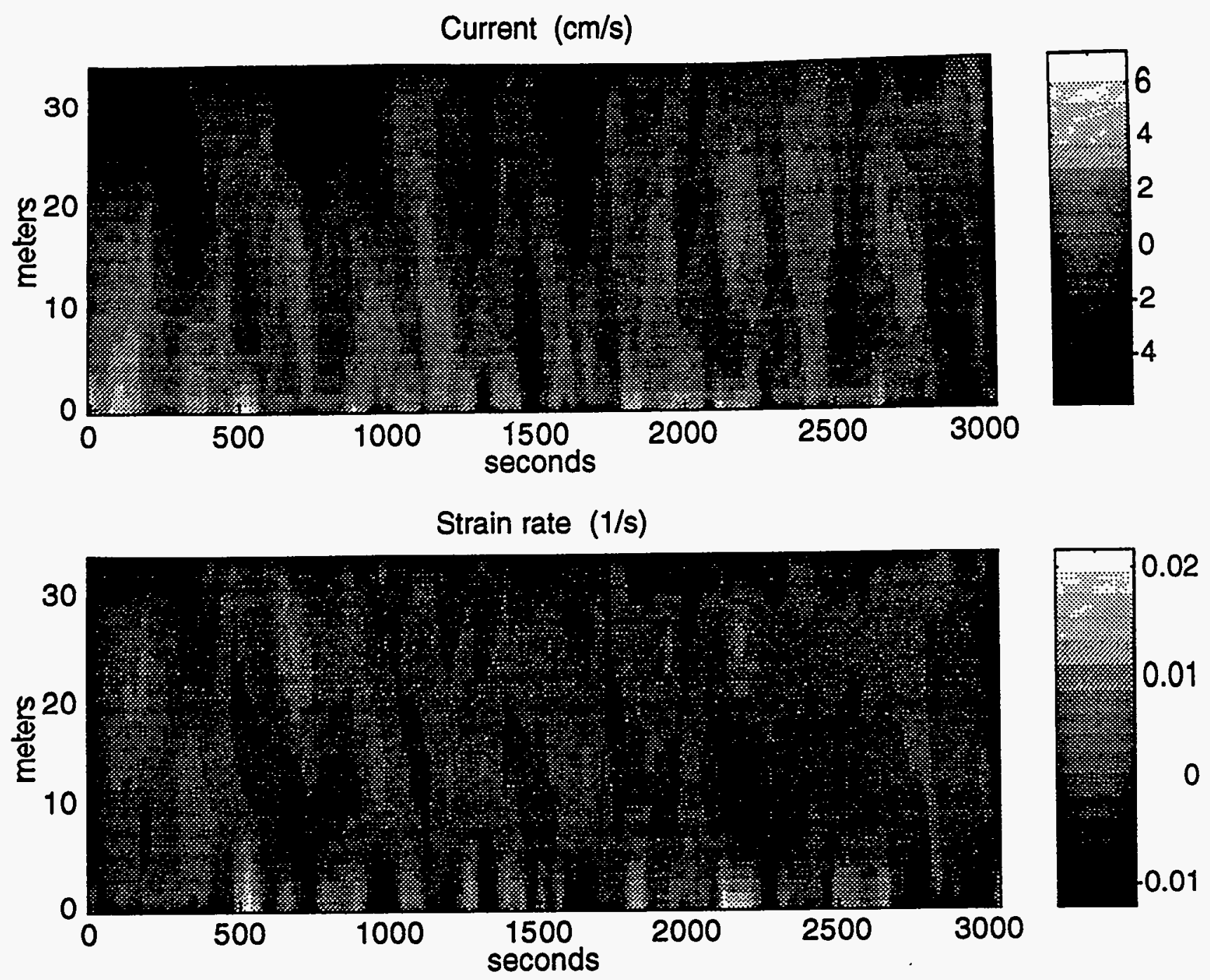
Serial 8, Run 3, 9/12/94

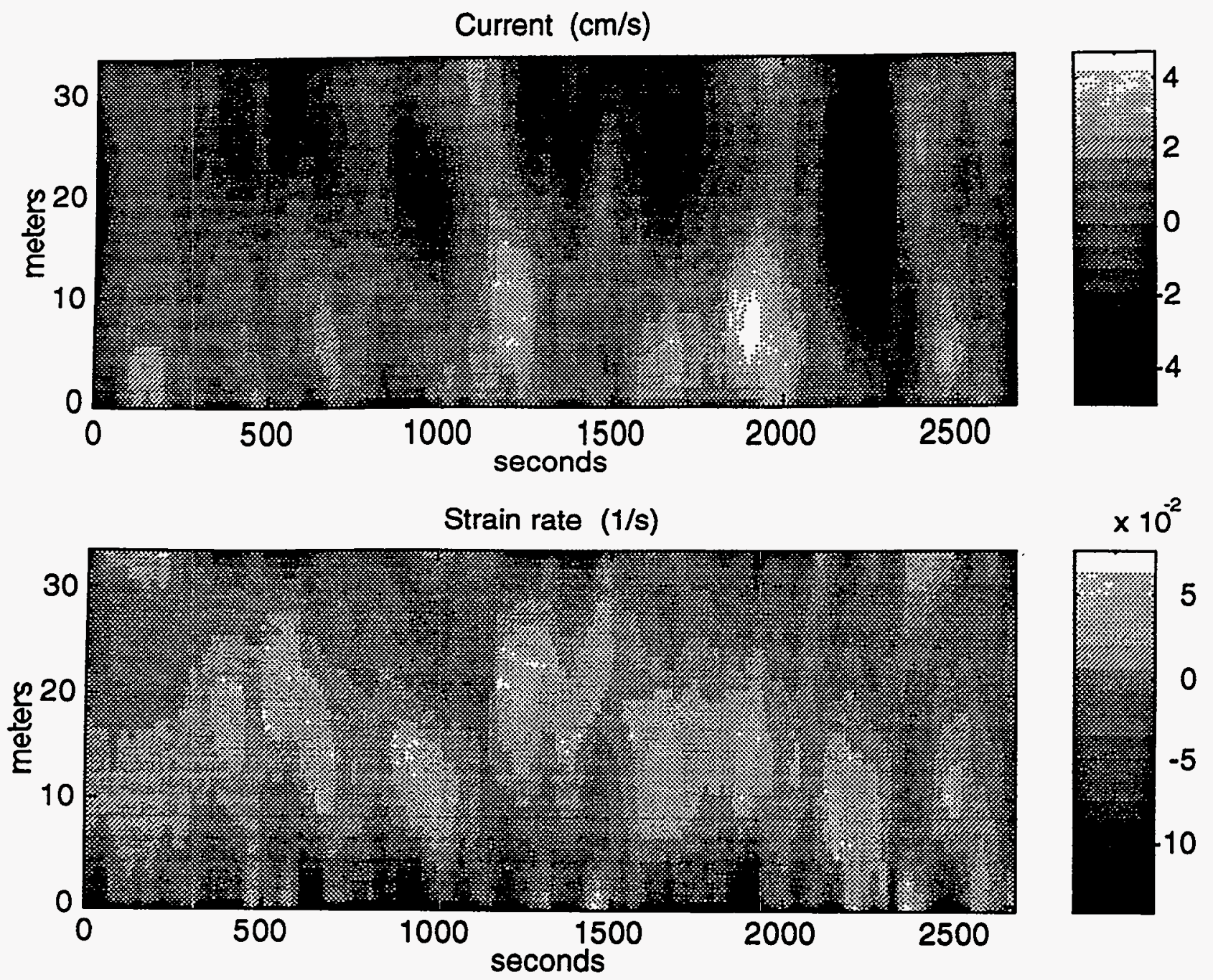


Serial 8, Run 4, 9/12/94

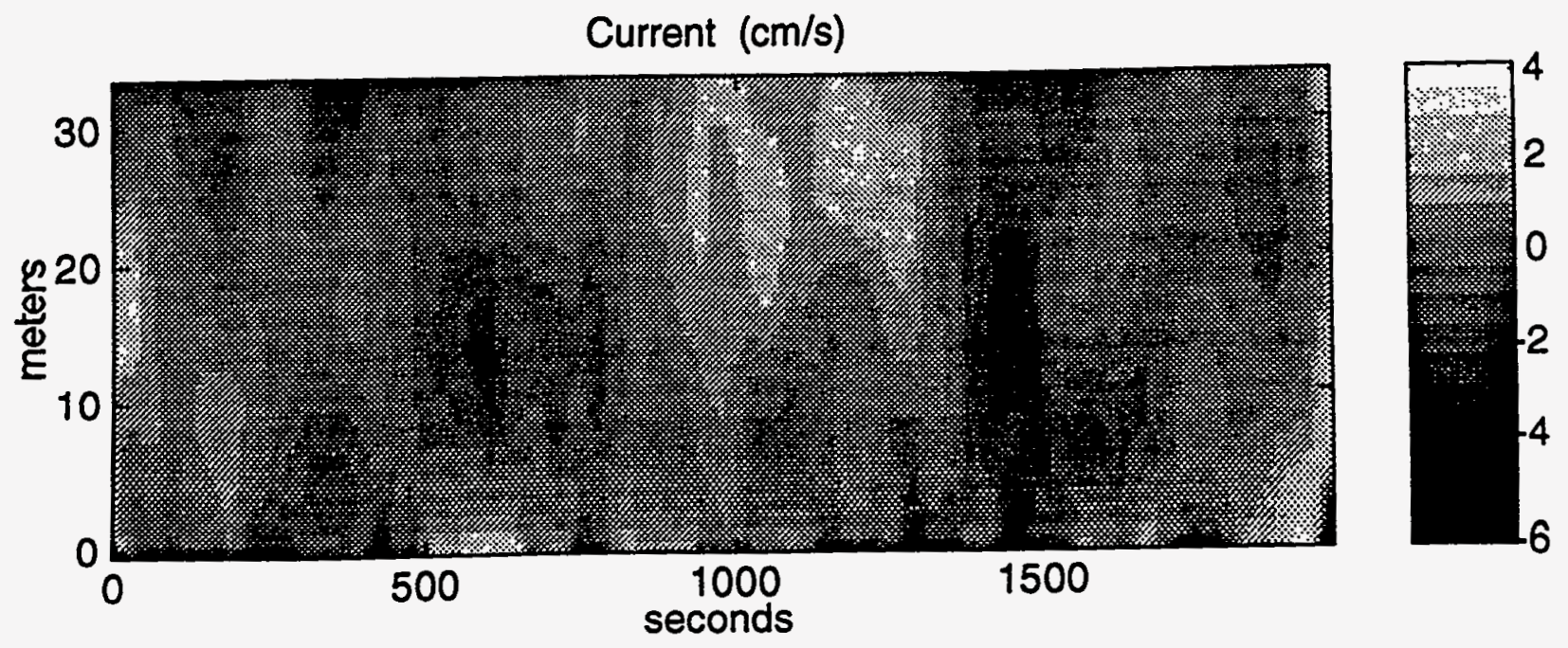

Strain rate $(1 / \mathrm{s})$

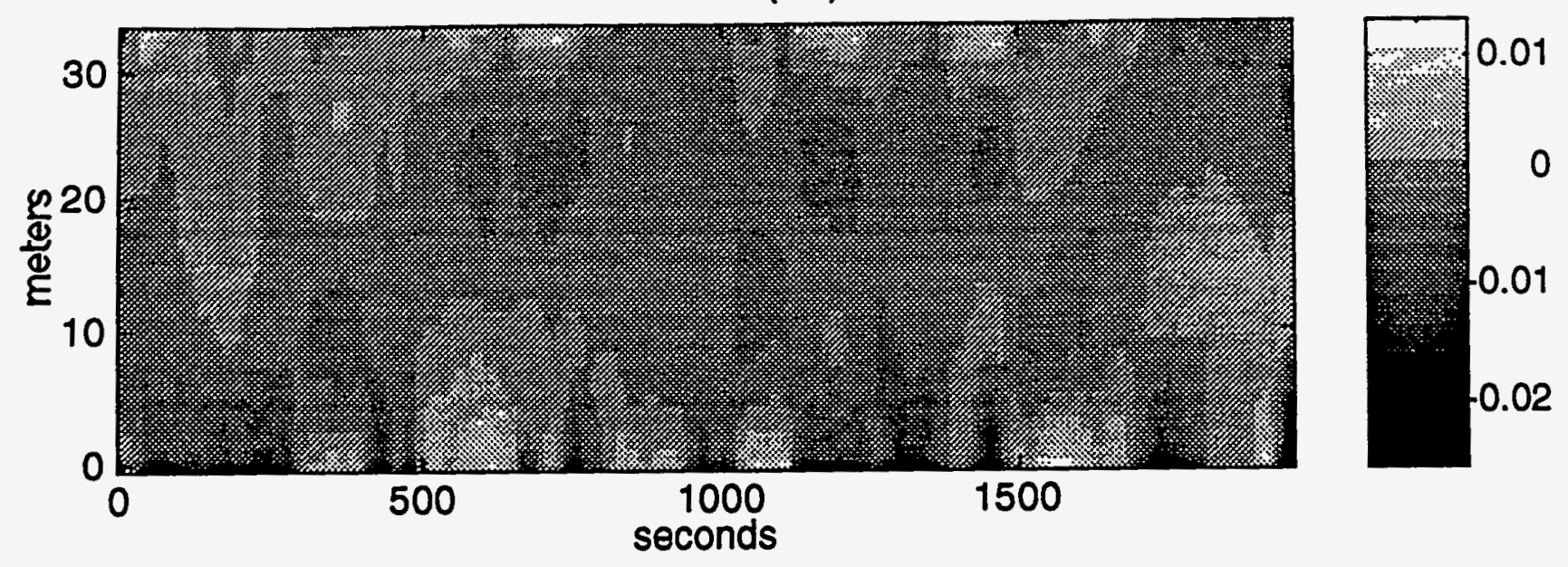


Serial 8 , Run 5, 9/12/94

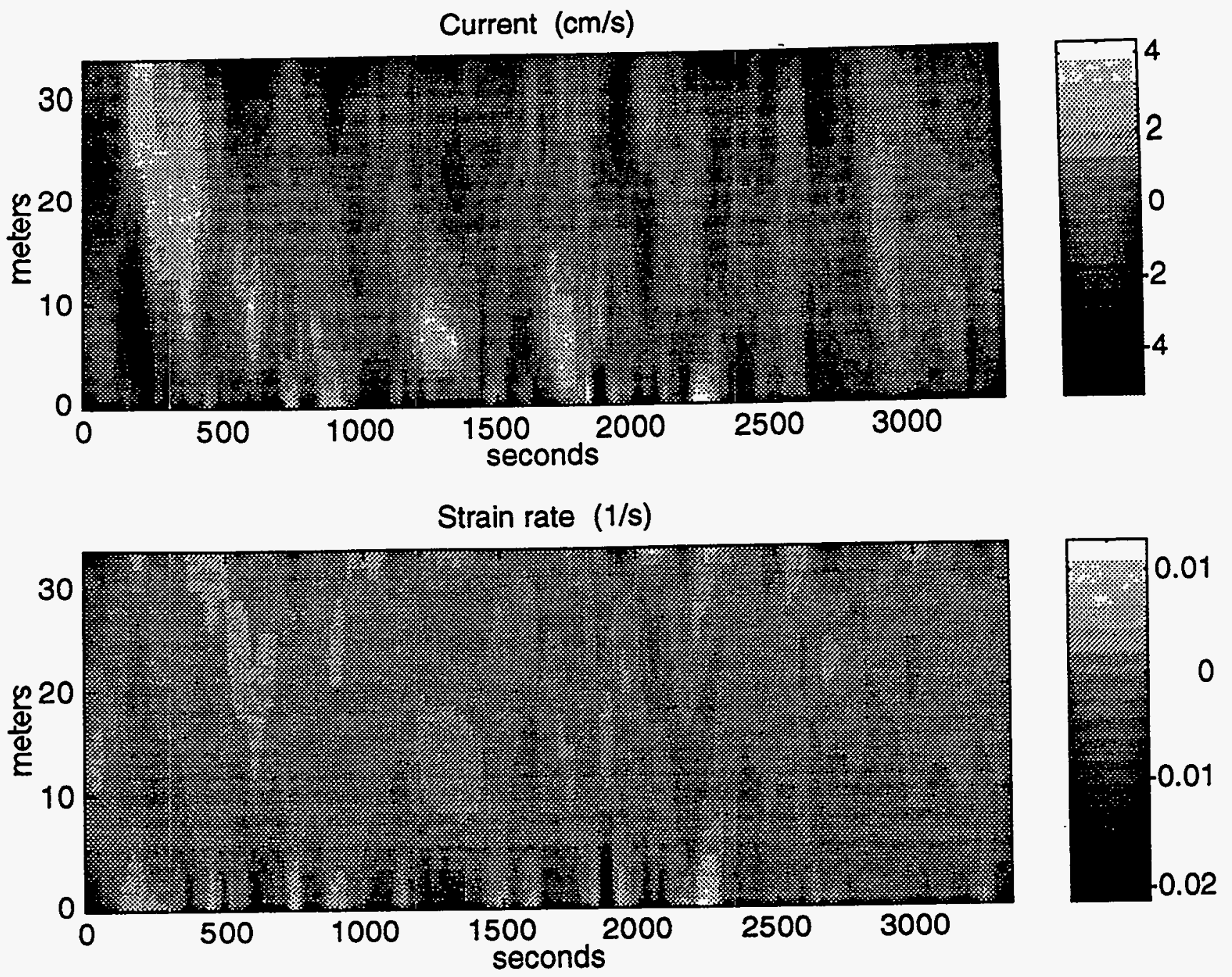


Serial 8 , Run $6,9 / 12 / 94$
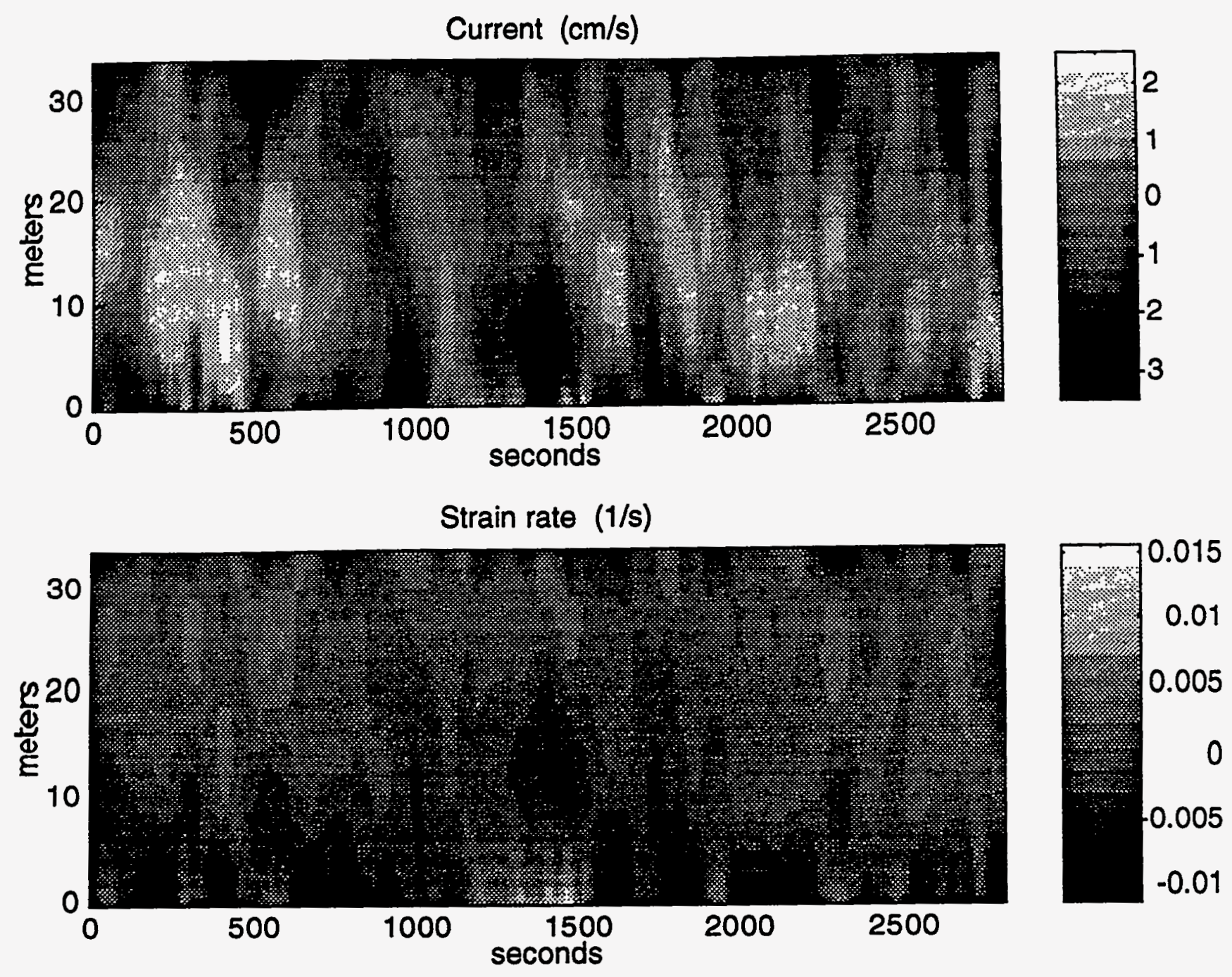
Serial 9, Run 1, 9/13/94

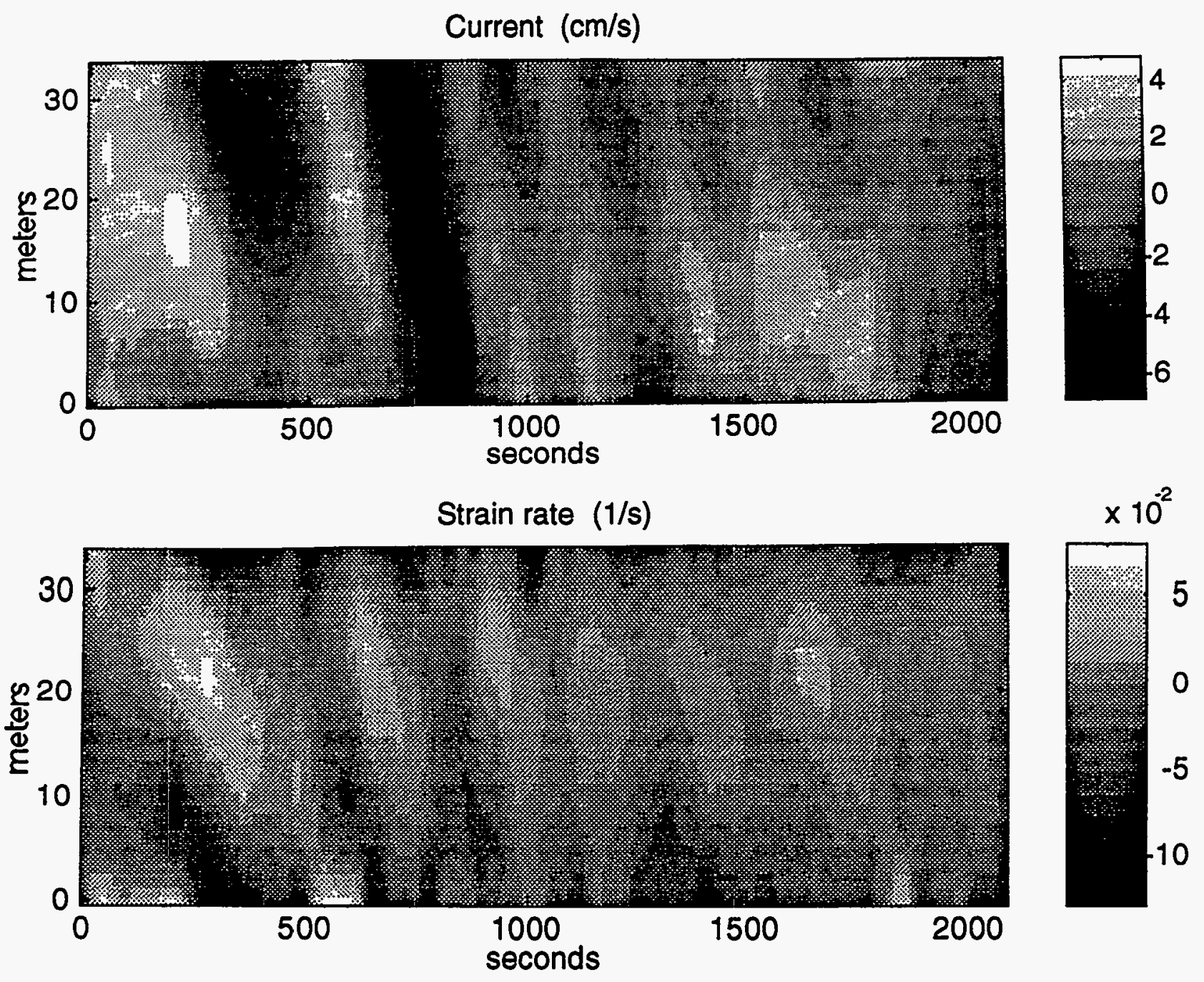


Serial 9, Run 2, 9/13/94
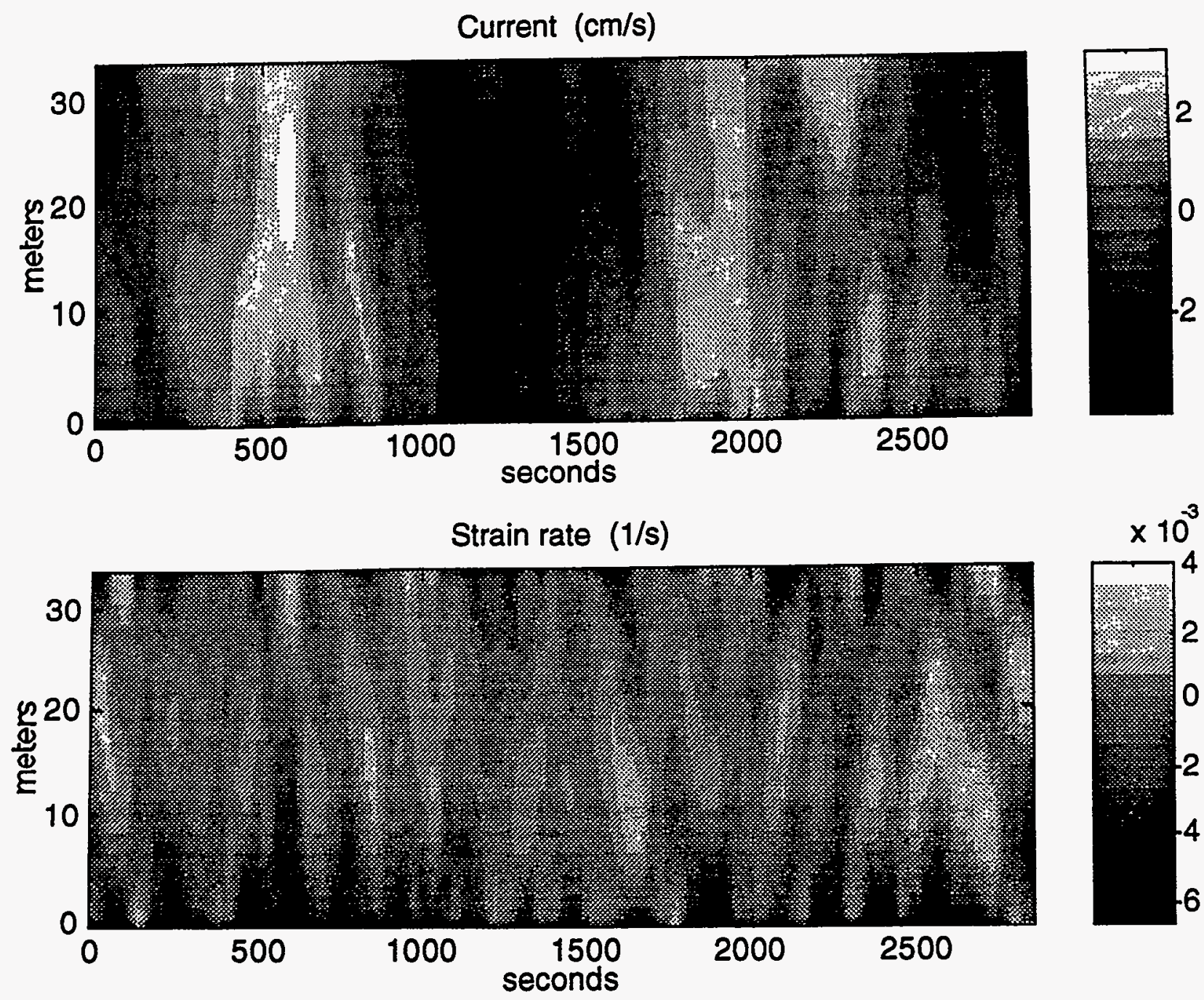
Serial 9, Run 3, 9/13/94

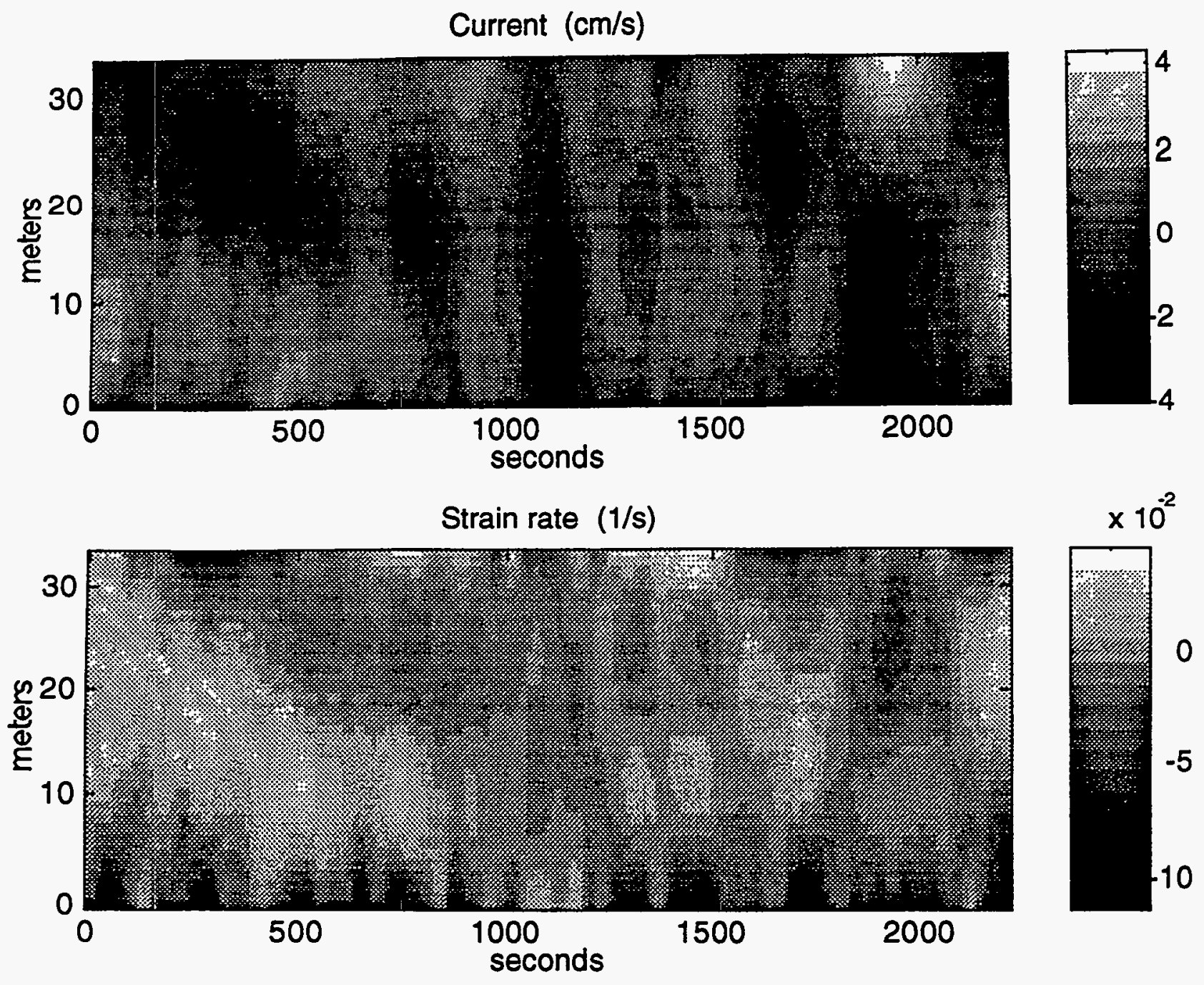


Serial 9, Run 4, 9/13/94
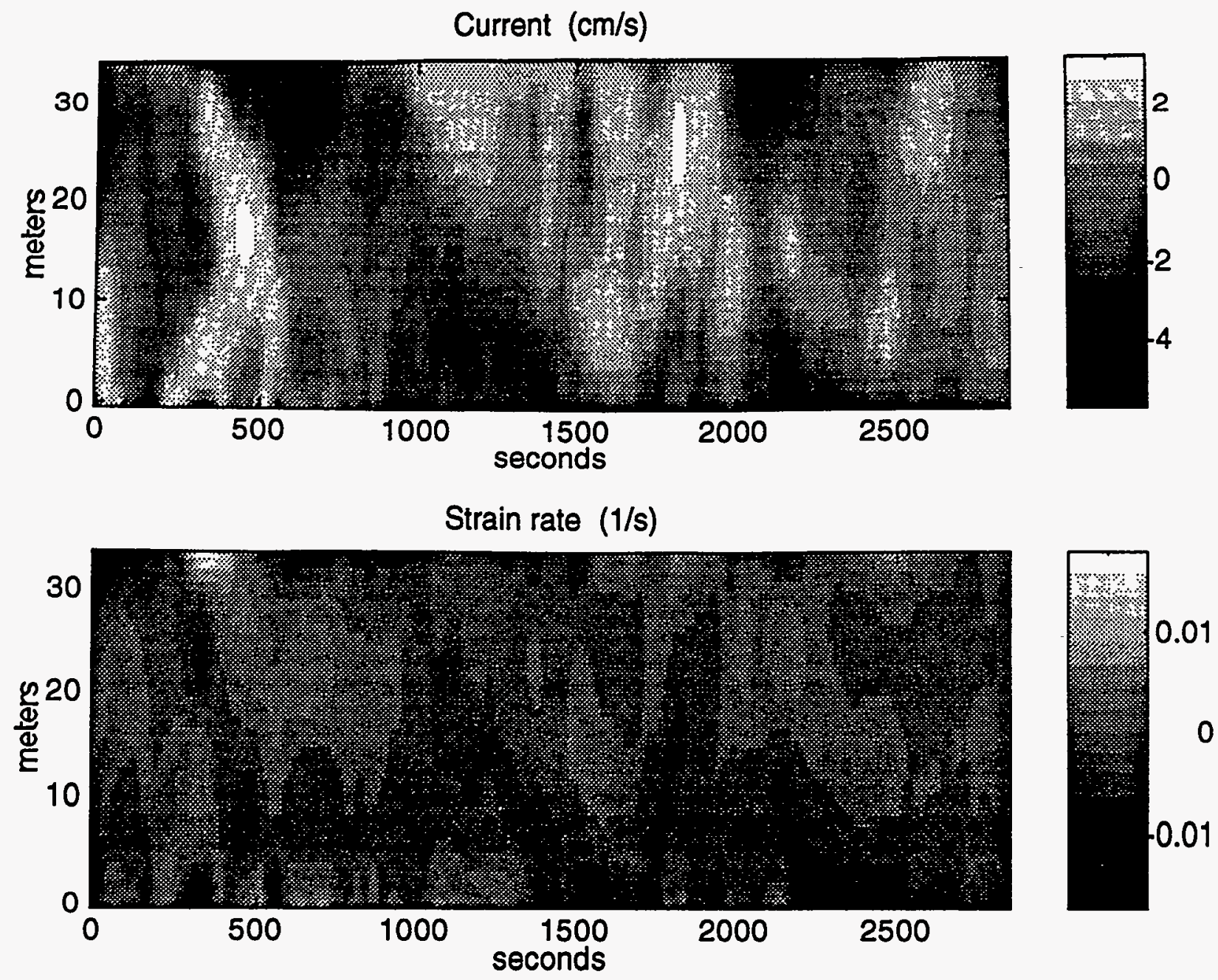
ప்
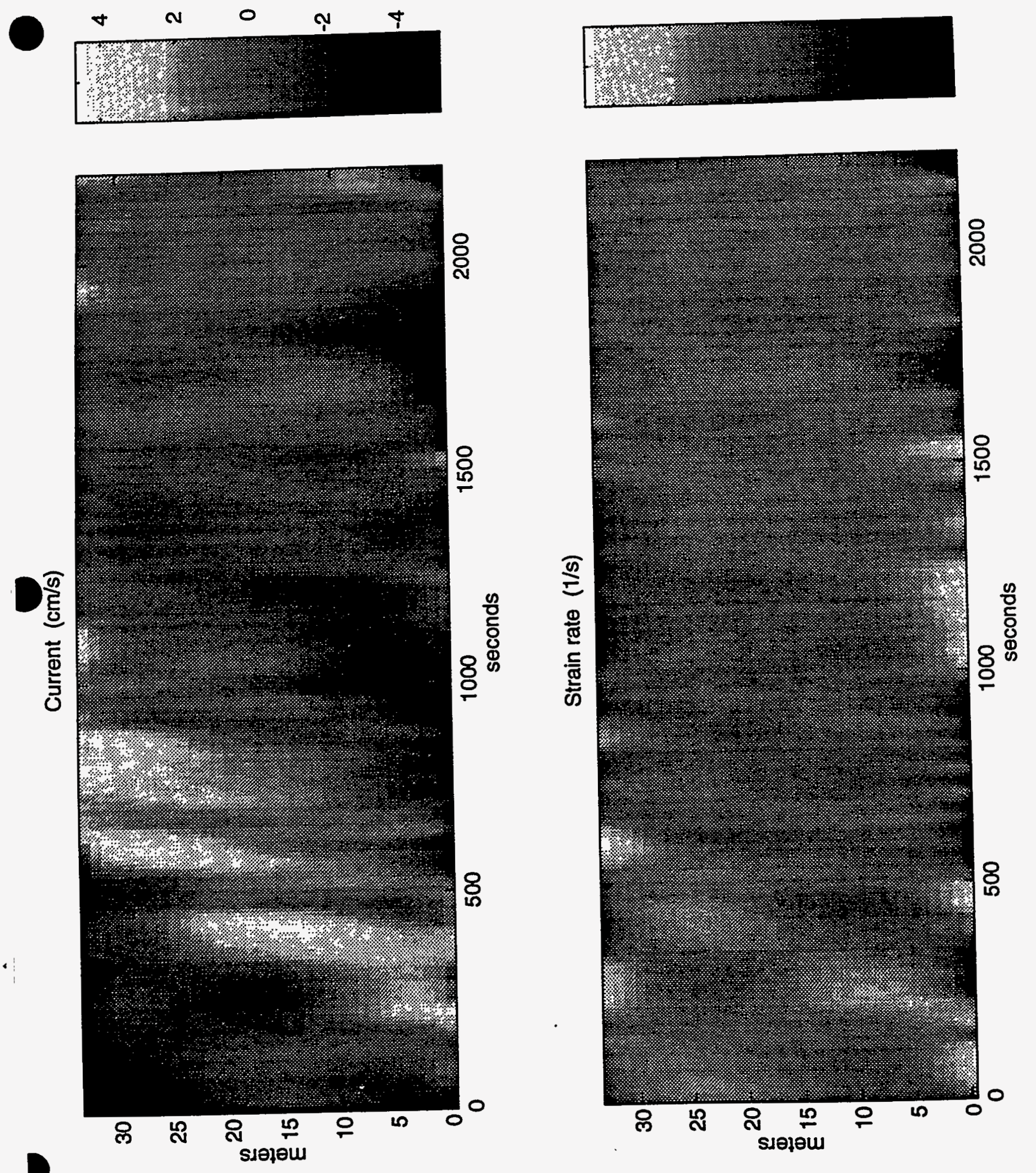

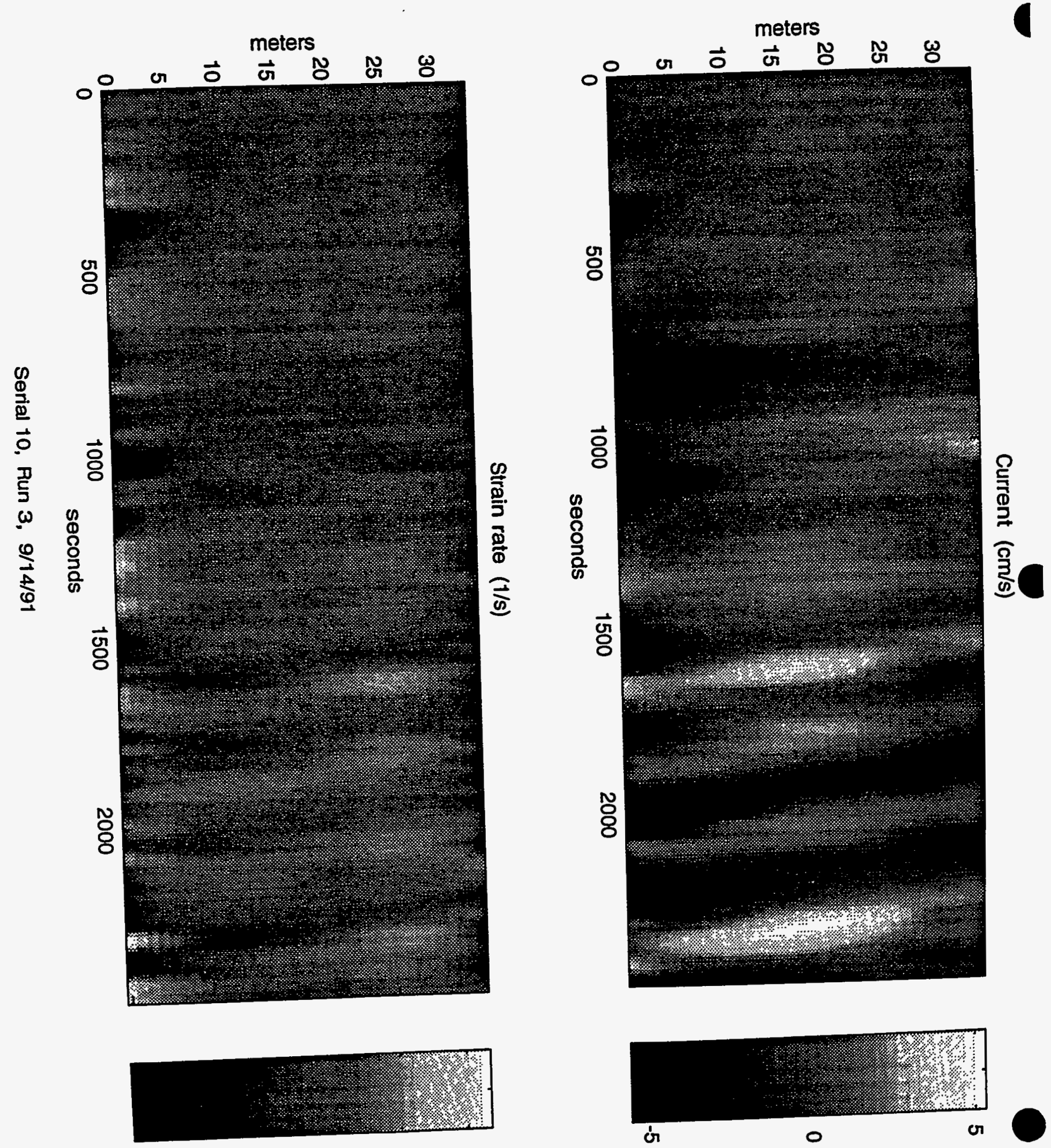

咅。竞 


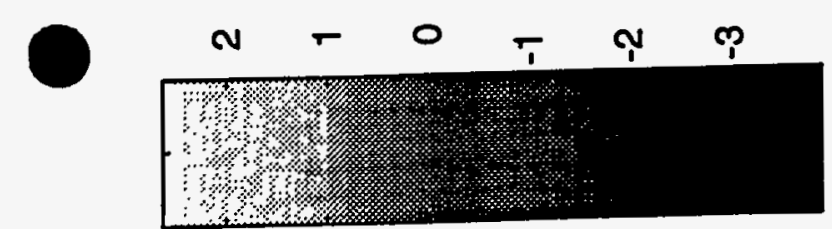

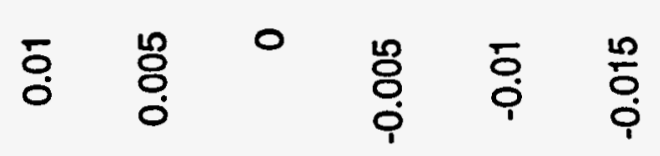
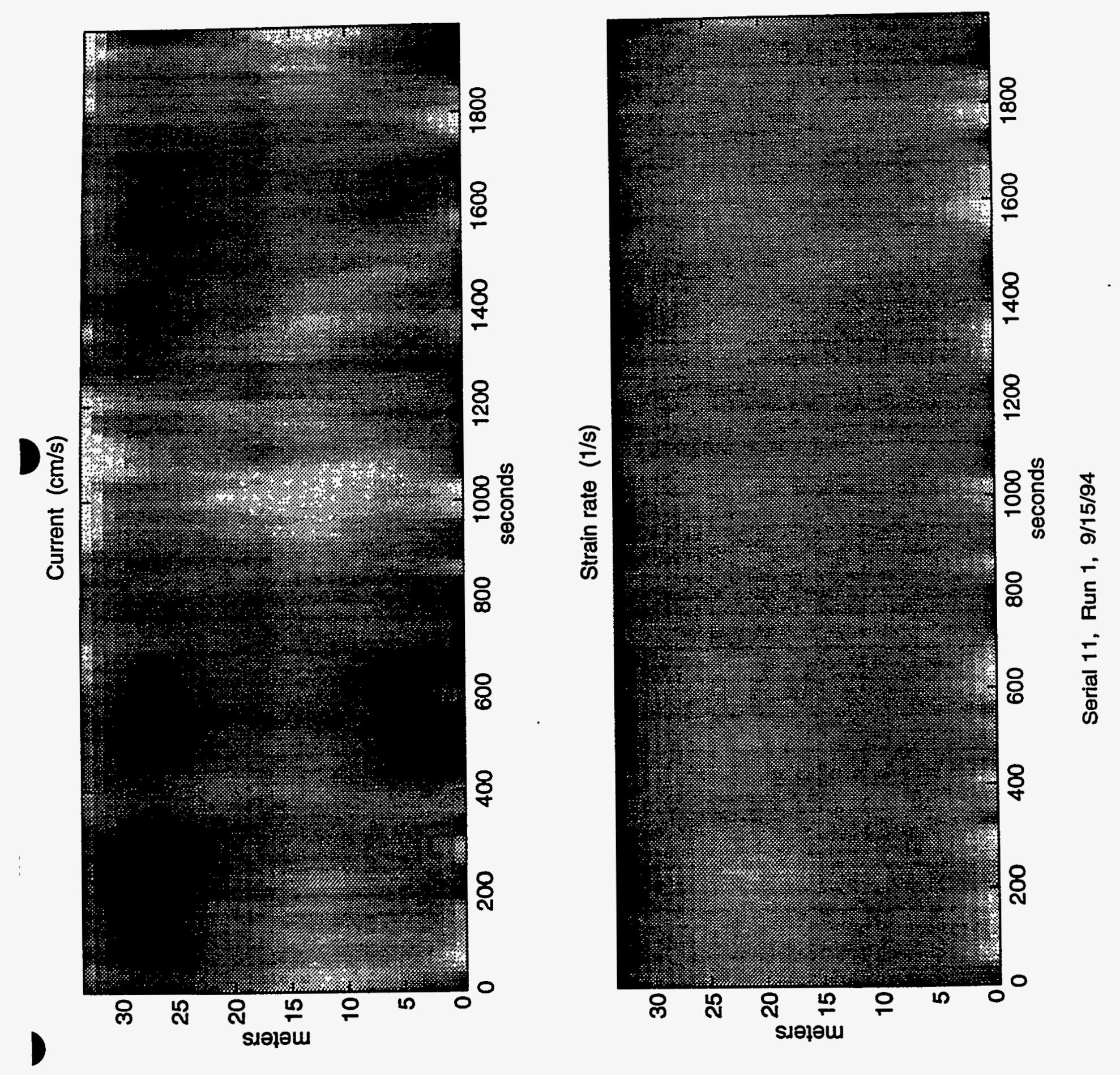


\section{Current $(\mathrm{cm} / \mathrm{s})$}
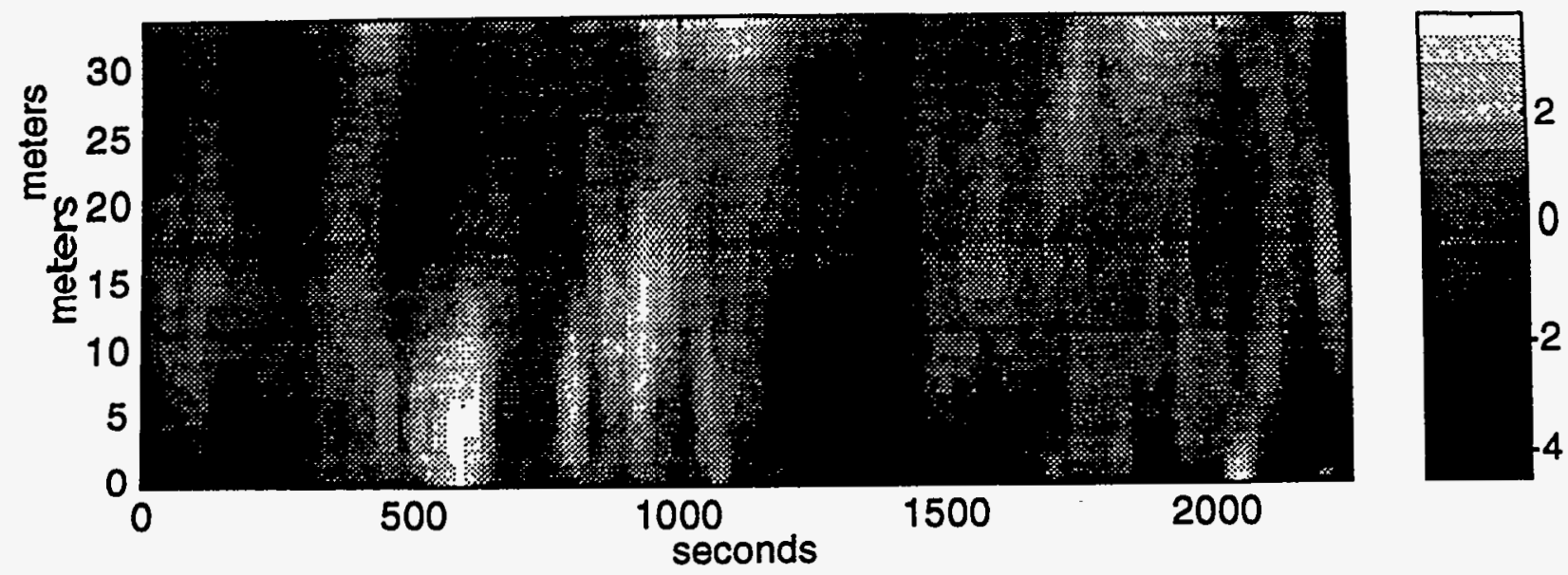

Strain rate $(1 / s)$
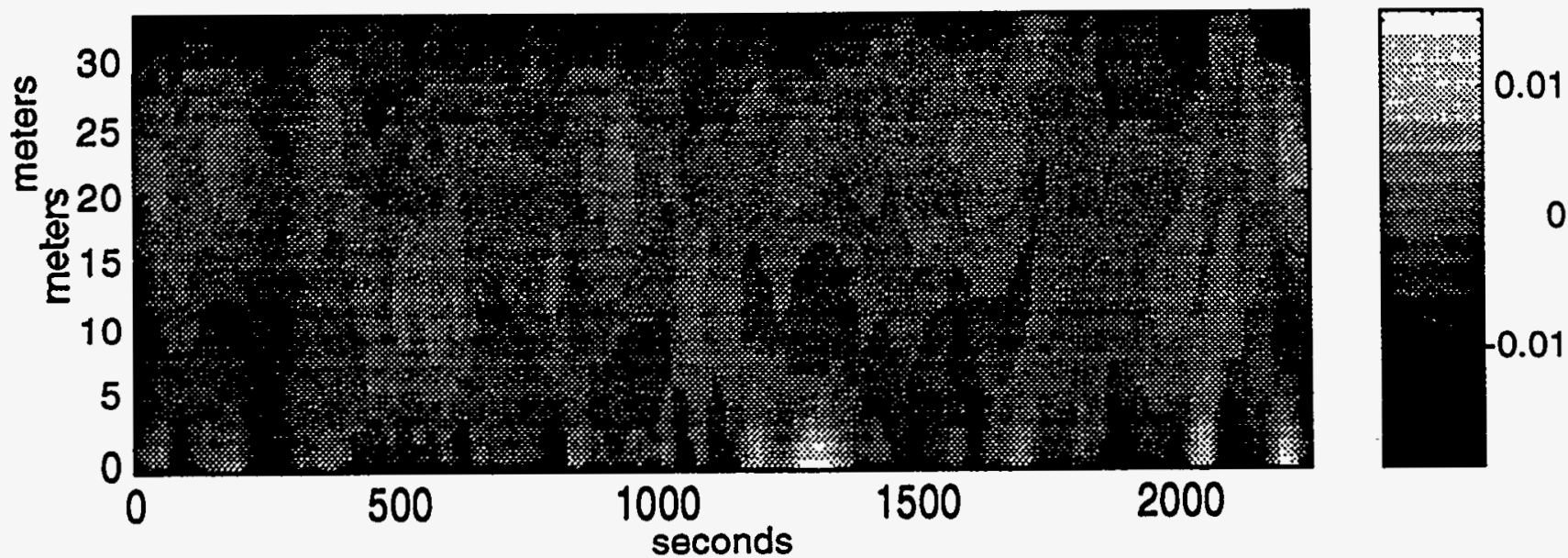

Serial 11, Run 3, 9/15/94 

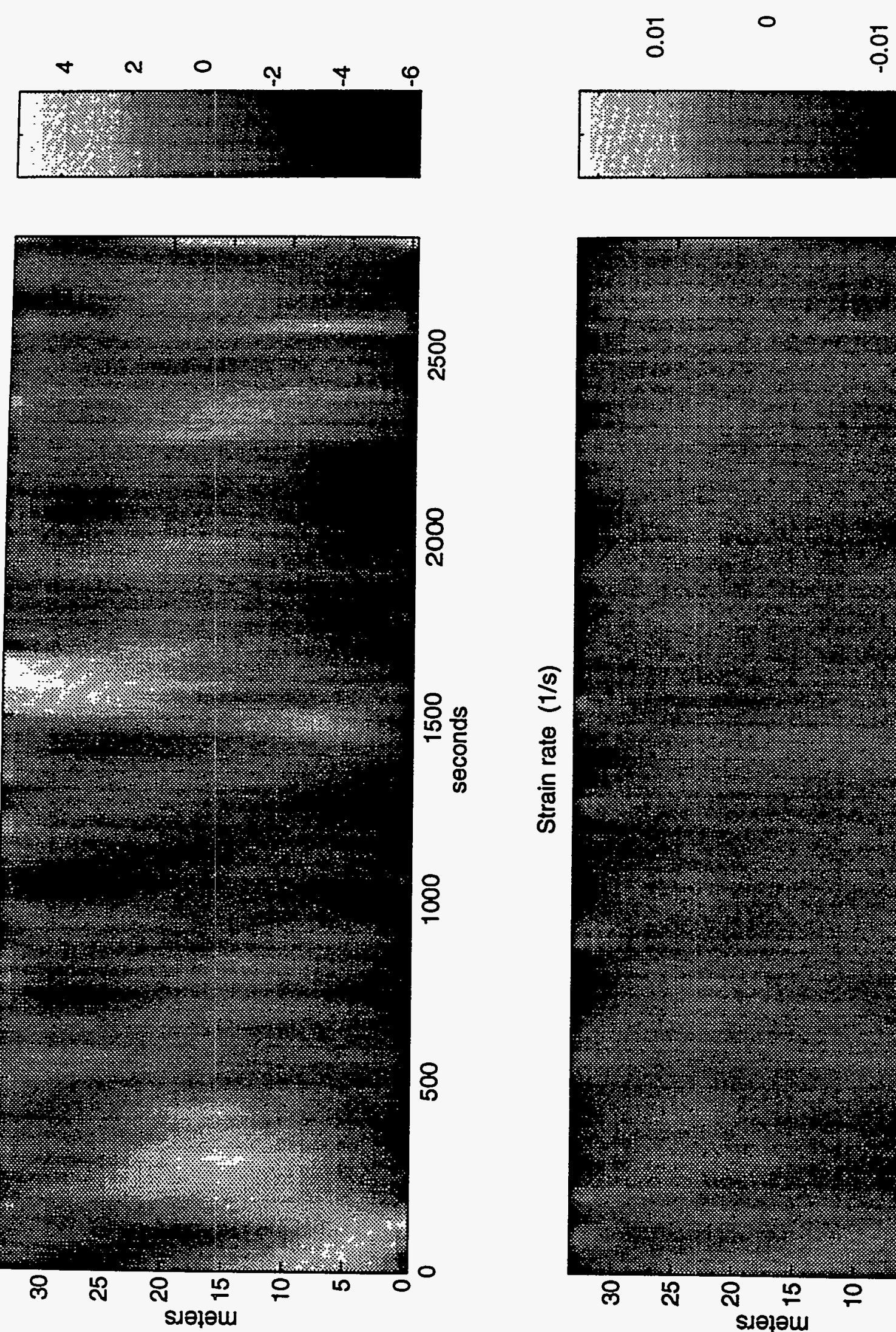

유
ठ্ণ
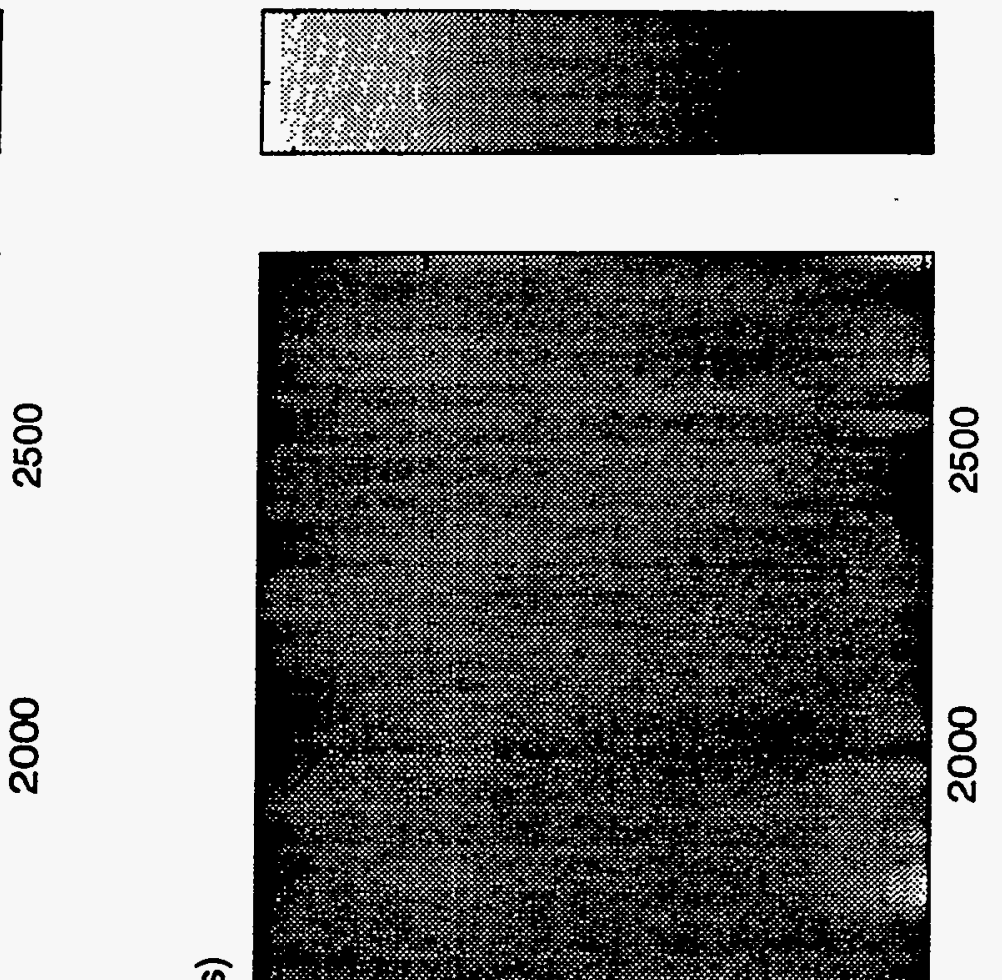

윰

옹

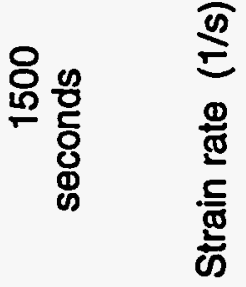

8

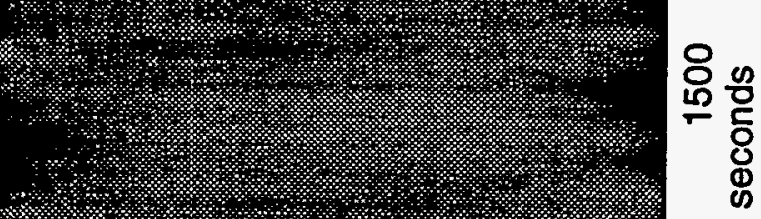

\$

8

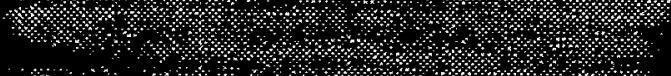

8 $\quad \frac{\bar{\sigma}}{8}$

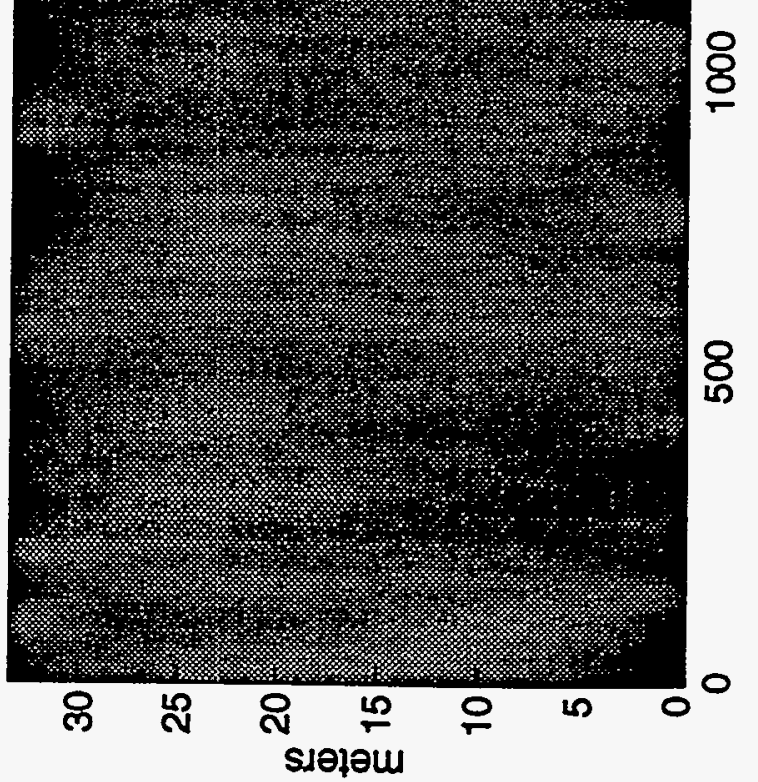



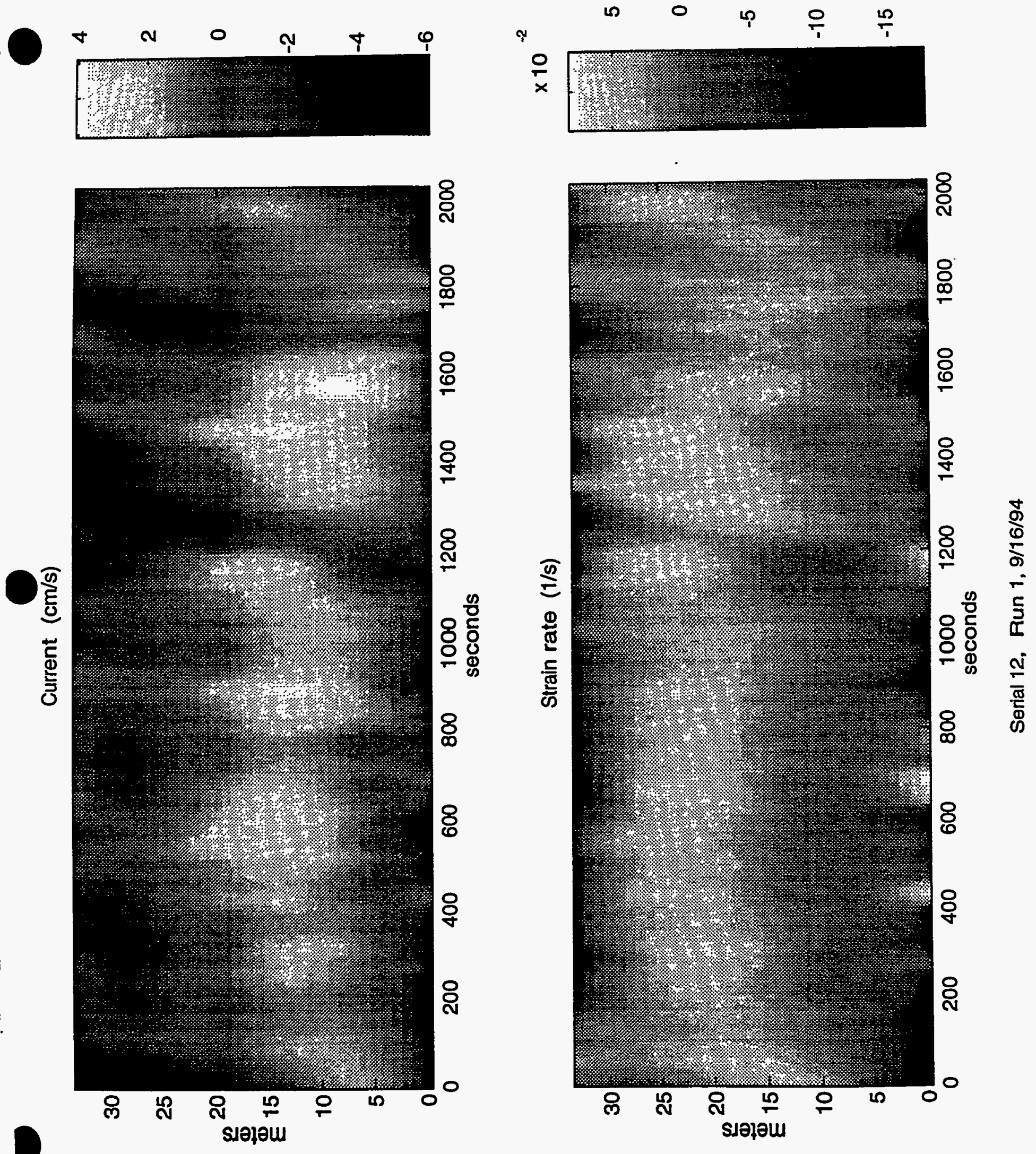
Current $(\mathrm{cm} / \mathrm{s})$

प्य

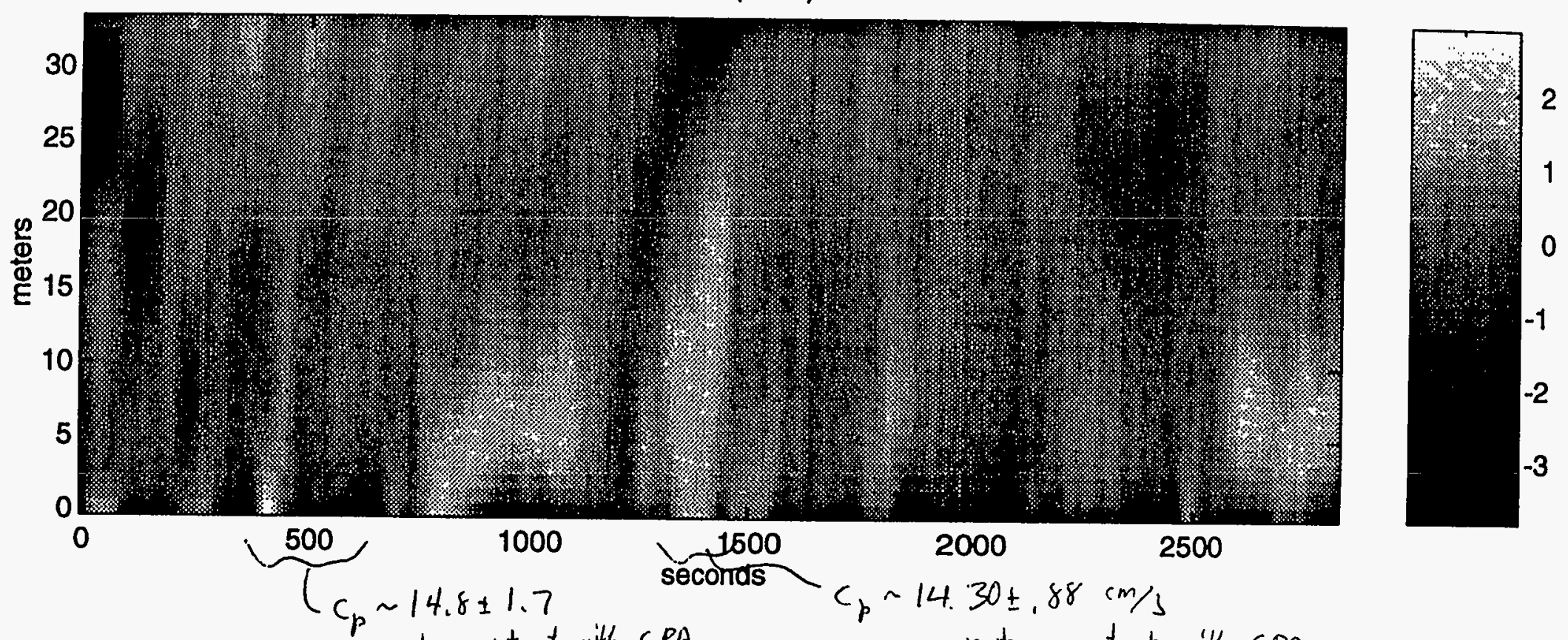
net consistemt with CPA

not consistent with CPA

$\times 10^{-2}$
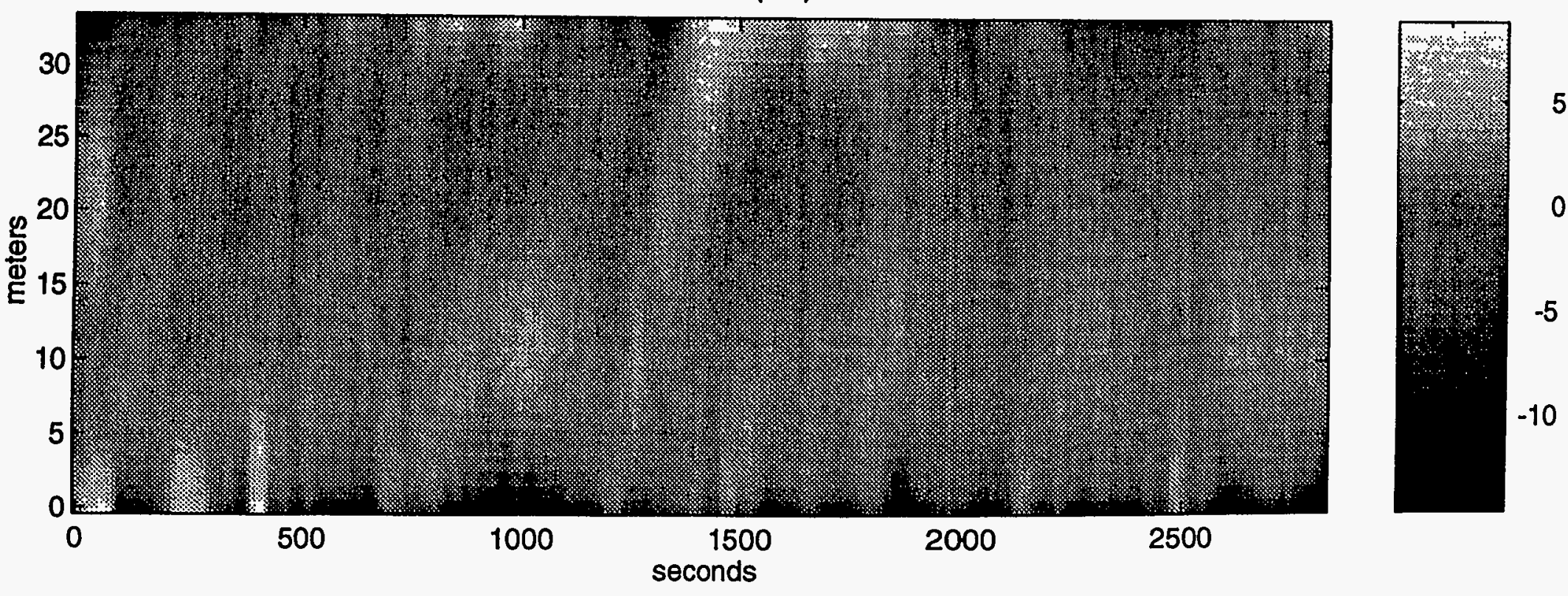

Serial 12, Run 2, 9/16/94 

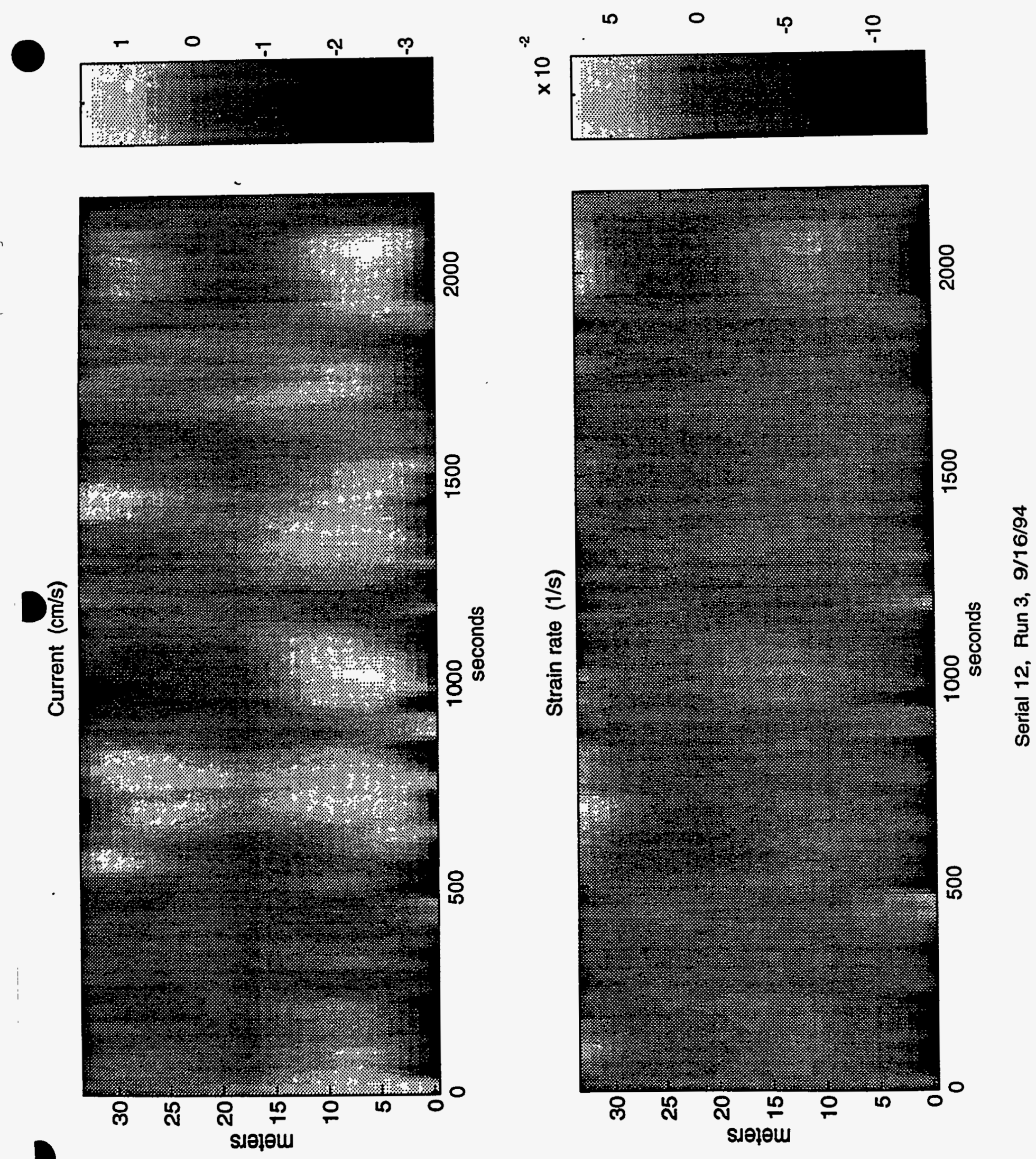
Current $(\mathrm{cm} / \mathrm{s})$

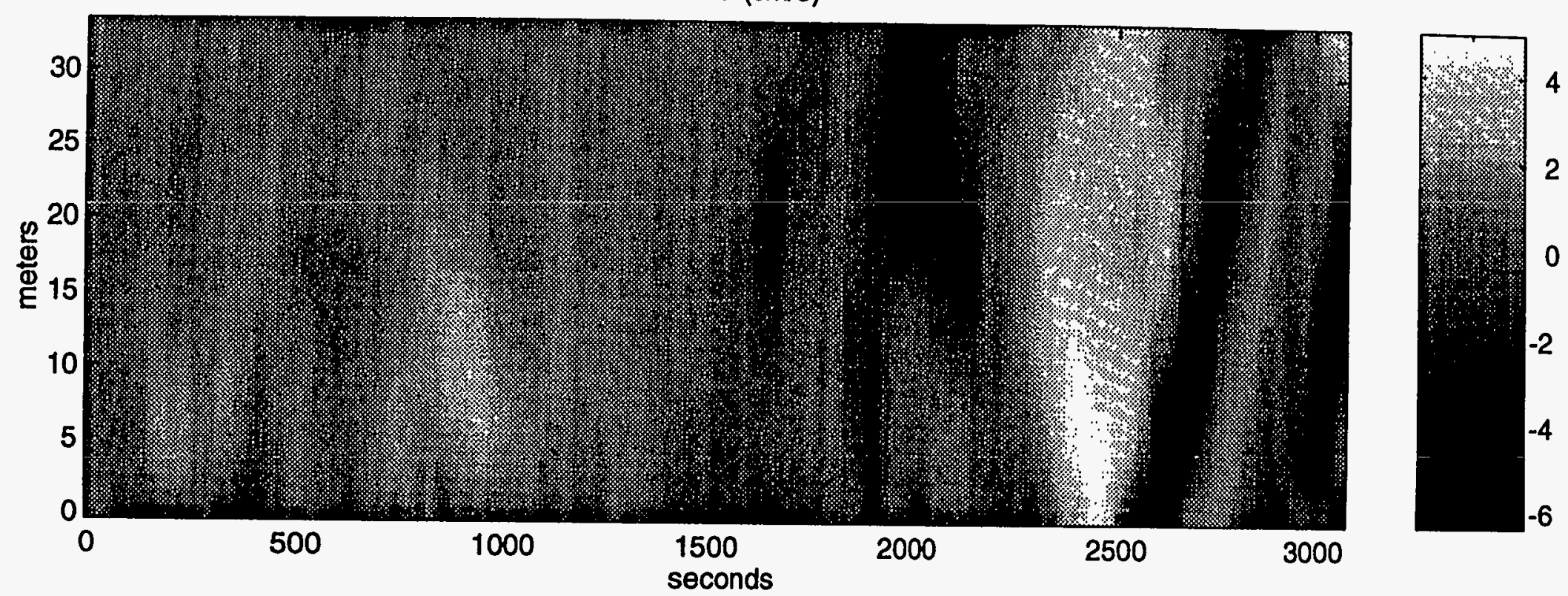

8

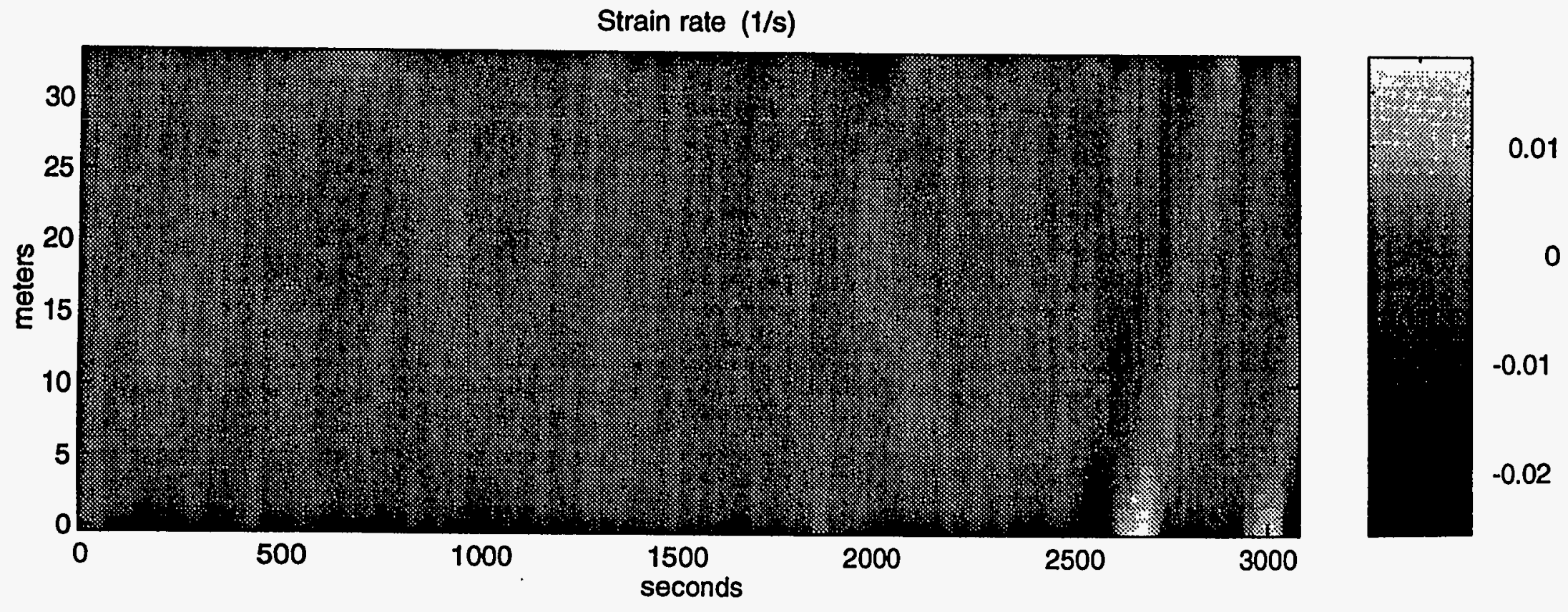

Serial 12, Run 4, 9/16/94 

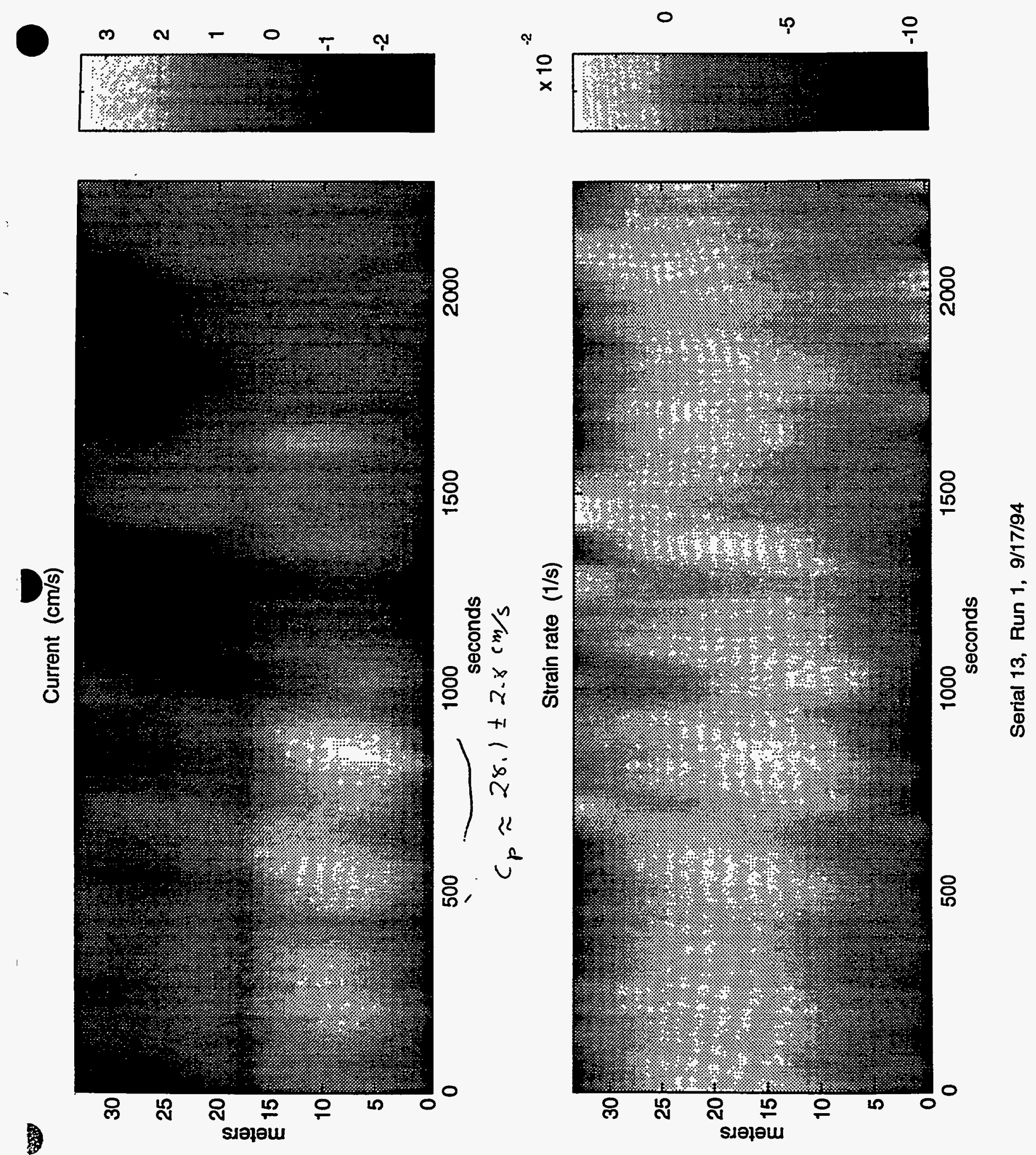


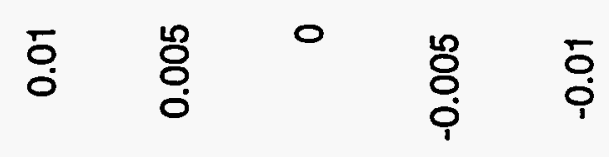
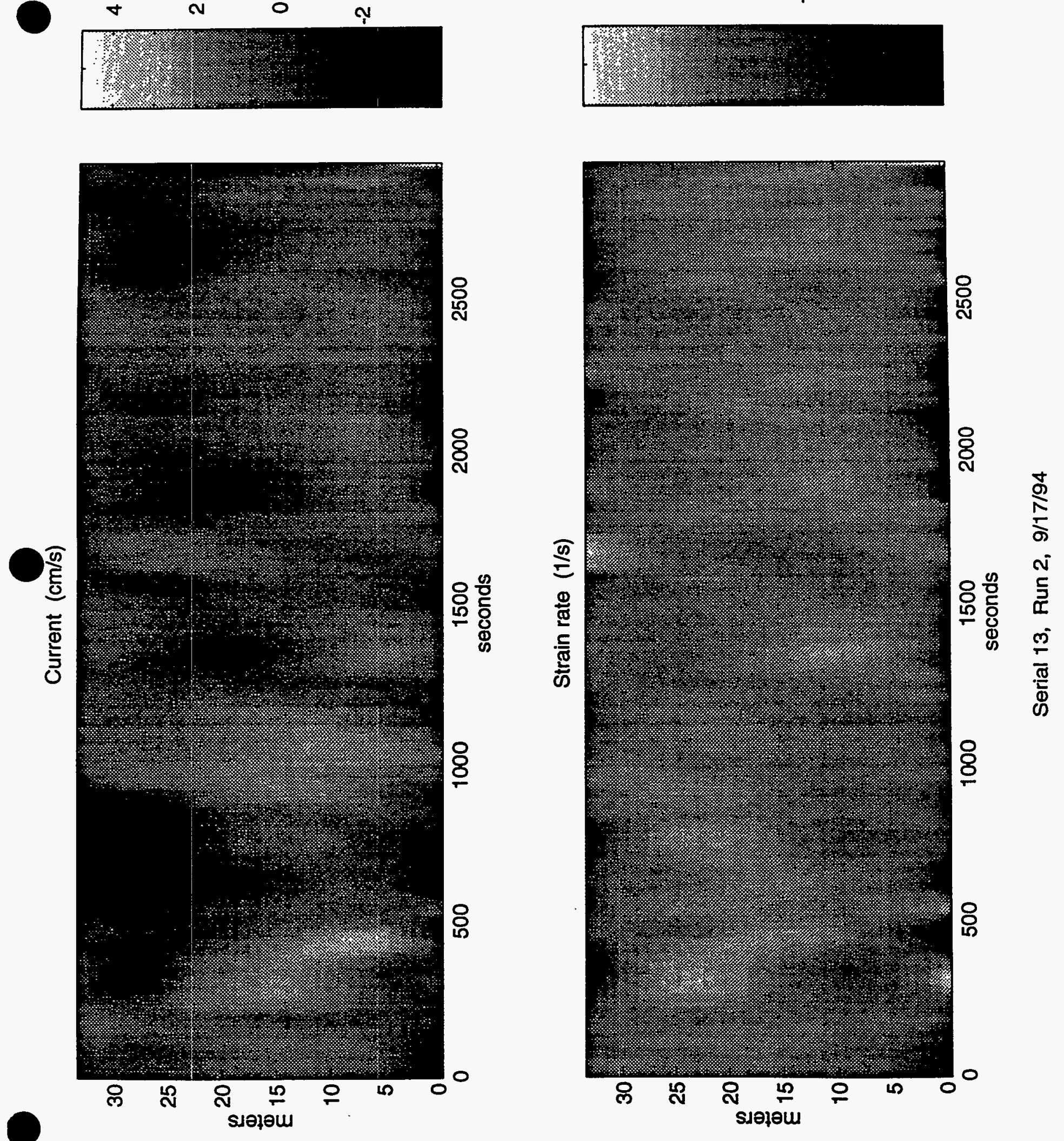


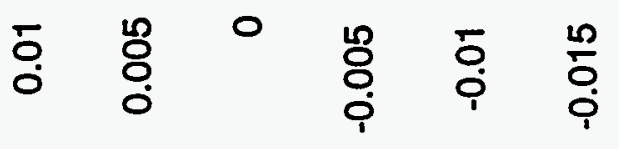
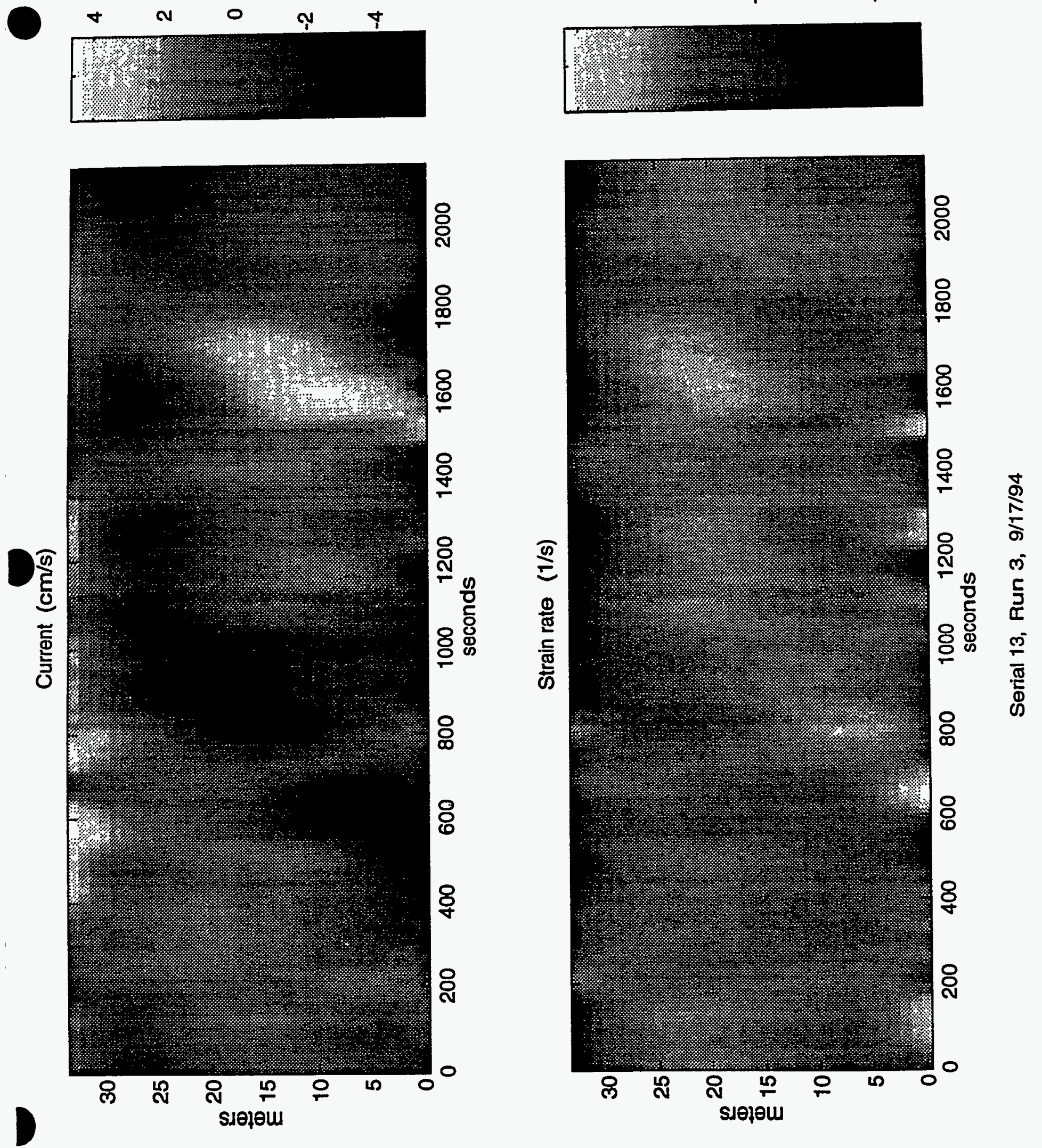
Current $(\mathrm{cm} / \mathrm{s})$
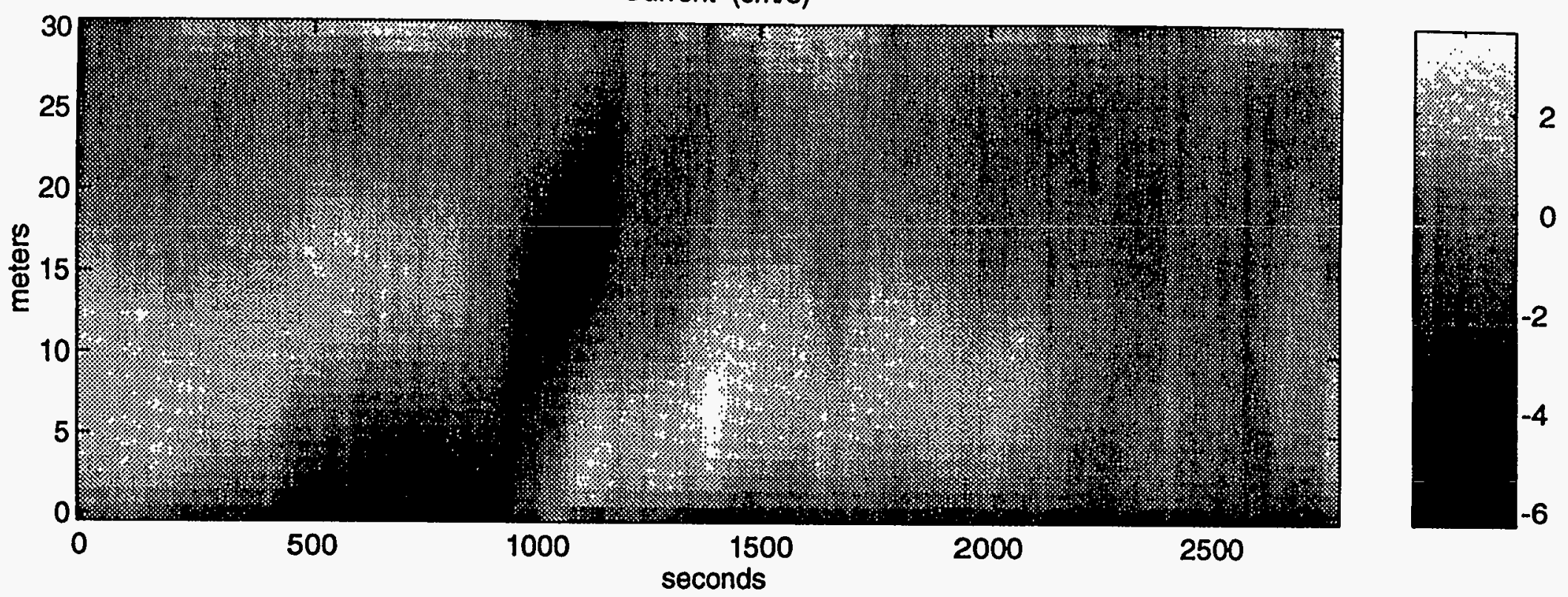

8

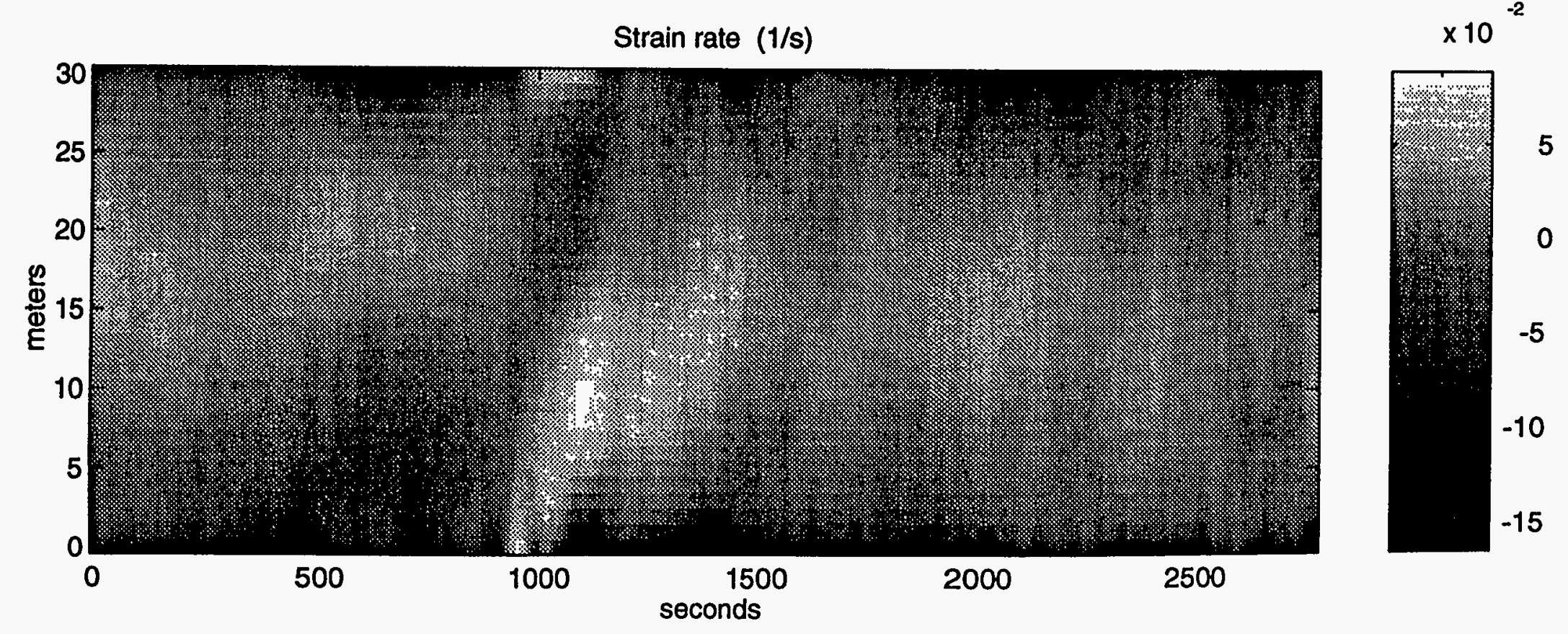

Serial 13, Run 4, 9/17/94 